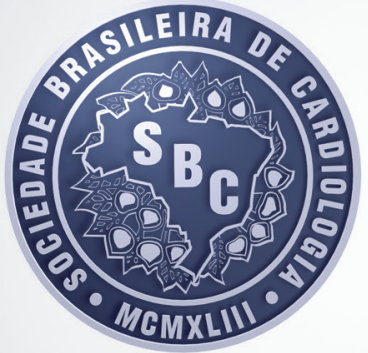

www.cardiol.br

Arquivos Brasileiros de

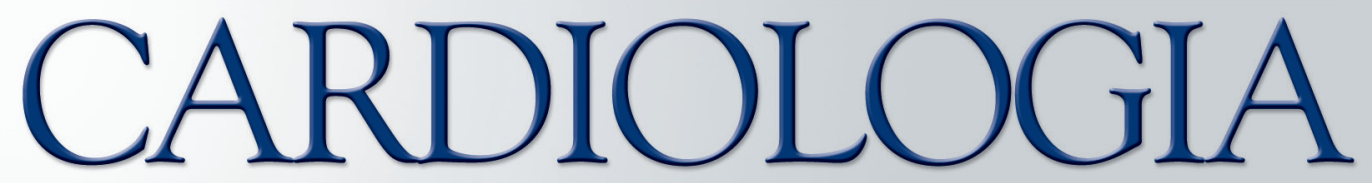

SOCIEDADE BRASILEIRA DE CARDIOLOGIA ISSN-0066-782X

\title{
ATUALIZAÇÃO DA DIRETRIZ BRASILEIRA DE INSUFICIÊNCIA CARDÍACA CRÔNICA - 2012
}



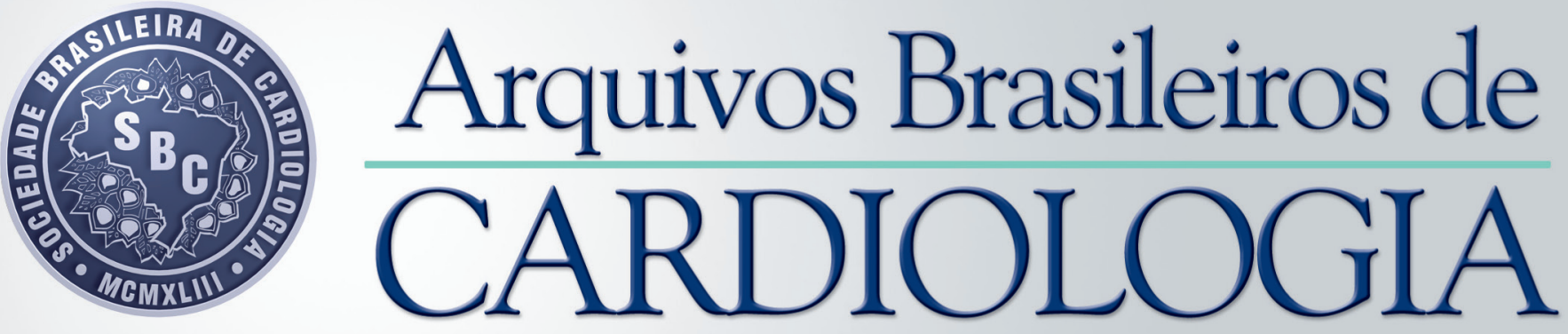

\section{ATUALIZAÇÃO DA \\ DIRETRIZ BRASILEIRA DE \\ INSUFICIÊNCIA CARDÍACA \\ CRÔNICA - 2012}

\section{Esta diretriz deverá ser citada como:}

Bocchi EA, Marcondes-Braga FG, Bacal F, Ferraz AS, Albuquerque D, Rodrigues D, et al. Sociedade Brasileira de Cardiologia. Atualização da Diretriz Brasileira de Insuficiência Cardíaca Crônica - 2012. Arq Bras Cardiol 2012: 98(1 supl. 1): 1-33 



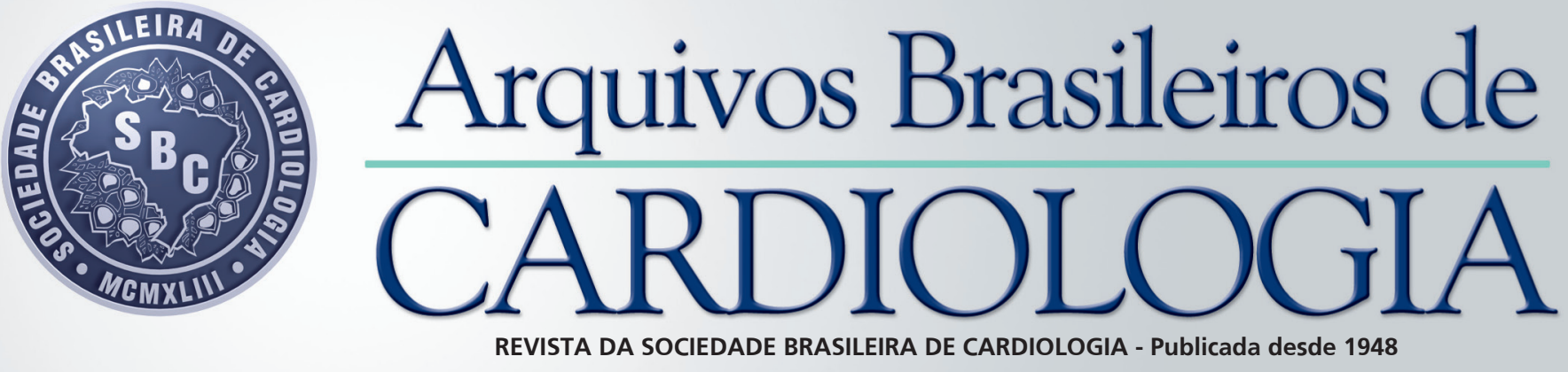

Diretor Científico

Luiz Alberto Piva e Mattos

Editor-Chefe

Luiz Felipe P. Moreira

Editores Associados

Cardiologia Clínica

José Augusto Barreto-Filho

Cardiologia Cirúrgica

Paulo Roberto B. Evora
CARDiologia IntervenCIONISTA

Pedro A. Lemos

Cardiologia Pediátrica/Congênitas

Antonio Augusto Lopes

Arritmias/Marcapasso

Mauricio Scanavacca

Métodos Diagnósticos Não-Invasivos Carlos E. Rochitte

Pesquisa Básica ou Experimental

Leonardo A. M. Zornoff
Epidemiologia/Estatística

Lucia Campos Pellanda

Hipertensão Arterial

Paulo Cesar B. V. Jardim

Ergometria, Exercício e

Reabilitação Cardíaca

Ricardo Stein

Primeiro Editor (1948-1953)

† Jairo Ramos

\section{CONSELHO EDITORIAL}

\section{Brasil}

Adib D. Jatene (SP)

Alexandre A. C. Abizaid (SP)

Alfredo José Mansur (SP)

Álvaro Avezum (SP)

Amanda G. M. R. Sousa (SP)

André Labrunie (PR)

Andrei Sposito (DF)

Angelo A. V. de Paola (SP)

Antonio Augusto Barbosa Lopes (SP)

Antonio Carlos C. Carvalho (SP)

Antônio Carlos Palandri Chagas (SP)

Antonio Carlos Pereira Barretto (SP)

Antonio Cláudio L. Nóbrega (R)

Antonio de Padua Mansur (SP)

Ari Timerman (SP)

Armênio Costa Guimarães (BA)

Ayrton Klier Péres (DF)

Ayrton Pires Brandão (RJ)

Barbara M. Ianni (SP)

Beatriz Matsubara (SP)

Braulio Luna Filho (SP)

Brivaldo Markman Filho (PE)

Bruce B. Duncan (RS)

Bruno Caramelli (SP)

Carisi A. Polanczyk (RS)

Carlos Alberto Pastore (SP)

Carlos Eduardo Negrão (SP)

Carlos Eduardo Rochitte (SP)

Carlos Eduardo Suaide Silva (SP)

Carlos Vicente Serrano Júnior (SP)

Celso Amodeo (SP)

Charles Mady (SP)

Claudio Gil Soares de Araujo (RJ)

Cleonice Carvalho C. Mota (MG)

Dalton Valentim Vassallo (ES)

Décio Mion Jr (SP)

Denilson Campos de Albuquerque (RJ)

Dikran Armaganijan (SP)

Djair Brindeiro Filho (PE)

Domingo M. Braile (SP)

Edmar Atik (SP)

Edson Stefanini (SP)

Elias Knobel (SP)

Eliudem Galvão Lima (ES)

Emilio Hideyuki Moriguchi (RS)

Enio Buffolo (SP)
Eulógio E. Martinez Fo (SP)

Evandro Tinoco Mesquita (RJ)

Expedito E. Ribeiro da Silva (SP)

Fábio Sândoli de Brito Jr. (SP)

Fábio Vilas-Boas (BA)

Fernando A. P. Morcerf (RJ)

Fernando Bacal (SP)

Flávio D. Fuchs (RS)

Francisco Antonio Helfenstein Fonseca (SP)

Francisco Laurindo (SP)

Francisco Manes Albanesi Fo (RJ)

Gilmar Reis (MG)

Gilson Soares Feitosa (BA)

Ínes Lessa (BA)

Iran Castro (RS)

Ivan G. Maia (RJ)

Ivo Nesralla (RS)

Jarbas Jakson Dinkhuysen (SP)

João Pimenta (SP)

Jorge Ilha Guimarães (RS)

Jorge Pinto Ribeiro (RS)

José A. Marin-Neto (SP)

José Antonio Franchini Ramires (SP)

José Augusto Soares Barreto Filho (SE)

José Carlos Nicolau (SP)

José Geraldo de Castro Amino (RJ)

José Lázaro de Andrade (SP)

José Péricles Esteves (BA)

José Teles Mendonça (SE)

Leopoldo Soares Piegas (SP)

Luís Eduardo Rohde (RS)

Luiz A. Machado César (SP)

Luiz Alberto Piva e Mattos (SP)

Lurildo Saraiva (PE)

Marcelo C. Bertolami (SP)

Marcia Melo Barbosa (MG)

Marco Antônio Mota Gomes (AL)

Marcus V. Bolívar Malachias (MG)

Maria Cecilia Solimene (SP)

Mario S. S. de Azeredo Coutinho (SC)

Maurício I. Scanavacca (SP)

Mauricio Wajngarten (SP)

Max Grinberg (SP)

Michel Batlouni (SP)

Nabil Ghorayeb (SP)

Nadine O. Clausell (RS)

Nelson Souza e Silva (RJ)
Orlando Campos Filho (SP)

Otávio Rizzi Coelho (SP)

Otoni Moreira Gomes (MG)

Paulo A. Lotufo (SP)

Paulo Cesar B. V. Jardim (GO)

Paulo J. F. Tucci (SP)

Paulo J. Moffa (SP)

Paulo R. A. Caramori (RS)

Paulo R. F. Rossi (PR)

Paulo Roberto S. Brofman (PR)

Paulo Zielinsky (RS)

Protásio Lemos da Luz (SP)

Renato A. K. Kalil (RS)

Roberto A. Franken (SP)

Roberto Bassan (RJ)

Ronaldo da Rocha Loures Bueno (PR)

Sandra da Silva Mattos (PE)

Sergio Almeida de Oliveira (SP)

Sérgio Emanuel Kaiser (RJ)

Sergio G. Rassi (GO)

Sérgio Salles Xavier (RJ)

Sergio Timerman (SP)

Silvia H. G. Lage (SP)

Valmir Fontes (SP)

Vera D. Aiello (SP)

Walkiria S. Avila (SP)

William Azem Chalela (SP)

Wilson A. Oliveira Jr (PE)

Wilson Mathias Jr (SP)

\section{Exterior}

Adelino F. Leite-Moreira (Portugal)

Alan Maisel (Estados Unidos)

Aldo P. Maggioni (Itália)

Cândida Fonseca (Portugal)

Fausto Pinto (Portugal)

Hugo Grancelli (Argentina)

James de Lemos (Estados Unidos)

João A. Lima (Estados Unidos)

John G. F. Cleland (Inglaterra)

Maria Pilar Tornos (Espanha)

Pedro Brugada (Bélgica)

Peter A. McCullough (Estados Unidos)

Peter Libby (Estados Unidos)

Piero Anversa (Itália) 


\section{SOCIEDADE BRASILEIRA DE CARDIOLOGIA}

Presidente

Jadelson Pinheiro de Andrade

Vice-Presidente

Dalton Bertolim Précoma

Diretor Administrativo

Marcelo Souza Hadlich

Diretora Financeira

Eduardo Nagib Gau

Diretor de Relações Governamentais

Daniel França Vasconcelos

Diretor de Comunicação

Carlos Eduardo Suaide Silva

Diretor de Qualidade Assistencial

José Xavier de Melo Filho

Diretor Científico

Luiz Alberto Piva e Mattos

Diretor de Promocão de Saúde

Cardiovascular - SBC/Funcor

Carlos Alberto Machado

Diretor de Relações Estaduais e Regionais Marco Antonio de Mattos

Diretor de Departamentos Especializados Gilberto Venossi Barbosa

Diretor de Tecnologia da Informação Carlos Eduardo Suaide Silva

Diretor de Pesquisa

Fernando Bacal

Editor-Chefe Arquivos Brasileiros de Cardiologia

Luiz Felipe P. Moreira

Editor do Jornal SBC

Fábio Vilas-Boas Pinto

Coordenador do Conselho de Registros

Alexandre Schaan de Quadros

Coordenador do Conselho de Projeto

Epidemiológico

David de Pádua Brasil
Coordenadores do Conselho de Ações Sociais

Alvaro Avezum Junior

Ari Timerman

Coordenadora do Conselho de Novos Projetos

Glaucia Maria Moraes Oliveira

Coordenador do Conselho de Aplicação de Novas Tecnologias

Washington Andrade Maciel

Coordenador do Conselho de Inserção do lovem Cardiologista

Fernando Augusto Alves da Costa

Coordenador do Conselho de Avaliação da Qualidade da Prática Clínica e Segurança do Paciente

Evandro Tinoco Mesquita

Coordenador do Conselho de

Normatizações e Diretrizes

Harry Correa Filho

Coordenador do Conselho de Educação

Continuada

Antonio Carlos de Camargo Carvalho

Comitê de Atendimento de Emergência e Morte Súbita

Manoel Fernandes Canesin

Nabil Ghorayeb

Sergio Timerman

Comitê de Prevenção Cardiovascular

Antonio Delduque de Araujo Travessa

Sergio Baiocchi Carneiro

Regina Coeli Marques de Carvalho

Comitê de Planejamento Estratégico Fabio Sândoli de Brito

José Carlos Moura Jorge

Walter José Gomes

Comitê de Assistência ao Associado

Maria Fatima de Azevedo

Mauro José Oliveira Gonçalves

Ricardo Ryoshim Kuniyoshi

Comitê de Relações Internacionais

Antonio Felipe Simão

loão Vicente Vitola

Oscar Pereira Dutra
Presidentes das Estaduais e Regionais da SBC

SBC/AL - Alfredo Aurelio Marinho Rosa

SBC/AM - Jaime Giovany Arnez Maldonado

SBC/BA - Augusto José Gonçalves de Almeida

SBC/CE - Eduardo Arrais Rocha

SBC/CO - Hernando Eduardo Nazzetta (GO)

SBC/DF - Renault Mattos Ribeiro Junior

SBC/ES - Antonio Carlos Avanza Junior

SBC/GO - Luiz Antonio Batista de Sá

SBC/MA - Magda Luciene de Souza Carvalho

SBC/MG - Maria da Consolação Vieira Moreira

SBC/MS - Sandra Helena Gonsalves de Andrade

SBC/MT - José Silveira Lage

SBC/NNE - Aristoteles Comte de Alencar Filho (AM)

SBC/PA - Claudine Maria Alves Feio

SBC/PB - Alexandre Jorge de Andrade Negri

SBC/PE - Silvia Marinho Martins

SBC/PI - Ricardo Lobo Furtado

SBC/PR - Álvaro Vieira Moura

SBC/RJ - Glaucia Maria Moraes Oliveira

SBC/RN - Carlos Alberto de Faria

SBC/RS - Justo Antero Sayão Lobato Leivas

SBC/SC - Conrado Roberto Hoffmann Filho

SBC/SE - Eduardo José Pereira Ferreira

SBC/SP - Carlos Costa Magalhães

SBC/TO - Adalgele Rodrigues Blois

\section{PRESIDENTES DOS DEPARTAMENTOS ESPECIALIZADOS E GRUPOS DE ESTUDOS}

SBC/DA - Hermes Toros Xavier (SP)

SBC/DCC - Evandro Tinoco Mesquita (RJ)

SBC/DCM - Orlando Otavio de Medeiros (PE)

SBC/DCC/CP - Estela Suzana Kleiman Horowitz (RS)

SBC/DECAGE - Abrahão Afiune Neto (GO)

SBC/DEIC - João David de Souza Neto (CE)

SBC/DERC - Pedro Ferreira de

Albuquerque $(\mathrm{AL})$
SBC/DFCVR - José Carlos Dorsa Vieira Pontes (MS)

SBC/DHA - Weimar Kunz Sebba Barroso de Souza (GO)

SBC/DIC - Jorge Eduardo Assef (SP)

SBC/SBCCV - Walter José Gomes (SP)

SBC/SBHCI - Marcelo Antonio Cartaxo Queiroga Lopes (PB)

SBC/SOBRAC - Adalberto Menezes Lorga Filho (SP)

SBC/DCC/GAPO - Daniela Calderaro (SP)
SBC/DCC/GECETI - João Fernando Monteiro Ferreira (SP)

SBC/DCC/GEECABE - Luis Claudio Lemos Correia (BA)

SBC/DCC/GEECG - Carlos Alberto Pastore (SP)

SBC/DCP/GECIP - Angela Maria Pontes Bandeira de Oliveira (PE)

SBC/DERC/GECESP - Daniel Jogaib Daher (SP)

SBC/DERC/GECN - José Roberto Nolasco de Araújo (AL) 


\section{ARQUIVOS BRASILEIROS DE CARDIOLOGIA}

Volume 98, № 1, Suplemento 1, Janeiro 2012

Indexação: ISI (Thomson Scientific), Cumulated Index Medicus (NLM), SCOPUS, MEDLINE, EMBASE, LILACS, SciELO, PubMed

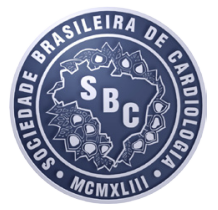

Av. Marechal Câmara, 160 - 3o andar - Sala 330

20020-907 • Centro • Rio de Janeiro, RJ • Brasil

Tel.: (21) 3478-2700

E-mail: arquivos@cardiol.br

www.arquivosonline.com.br

SCIELO: www.scielo.br

\section{Departamento Comercial}

Telefone: (11) 3411-5500

e-mail: comercialsp@cardiol.br

Produção Editorial

SBC - Núcleo Interno de Publicações
Produção Gráfica e Diagramação SBC - Núcleo Interno de Design

Impressão

Prol Editora Gráfica

Tiragem

11.000 exemplares
Os anúncios veiculados nesta edição são de exclusiva responsabilidade dos anunciantes, assim como os conceitos emitidos em artigos assinados são de exclusiva responsabilidade de seus autores, não refletindo necessariamente a opinião da SBC.
Material de distribuição exclusiva à classe médica. Os Arquivos Brasileiros de Cardiologia não se responsabilizam pelo acesso indevido a seu conteúdo e que contrarie a determinação em atendimento à Resolução da Diretoria Colegiada (RDC) no 96/08 da Agência Nacional de Vigilância Sanitária (Anvisa), que atualiza o regulamento técnico sobre Propaganda, Publicidade, Promoção e informação de Medicamentos. Segundo o artigo 27 da insígnia, "a propaganda ou publicidade de medicamentos de venda sob prescrição deve ser restrita, única e exclusivamente, aos profissionais de saúde habilitados a prescrever ou dispensar tais produtos (...)".

Garantindo o acesso universal, o conteúdo científico do periódico continua disponível para acesso gratuito e integral a todos os interessados no endereço: www.arquivosonline.com.br.

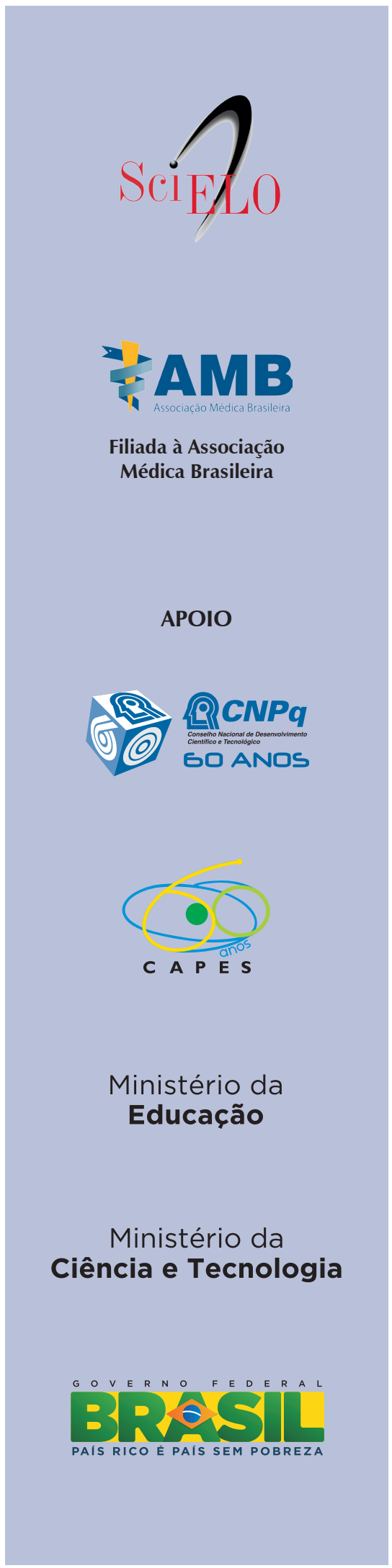




\section{Diretrizes}

\section{SUMÁRIO}

Introdução

página 2

1. Epidemiologia

página 2

2. Abordagem do Paciente com Insuficiência Cardíaca

página 3

2.1. Métodos Diagnósticos

página 4

2.1.1. Eletrocardiograma

página 4

2.1.2. Troponina e Polimorfismo.

página 4

2.1.3. BNP/NTproBNP

página 4

2.1.4. EcoDopplercardiograma

página 4

2.1.5. Imagem por Medicina Nuclear - SPECT e PET

página 4

2.1.6. Tomografia Computadorizada Cardíaca e Ressonância Magnética página 4

2.1.7. Teste Ergoespirométrico página 5

3. Seguimento Clínico

página 5

3.1. NT-proBNP e BNP

página 5

3.2. Telemonitoramento (Telemedicina)

página 6

3.3. Prognóstico

página 6

3.4. Avaliação Familiar

página 6

4. Tratamento Não Farmacológico

página 7

4.1. Ingestão de Sódio

página 7

4.2. Vacinação

página 7

4.3. Clínicas de IC e Programas de Manejo de Doença Crônica em IC

página 7

4.4. Reabilitação e Treinamento Físico

página 8

5. Tratamento Farmacológico

página 9

5.1. Betabloqueadores (BB)

página 9

5.2. Inibidores da Enzima Conversora da Angiotensina e Antagonistas dos Receptores da Angiotensina II

página 10

5.3. Antagonistas da Aldosterona.....

página 10

5.4. Diuréticos

página 10

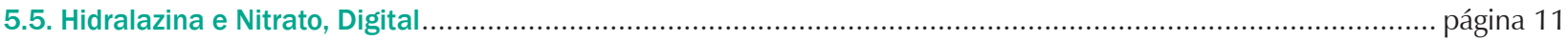

5.6. Anticoagulantes e Antiagregantes plaquetários ............................................................................. página 11

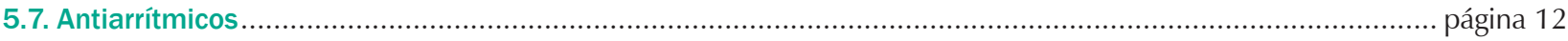

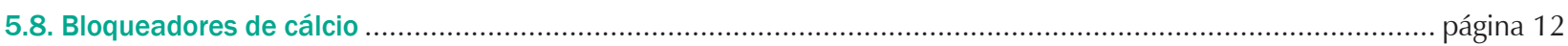

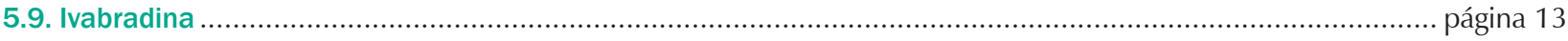

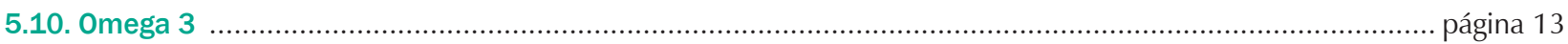

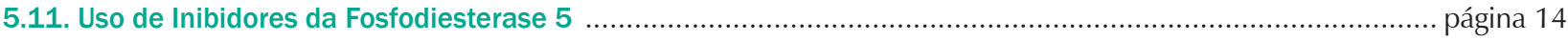

5.10. Moduladores do Metabolismo Enérgico Miocárdico............................................................................. página 14

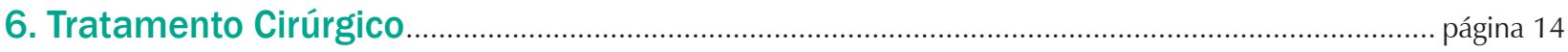

6.1. Cirurgia da Valva Mitral

página 14

6.2. Revascularização Miocárdica com Disfunção Isquêmica de Ventrículo Esquerdo e Remodelamento

Cirúrgico do Ventrículo Esquerdo 
6.5. Dispositivos Implantáveis de Estimulação Cardíaca - Terapia de Ressincronização Cardíaca e Cardioversor Desfibrilador Implantável

página 16

\section{Abordagem por Estágios} página 18

8. Insuficiência Cardíaca com Fração de Ejeção Preservada página 18

9. Insuficiência Cardíaca e Comorbidades

9.1. Insuficiência Renal Crônica página 18

9.2. Anemia e/ou Deficiência de Ferro

9.3. Diabetes Melito

9.4. Depressão

9.5. Cardiotoxidade dos Quimioterápicos

10. Subgrupos Especiais

10.1. IC na Doença de Chagas

10.2. IC na gestante

10.3. IC no idoso

10.4. IC no paciente com SIDA

10.5. IC direita e Hipertensão Pulmonar.

10.6. Miocardite.....

10.7. Miocárdio não Compactado

11. Opções Diagnósticas ou Terapêuticas Controversas, ou em Desenvolvimento, sem Papel Definido para a IC.

página 23

11.1. Monitorização Hemodinâmica

página 23

11.2. Bioimpedância Transtorácica (BTC) página 23

11.3. Hormônio do Crescimento página 23

11.4. Antagonistas da Vasopressina página 23

11.5. Antagonistas da Endotelina página 23

11.6. Antagonistas do Receptor A1 da Adenosina

página 23

11.7. Inibidores adrenérgicos centrais. página 23

11.8. G-CSF / Terapia Celular .... página 23

11.9. Relaxina. página 23

11.10. Quelantes de Potássio página 23

11.11. Ativadores da Miosina Cardíaca (omecamtiv mecarbil). página 24

11.12. Simpatectomia página 24

11.13. Estimulação Elétrica do Vago ou do Baroreflexo do Seio Carotídeo página 24

11.14. Inibidores da Renina página 24

11.15. Inibidores de Outros Sistemas além do Sistema Renina-Angiotensina-Aldosterona. página 24

11.16. Não Glicosídeos via Inibição da Na+/K+-ATPase e via Ativação Cálcio do Retículo Sarcoplasmático (SERCA 2a). 


\title{
REALIZAÇÃo
}

Sociedade Brasileira de Cardiologia

\section{Coordenador de Normatizações e Diretrizes da SBC}

\author{
Iran Castro e Harry Correa Filho
}

\section{Coordenadores da Diretriz}

Edimar Alcides Bocchi

\section{Comissão de Redação e Planejamento}

Fabiana Goulart Marcondes-Braga

\section{Autores}

'Edimar Alcides Bocchi, MD; ${ }^{1}$ Fabiana Goulart Marcondes-Braga, MD; ${ }^{1}$ Fernando Bacal, MD; ${ }^{2}$ Almir Sergio Ferraz, MD; ${ }^{3}$ Denilson Albuquerque, MD; ${ }^{4}$ Dirceu de Almeida Rodrigues, MD; ${ }^{5,6}$ Evandro Tinoco Mesquita, ${ }^{7}$ Fábio Vilas-Boas, MD; ${ }^{1}$ Fátima

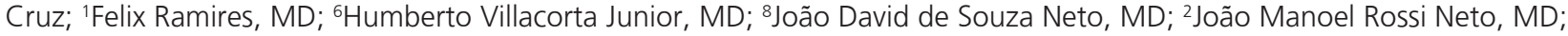

${ }^{9}$ Lídia Zytynski Moura, MD; ${ }^{10}$ Luís Beck-da-Silva, MD; ${ }^{1}$ Luiz Felipe Moreira, MD; ${ }^{11}$ Luis Eduardo Paim Rohde, MD; ${ }^{5}$ Marcelo

Westerlund Montera, MD; ${ }^{12}$ Marcus Vinicius Simões, MD; ${ }^{13}$ Maria da Consolação Moreira, MD; ${ }^{11}$ Nadine Clausell, MD;

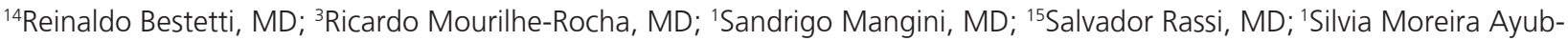
Ferreira, MD; ${ }^{16}$ Silvia Marinho Martins, MD; ${ }^{17}$ Solange Bordignon, MD; ${ }^{1}$ Victor Sarli Issa, MD.

\section{INSTITUIÇõES}

"nstituto do Coração (InCor) do Hospital das Clínicas da Faculdade de Medicina da Universidade de São Paulo; ${ }^{2}$ Instituto Dante Pazzanese de Cardiologia; ${ }^{3}$ Universidade Estadual do Rio de Janeiro (UERJ); ${ }^{4}$ Universidade Federal de São Paulo; ${ }^{5}$ Hospital Pró-

Cardíaco do Rio de Janeiro; ${ }^{6}$ Universidade Federal Fluminense; ${ }^{7}$ Hospital Espanhol, Hospital Santa Izabel; ${ }^{8}$ Hospital de Messejana Dr. Carlos Alberto Studart Gomes - Fortaleza-CE; ${ }^{9}$ Pontífica Universidade Católica do Paraná; ${ }^{10 H o s p i t a l ~ d e ~ C l i ́ n i c a s ~ d e ~ P o r t o ~ A l e g r e ~}$

da Universidade Federal do Rio Grande do Sul; "1'Serviço de Cardiologia do Hospital de Clínicas de Porto Alegre e Departamento de Medicina Interna da Faculdade de Medicina/UFRGS; ${ }^{12}$ Hospital das Clínicas da Faculdade de Medicina de Ribeirão Preto

- Universidade de São Paulo; ${ }^{13}$ Faculdade de Medicina e Hospital das Clínicas da Universidade Federal de Minas Gerais, Belo Horizonte; ${ }^{14}$ Hospital de Base São José do Rio Preto, e Curso de Medicina da Associação de Ensino de Ribeirão Preto; ${ }^{15} F a c u l d a d e$ de Medicina da Universidade Federal de Goiás; ${ }^{16}$ Pronto Socorro Cardiológico de Pernambuco - PROCAPE / Universidade de

Pernambuco, Real Hospital Português da Beneficência em Pernambuco; ${ }^{17}$ Instituto de Cardiologia do Rio Grande do Sul/Fundação Universitária de Cardiologia e Hospital Nossa Senhora da Conceição

\section{Revisores}

Adalberto Menezes Lorga, Álvaro Vieira Moura, Antonio Carlos Sobral Sousa, Harry Corrêa Filho, Iran Castro

\section{Palavras-chave}

Insuficiência Cardíaca, Tratamento, Diretrizes, Diagnóstico, Revisão, Prognóstico, Tratamento Médico, Tratamento Cirúrgico, Cirurgia, CDI.

\section{KeYWORDS}

Heart Failure; Treatment; Guidelines; Diagnosis; Review; Prognosis; Medical Treatment; Surgical Treatment; Surgery; CDI.

\section{Correspondência:}

Edimar Alcides Bocchi - Rua Dr. Melo Alves 690 apto 41, Bairro Cerqueira César - São Paulo - SP

CEP 01417-010. E-mail: dcledimar@incor.usp.br 
Declaração de potencial conflito de interesses dos autores/colaboradores da Atualização da Diretriz Brasileira de Insuficiência Cardíaca Crônica - 2012

Se nos últimos 3 anos o autor/colaborador das Diretrizes:

\begin{tabular}{|c|c|c|c|c|c|c|c|}
\hline $\begin{array}{c}\text { Nomes Integrantes da } \\
\text { Diretriz }\end{array}$ & $\begin{array}{c}\text { Participou } \\
\text { de estudos } \\
\text { clínicos elou } \\
\text { experimentais } \\
\text { subvencionados } \\
\text { pela indústria } \\
\text { farmacêutica ou } \\
\text { de equipamentos } \\
\text { relacionados } \\
\text { à diretriz em } \\
\text { questão }\end{array}$ & $\begin{array}{l}\text { Foi palestrante } \\
\text { em eventos } \\
\text { ou atividades } \\
\text { patrocinadas } \\
\text { pela indústria } \\
\text { relacionados } \\
\text { à diretriz em } \\
\text { questão }\end{array}$ & $\begin{array}{c}\text { Foi (é) membro } \\
\text { do conselho } \\
\text { consultivo } \\
\text { ou diretivo } \\
\text { da indústria } \\
\text { farmacêutica } \\
\text { ou de } \\
\text { equipamentos }\end{array}$ & $\begin{array}{l}\text { Participou } \\
\text { de comitês } \\
\text { normativos } \\
\text { de estudos } \\
\text { científicos } \\
\text { patrocinados } \\
\text { pela indústria }\end{array}$ & $\begin{array}{l}\text { Recebeu } \\
\text { auxílio pessoal } \\
\text { ou institucional } \\
\text { da indústria }\end{array}$ & $\begin{array}{c}\text { Elaborou } \\
\text { textos } \\
\text { científicos em } \\
\text { periódicos } \\
\text { patrocinados } \\
\text { pela indústria }\end{array}$ & $\begin{array}{c}\text { Tem ações da } \\
\text { indústria }\end{array}$ \\
\hline Adalberto Menezes Lorga & Não & Não & Não & Não & Não & Não & Não \\
\hline Almir Sergio Ferraz & Não & Pfizer & Daiichi-Sankyo & Não & Não & Cardios & Não \\
\hline Álvaro Vieira Moura & Não & Não & Não & Não & Não & Não & Não \\
\hline $\begin{array}{c}\text { Antonio Carlos Sobral } \\
\text { Sousa }\end{array}$ & Não & Não & Não & Não & Não & Não & Não \\
\hline Denilson Albuquerque & Não & $\begin{array}{c}\text { Pfizer, BMS, } \\
\text { Otsuka, MSD, } \\
\text { Servier }\end{array}$ & $\begin{array}{c}\text { Servier, } \\
\text { Sanofi-Aventis, } \\
\text { AstraZeneca }\end{array}$ & Não & $\begin{array}{l}\text { Sanofi-Aventis, } \\
\text { Pfizer, BM }\end{array}$ & Não & Não \\
\hline Dirceu Rodrigues & Não & $\begin{array}{c}\text { Servier, } \\
\text { Novartis, Amgen }\end{array}$ & $\begin{array}{c}\text { Pfizer, Baldacci, } \\
\text { Merck-Serono, } \\
\text { Servier }\end{array}$ & Não & Não & Não & Não \\
\hline Edimar Alcides Bocchi & Não & Amgen, Servier & $\begin{array}{l}\text { Servier, } \\
\text { Baldacci }\end{array}$ & Não & Não & Servier, Merck & Não \\
\hline Evandro Tinoco & Não & Não & $\begin{array}{c}\text { AstraZeneca, } \\
\text { Merck, Bohering }\end{array}$ & Não & Não & Não & $\begin{array}{c}\text { Sigmafarma, } \\
\text { Eurofarma }\end{array}$ \\
\hline $\begin{array}{c}\text { Fabiana Goulart Marcondes } \\
\text { Braga }\end{array}$ & Não & Não & Não & Não & Não & Merck & Não \\
\hline Fábio Vilas-Boas & Não & $\begin{array}{c}\text { Novartis, } \\
\text { Sanofi-Aventis, } \\
\text { Daiichi-Sankyo, } \\
\text { Jassen-Cilag, } \\
\text { Takeda, PGX } \\
\text { Health }\end{array}$ & $\begin{array}{c}\text { Novartis, } \\
\text { Servier, } \\
\text { Astrazeneca }\end{array}$ & Não & Não & Não & Não \\
\hline Fátima Cruz & Não & Não & Não & Não & Não & Não & Não \\
\hline Felix Ramires & Não & Novartis & Não & Não & Novartis & Não & Não \\
\hline Fernando Bacal & Não & não & Novartis & Não & não & Novartis & Não \\
\hline Harry Corrêa Filho & Não & Não & Não & Não & Não & Não & Não \\
\hline Humberto Villacorta Junior & Não & Não & Não & Não & Não & Não & Não \\
\hline Iran Castro & Não & Não & Não & Não & Não & Não & Não \\
\hline João David de Souza Neto & Não & $\begin{array}{c}\text { Novartis, } \\
\text { Amgen, Roche }\end{array}$ & $\begin{array}{c}\text { MSD, Merck } \\
\text { Serono, } \\
\text { Novartis }\end{array}$ & Não & Não & Não & Torrent \\
\hline João Manoel Rossi Neto & Não & Não & Não & Não & Não & Não & Não \\
\hline Lídia Zytynski Moura & Não & Novartis, Amgen & Não & Não & Não & Novartis & Não \\
\hline Luís Beck da Silva & Não & Não & $\begin{array}{l}\text { AstraZeneca, } \\
\text { Roche }\end{array}$ & Não & Não & Não & Não \\
\hline Luis Eduardo Rodhe & Não & Não & Não & Não & Não & Não & Não \\
\hline Luiz Felipe Moreira & Não & Não & Não & Não & Não & Não & Não \\
\hline
\end{tabular}




\begin{tabular}{|c|c|c|c|c|c|c|c|}
\hline $\begin{array}{c}\text { Nomes Integrantes da } \\
\text { Diretriz }\end{array}$ & $\begin{array}{l}\text { Participou } \\
\text { de estudos } \\
\text { clínicos e/ou } \\
\text { experimentais } \\
\text { subvencionados } \\
\text { pela indústria } \\
\text { farmacêutica ou } \\
\text { de equipamentos } \\
\text { relacionados } \\
\text { à diretriz em } \\
\text { questão }\end{array}$ & $\begin{array}{l}\text { Foi palestrante } \\
\text { em eventos } \\
\text { ou atividades } \\
\text { patrocinadas } \\
\text { pela indústria } \\
\text { relacionados } \\
\text { à diretriz em } \\
\text { questão }\end{array}$ & $\begin{array}{l}\text { Foi (é) membro } \\
\text { do conselho } \\
\text { consultivo } \\
\text { ou diretivo } \\
\text { da indústria } \\
\text { farmacêutica } \\
\text { ou de } \\
\text { equipamentos }\end{array}$ & $\begin{array}{l}\text { Participou } \\
\text { de comitês } \\
\text { normativos } \\
\text { de estudos } \\
\text { científicos } \\
\text { patrocinados } \\
\text { pela indústria }\end{array}$ & $\begin{array}{c}\text { Recebeu } \\
\text { auxílio pessoal } \\
\text { ou institucional } \\
\text { da indústria }\end{array}$ & $\begin{array}{c}\text { Elaborou } \\
\text { textos } \\
\text { científicos em } \\
\text { periódicos } \\
\text { patrocinados } \\
\text { pela indústria }\end{array}$ & $\begin{array}{l}\text { Tem ações da } \\
\text { indústria }\end{array}$ \\
\hline Marcelo Montera & Não & Não & $\begin{array}{l}\text { Merck Serono, } \\
\text { Abbott }\end{array}$ & $\begin{array}{l}\text { Servier, Merck } \\
\quad \text { Serono }\end{array}$ & Não & Não & Não \\
\hline Marcus Vinicius Simões & Não & $\begin{array}{c}\text { Novartis, } \\
\text { Amgen, Daiichi- } \\
\text { Sankyo }\end{array}$ & Não & Não & Não & Não & Não \\
\hline $\begin{array}{c}\text { Maria da Consolação } \\
\text { Moreira }\end{array}$ & Não & Não & Não & Não & Não & Não & Não \\
\hline Nadine Clausell & Não & Amgen & Não & Não & Não & Não & Não \\
\hline Reinaldo Bestetti & Não & Não & Saint-Jude & Não & Não & Não & Não \\
\hline Ricardo Mourilhe Rocha & Não & Amgen, $\mathrm{NIH}$ & Não & Não & Não & Não & Não \\
\hline Salvador Rassi & Não & $\begin{array}{l}\text { MSD, Novartis, } \\
\text { Servier, Astra- } \\
\text { Zaneca }\end{array}$ & Novartis, Biolab & Não & Não & Novartis & Não \\
\hline Sandrigo Mangini & Não & Não & Não & Não & Não & Não & Não \\
\hline Silvia Martins & Não & Novartis & Sanofi-Aventis & Não & Não & Não & Não \\
\hline Silvia Moreira Ayub Ferreira & Não & Amgen & Não & Não & Não & Não & Não \\
\hline Solange Bordignon & Não & Não & Não & Não & Não & Não & Não \\
\hline Victor Sarli Issa & Não & Não & Não & Não & Não & Não & Não \\
\hline
\end{tabular}




\section{Resumo}

Esta atualização da Diretriz de Insuficiência Cardíaca Crônica (IC) - 2012 surge para reavaliar as recomendações através de uma avaliação criteriosa das pesquisas (considerando-se a qualidade dos estudos), fundamental para que se atinja esse propósito. Para tanto, foi dada ênfase ao efeito em desfechos de morte, à qualidade "CONSORT" (Consolidated Standards of Reporting Trials), à descrição qualitativa e quantitativa da otimização da medicação, à população realmente incluída, às metanálises somente de estudos qualidade "CONSORT", à custo-efetividade, à existência de efeito de classe, ao número de pacientes incluídos e à análise de subgrupos apenas para gerar hipóteses. Na área da epidemiologia, as recentes abordagens das características da IC com fração de ejeção preservada (ICFEP) e da importância da IC como causa de morte no Brasil foram revisadas. Além disso, este documento contempla a reavaliação do valor dos biomarcadores no diagnóstico e no seguimento da IC, o papel diagnóstico da angiotomografia coronariana nos casos de risco intermediário ou baixo risco de doença coronariana, a não recomendação de rotina do telemonitoramento; o surgimento da avaliação familiar como recomendação importante, e a reavaliação da restrição da adição de sal na dieta. As clínicas de IC e reabilitação física, apesar de alguns resultados negativos ou controversos quanto à mortalidade, continuam com recomendação importante. No campo do tratamento farmacológico, abrange-se a reavaliação da indicação do nebivolol, introduz-se a ivabradina como um novo paradigma no tratamento, os antagonistas da aldosterona não têm efeito de classe reconhecido, o ômega 3 passa a ser recomendado, o ferro administrado por via endovenosa e o sildenafil recebem indicação em casos selecionados. Todas as recomendações para outras etiologias são expandidas para a Doença de Chagas. Na área da anticoagulação, recomenda-se a utilização dos escores CHA2DS2VASC e o HAS-BLED na fibrilação atrial, com introdução de inibidores da trombina e do fator Xa como alternativas na anticoagulação. No tratamento cirúrgico da IC, considerou-se que resultados neutros do estudo STICH influenciaram as recomendações, o transplante cardíaco continua a ser o tratamento indicado nas fases evolutivas tardias de IC, os dispositivos de assistência circulatória mecânica para terapia de destino passam a ter recomendação, a duração do QRS foi fundamental na indicação de TRV-AV, e o CDI continua com recomendação I para miocardiopatia isquêmica. Entretanto, baseada em análise crítica dos estudos considerando-se o custo-efetividade, o CDI não atingiu recomendação I para classes menos graves devido as limitações dos estudos. Também a importância da cardiotoxicidade por drogas para tratamento de neoplasias foi ressaltada, o tratamento da IC na gravidez e da miocardite foi revisado. Novos potenciais métodos de tratamento em fase de pesquisa são apresentados e novos fluxogramas de diagnóstico e tratamento da IC, reformulados, foram incluídos. 


\section{Diretrizes}

\section{Introdução}

Um dos desafios no desenvolvimento de Diretrizes é manter a constante atualização embasada em novos conhecimentos ou experiência na área de interesse. Com o objetivo de disponibilizar rapidamente uma atualização da III Diretriz Brasileira de Insuficiência Cardíaca, o Departamento de Insuficiência Cardíaca da Sociedade Brasileira de Cardiologia (DEIC) elaborou esta atualização centrada nos recentes avanços na área. Entre os critérios para inclusão de conhecimentos recentes destacaram-se: (1) publicações a partir de 2008 com revisões por pares; (2) estudos randomizados prospectivos controlados com placebo com qualidade "CONSORT"; (3) dados de estudos não randomizados de especial importância que influenciam decisões em insuficiência cardíaca; (4) reinterpretação de resultados de publicações anteriores a 2008; (5) prioridade para publicações de investigadores brasileiros; e (6) maior atenção para publicações nos Arq Bras Cardiol envolvendo temas de problemas brasileiros.

Quando a informação estava disponível na literatura, esta atualização da III Diretriz de Insuficiência Cardíaca, de maneira inovadora, também considerou a relação custo-benefício de cada procedimento para melhor aplicação de classe de recomendação.

Critério para classe de recomendação:

Classe I: consenso das opiniões dos especialistas ou evidências indicam o procedimento.

Classe Ila: evidências favorecem a indicação do procedimento ou a maioria dos especialistas na área indica o procedimento.

Classe Ilb: evidências são insuficientes para a indicação do procedimento ou não favorecem ou a maioria dos especialistas não indica o procedimento

Classe III: consenso ou evidências não indicam o procedimento.

Critério para Nível de Evidência:

a) Dados obtidos conforme orientações do CONSORT (Consolidated Standards of Reporting Trials), a partir de estudos de fase III, randomizados, prospectivos, placebo controlados ou de um estudo único de fase III com número elevado de pacientes (> 1000), com baixa incidência de efeitos adversos ou metanálises de estudos que também seguem as orientações do CONSORT. Para procedimentos invasivos são necessários pelo menos dois estudos com qualidade CONSORT. Ensaios clínicos não foram considerados conjuntamente quando não caracterizam efeito de classe. Para que novos estudos com qualidade CONSORT pudessem determinar modificações ou uma nova indicação para classe recomendação I, exigiu-se qualidade principalmente quanto ao critério de inclusão, desenho do estudo, poucas limitações, consistência, e nos desfechos analisados. Também foram considerados: (1) análise baseada na real característica da população incluída e não somente no critério de inclusão; (2) que os critérios de inclusão estivessem adequadamente esclarecidos; (3) quando era um procedimento de adição, foi necessário que o tratamento otimizado atingisse qualidade aceitável e estivesse devidamente descrito (exemplo: estudos com dispositivos não descrevem a dose de betabloqueador utilizada); (4) qualquer ajuste estatístico para fatores deve ter sido planejado na randomização; (5) efeito benéfico em desfecho "duro" isolado de mortalidade teve impacto maior para recomendação Classe I; (6) necessidade de perda de pacientes $<5 \%$; (7) número adequado de pacientes incluídos; (8) resultado não só com resultado estatístico positivo, mas com intensidade de impacto relevante; (9) disponibilidade de outros procedimentos alternativos para redução de objetivos envolvendo objetivos "não duros"; (10) estudo multicêntrico com maior importância do que unicêntrico; (11) análise de subgrupos geram hipóteses e não devem ser considerados como nível de evidência $A$. Exceção a ser analisada pode ocorrer quando o número de pacientes incluídos é de milhares; (12) duração do estudo; e (13) número da amostra com poder estatístico.

B) Dados obtidos de um único ensaio clínico de fase III randomizado, prospectivo randomizado, controlado, duplo-cego de qualidade CONSORT, sem inclusão de número elevado de pacientes; ou de estudos de fase II com inclusão de número limitado de pacientes, ou de vários estudos não randomizados com alto impacto clínico.

C) Dados obtidos de estudos que incluíram série de casos e dados obtidos do consenso e opiniões de especialistas.

Para consideração de Classe I, também foi verificada a relação custo-efetividade do procedimento, principalmente para tratamento de alto custo/complexidade, respeitando-se a política pública na área, os recursos disponíveis e as prioridades. Também, para recomendação de Classe I, deu-se preferência para procedimentos/tratamento com nível de evidência A, desde que embasados em estudos de qualidade. Procedimentos com relação custo-efetividade não aceitável para a realidade social brasileira não receberam Classe I de recomendação.

Buscando evidências de investigações científicas baseadas na população brasileira e problemas brasileiros, pesquisa utilizando as palavras heart failure and Brazil no http://www.ncbi.nlm.nih. gov/pubmed obteve 351 publicações. Destas, foram excluídas da análise investigações em IC descompensada, revisões, estudos experimentais, investigações de fisiopatologia não passíveis de inclusão, relatos de casos, não relacionados ao tema, impossibilidade de acesso à publicação e pesquisa publicada dentro de um efeito "salame", restando 111 publicações. Para inclusão na atualização, foi julgado o mérito de cada publicação quanto a sua relevância no tema, tendo sido incluídas 52 publicações adicionalmente na revisão final do texto.

O Departamento de Insuficiência Cardíaca da Sociedade Brasileira de Cardiologia orientou que esta Diretriz fosse isenta de influência de conflito de interesses. Assim, todos os participantes declararam os seus.

\section{Epidemiologia}

No último censo (2010), observa-se crescimento da população idosa no Brasil e, portanto, com potencial crescimento de pacientes em risco ou portadores de insuficiência cardíaca (IC). Na cidade de Niterói, 64,2\% das IC se caracterizaram como IC de fração de ejeção preservada (ICFEP) em uma população com idade média de 61 anos ${ }^{1}$. A ICFEP foi mais prevalente em mulheres idosas. A IC com fração de ejeção reduzida foi mais comum em homens e associada com edema, doença coronariana, insuficiência renal crônica, escores de Boston mais 
elevados, uso de álcool, cigarro e hospitalizações. Em outro estudo, a prevalência de ICFEP foi de $31 \%$ em pacientes internados e associada à idade $>70$ anos, sexo feminino, etiologia não isquêmica, fibrilação ou fluter atrial, anemia, pressão de pulso $>45 \mathrm{mmhg}$ e ausência de alteração eletrocardiográfica². Entretanto, disfunção sistólica foi encontrada em $55 \%$ dos pacientes com IC descompensada em outro estudo e as etiologias foram isquêmica em $29,7 \%$; hipertensiva em 20,8\%; valvular em 15\%; chagásica em $14,7 \%$; idiopática em $8 \%$ e outras em $11,8 \%{ }^{3}$. Na cidade de Niterói, de 1998 a 2007, houve aumento da mortalidade por IC e doença cerebrovascular ${ }^{4}$. Em regiões endêmicas, a doença de Chagas é a principal etiologia da IC em $41 \%$ dos pacientes ${ }^{5}$. Entretanto, houve redução da mortalidade devido à IC por doença de Chagas no Estado de São Paulo, entre 1985 e $2006^{6}$. Em zonas rurais, estudos mostram que a etiologia mais frequente é a hipertensão arterial. A ICFEP é mais frequente no sexo feminino e a IC com FE reduzida no sexo masculino, havendo predomínio da etiologia isquêmica ${ }^{7}$

Dados da Fundação Seade revelam que, em 2006, a IC ou etiologias associadas com IC foram responsáveis por 6,3\% dos óbitos no Estado de São Paulo ${ }^{8}$. Em 42\% dos casos, não foi possível determinar a etiologia, sendo observada cardiomiopatia em 23\% destes, hipertensão arterial em $14 \%$, doença isquêmica em $9 \%$, doença de Chagas em $8 \%$, choque cardiogênico em $1 \%$, doença pericárdica em $0,04 \%$, amiloidose em $0,1 \%$, doença de Chagas aguda em $0,006 \%$, e outras cardiopatias em $3 \%$. Houve tendência de redução de mortalidade por IC entre 1999 a 2005, exceto para pacientes acima de 80 anos, com média de $11 \pm 9,3 \%{ }^{9}$.

Dados recentes do estudo MESA (Multi-Ethnic Study of Atherosclerosis) demonstram que diabetes e hipertensão são os responsáveis pela maior incidência de IC em afroamericanos ${ }^{10}$. Neste mesmo estudo, interleucina 6, ou proteína $\mathrm{C}$ reativa, e macroalbuminúria foram preditores independentes do desenvolvimento de $\mathrm{IC}^{11}$. Outros fatores de risco para IC são infecção e proliferação do vírus da imunodeficiência adquirida e medicações para tratamento de neoplasias malignas ${ }^{12,13}$.

\section{Abordagem do Paciente com Insuficiência Cardíaca}

A Figura 1 sugere um fluxograma para melhor diagnóstico da IC.

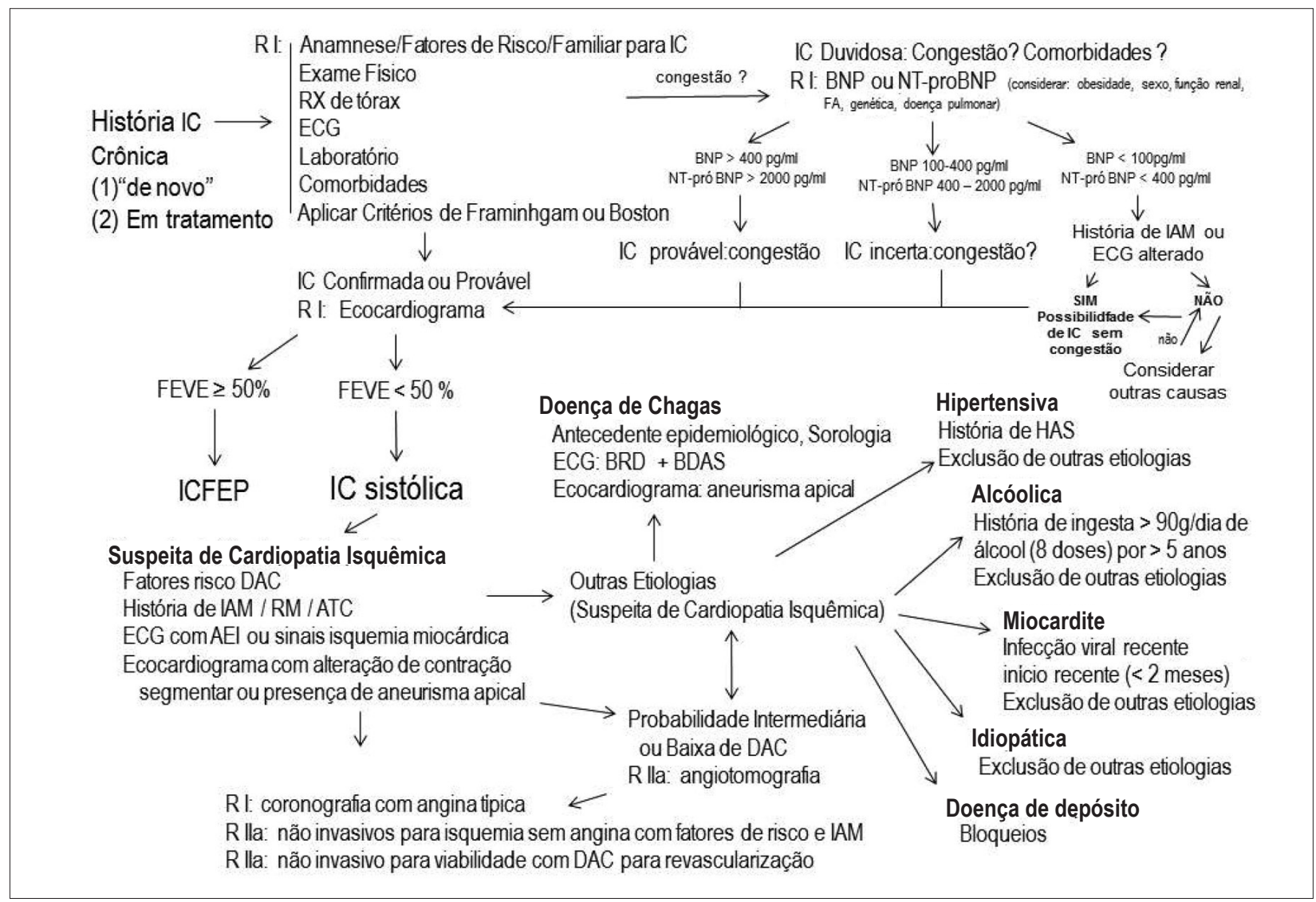

Figura 1 - Fluxograma de Diagnóstico da Insuficiência Cardíaca e da Etiologia. IC significa insuficiência cardíaca; $R$, classe de recomendação; $R X$, radiografia de tórax; $B N P$, brain natriuretic peptide; FEVE, fração de ejeção de ventrículo esquerdo; ICFEP, insuficiência cardíaca com fração de ejeção preservada; DAC, doença arterial coronariana; IAM, infarto agudo do miocárdio; RM, revascularização miocárdica; ECG, eletrocardiograma; AEI, área inativa; BRD, bloqueio de ramo direito; BDAS, bloqueio divisional anterossuperior; HAS, hipertensão arterial sistêmica. Figura modificada de Bocchi EA. Aula para Graduação. 


\section{Diretrizes}

\subsection{Métodos Diagnósticos}

\subsubsection{Eletrocardiograma}

Recentemente se demonstrou que escore eletrocardiográfico tem correlação positiva com fibrose miocárdica e correlação negativa com a fração de ejeção de ventrículo esquerdo (FEVE) em pacientes com cardiomiopatia chagásica ${ }^{14}$. Também a variabilidade de amplitude da onda T em pacientes chagásicos foi relacionada a pior prognóstico ${ }^{15}$.

\subsubsection{Troponina e Polimorfismo}

Nos últimos anos, a detecção de troponina e sua magnitude têm sido motivo de investigação no cenário da IC crônica, sendo verificado valor na avaliação de injúria miocárdica mesmo subclínica, e também estratificação prognóstica ${ }^{16}$. Limitações quanto à sensibilidade motivaram o desenvolvimento de método mais acurado, como a troponina ultrassensível, que em estudos iniciais tem demonstrado sua importância especialmente quando comparado à troponina sérica convencional ${ }^{17}$. Ensaios futuros relevantes devem definir sua real indicação e importância na prática clínica. Certos polimorfismos da metaloproteinases podem estar associados a maior incidência de doença isquêmica e melhor prognóstico ${ }^{18}$.

\subsubsection{BNP/NTproBNP (Tabela 1)}

Nas situações em que há dúvida no diagnóstico da IC de FE reduzida e IC de FE preservada (ICFEP), a dosagem do pepídeo natriurético do tipo $\mathrm{B}$ (BNP) pode ser útil para o diagnóstico de congestão pulmonar. Em metanálise recentemente publicada, a adição da dosagem de BNP ao exame clínico aumentou a acurácia diagnóstica ${ }^{19}$. Portanto, nas situações de dúvida, o BNP pode ser utilizado, somado ao exame clínico. Os valores de corte para IC crônica não foram especificamente estudados.
Nos casos de pacientes sem história de infarto do miocárdio ou ECG normal, pode ser realizado antes do ecocardiograma, segundo análises de custo-efetividade ${ }^{20}$. A dosagem de BNP no líquido pleural pode ser útil para diagnóstico de derrame pleural devido a IC ${ }^{21}$. Na doença de Chagas, BNP e peptídeo natriurético atrial (ANP) têm valor prognóstico e podem estar elevados em pacientes assintomáticos ${ }^{22}$.

\subsubsection{Ecodopplercardiograma (Tabela 2)}

Reavaliação ecocardiográfica periódica não deve ser procedimento de rotina em pacientes estáveis. Pode ter utilidade clínica em pacientes que apresentam piora clínica evidente, visando readequar manejo terapêutico. Neste contexto, informações úteis são: piora de parâmetros de função ventricular esquerda e direita, estimativas hemodinâmicas e surgimento de valvulopatias funcionais.

\subsubsection{Imagem por Medicina Nuclear - SPECT e PET} (Tabela 3)

Os resultados do estudo $\mathrm{STICH}$, comparando os desfechos clínicos em função da presença ou não de viabilidade através de SPECT ou ecocardiografia de estresse arrefeceram o entusiasmo com a sua pesquisa sistemática, uma vez que a melhora com a revascularização, nesse estudo, foi independente da presença de viabilidade, pesquisada por esses métodos ${ }^{23}$. Dúvidas persistem se os resultados teriam sido diferentes caso o método de pesquisa de viabilidade tivesse sido PET ou ressonância cardíaca.

\subsubsection{Tomografia Computadorizada Cardíaca e Ressonância Magnética (Tabelas 3 e 4)}

A angiotomografia coronária permite excluir de forma não invasiva a presença de doença arterial coronariana significativa, principalmente em pacientes de baixo risco ou

Tabela 1 - Orientações para o uso do BNP e NT-proBNP na Insuficiência Cardíaca Crônica

\begin{tabular}{|c|c|c|}
\hline Classe de Recomendação & Indicações & Nível de Evidência \\
\hline I & Dosagem do BNP/NT-proBNP quando há dúvida no diagnóstico da IC & A \\
\hline Ila & Dosagem do BNP/NT-proBNP para estratificação prognóstica em pacientes com IC & A \\
\hline Ilb & $\begin{array}{l}\text { Medidas seriadas de BNP/NT-proBNP como complemento ao exame físico para guiar tratamento } \\
\text { em pacientes com IC }\end{array}$ & $A$ \\
\hline
\end{tabular}

IC significa insuficiência cardíaca; BNP, peptídeo natriurético do tipo B; NT-proBNP, fração N-terminal do pro-hormônio BNP

Tabela 2 - Orientações para o uso do Ecodopplercardiograma na Insuficiência Cardíaca Crônica

\begin{tabular}{lrc}
\hline Classe de Recomendação & Indicações & Nível de Evidência \\
\hline I & Ecodopplercardiograma na avaliação inicial de todo paciente com IC & C \\
\hline Ila & Reavaliação ecocardiográfica quadro clínico indica modificação do manejo terapêutico & C \\
\hline III & Ecodopplercardiograma como parâmetro único para selecionar candidatos à terapêutica de \\
ressincronização & \\
\hline
\end{tabular}

IC significa insuficiência cardíaca 
risco intermediário ${ }^{24}$. Esse método pode ser utilizado ainda para avaliar a função ventricular, direita e esquerda, quando outras metodologias não estão disponíveis (portadores de marca-passo ou janela ecocardiográfica inadequada).

\subsubsection{Teste Ergoespirométrico}

Diante da estabilidade clínica e sem contraindicações ao exercício, indica-se preferencialmente para avaliação do paciente o teste de esforço ergoespirométrico ou alternativamente o teste de caminhada de 6 minutos usual ou monitorizado $^{25}$, ou o teste ergométrico ${ }^{26,27}$. Sabe-se que o uso de betabloqueador (BB) reduz a frequência cardíaca máxima durante exercício ${ }^{28}$. Com a utilização de BB, o valor de consumo máximo de oxigênio durante exercício $\left(\mathrm{VO}_{2}\right)$ de 10-12,5 ml $/ \mathrm{kg}$ / min e a inclinação da relação VE/VCO2 > 35 parecem separar pacientes com IC quanto ao prognóstico ${ }^{29,30}$.

\section{Seguimento Clínico (Tabela 5)}

\subsection{NT-proBNP e BNP}

Três novos estudos e uma metanálise, avaliando o papel de dosagens seriadas de BNP ou da fração $\mathrm{N}$-terminal do prohormônio do BNP (NT-proBNP) para guiar tratamento foram publicados. O estudo TIME-CHF avaliou 499 pacientes com idade $\geq 60$ anos e Fração de Ejeção do Ventrículo Esquerdo $(\mathrm{FEVE})<45 \%{ }^{31}$. Não houve diferença entre o grupo guiado por BNP e o grupo guiado por sintomas em relação ao desfecho primário - sobrevida livre de hospitalização por todas as causas. No entanto, houve benefício no desfecho secundário de sobrevida livre de hospitalização por IC. Houve benefício para grupo guiado por BNP na idade entre 60 a 75 anos, mas não no acima de 75 anos. O estudo BATTLESCARED não demonstrou benefício de dosagens seriadas de NT-proBNP para

Tabela 3 - Investigação da Cardiopatia Isquêmica no Paciente com Insuficiência Cardíaca e Disfunção Sistólica

\begin{tabular}{lc}
\hline Classe de Recomendação & Indicações \\
\hline I & Coronariografia no paciente com IC e angina típica \\
\hline & $\begin{array}{c}\text { Coronariografia no paciente com IC, sem angina, com fatores de risco para DAC ou com história de IAM } \\
\text { Métodos de avaliação não invasiva de isquemia (eco estresse, medicina nuclear ou RMC) em } \\
\text { paciente com IC, sem angina típica, com fatores de risco para DAC ou com história de IAM }\end{array}$ \\
\cline { 2 - 3 } & $\begin{array}{c}\text { Métodos de avaliação não invasiva de viabilidade miocárdica (eco estresse, medicina nuclear ou } \\
\text { RMC) em paciente com IC com DAC considerados para revascularização miocárdica }\end{array}$ \\
\cline { 2 - 3 } & Angiotomografia coronária para detecção de doença arterial coronária obstrutiva em pacientes com \\
fração de ejeção reduzida e baixa probabilidade ou intermediária de DAC.
\end{tabular}

IC significa insuficiência cardíaca; DAC , doença arterial coronária; IAM, infarto agudo do miocárdico; RNM, ressonância nuclear magnética

Tabela 4 - Indicações de Tomografia Cardíaca em Pacientes com Disfunção Ventricular, Doenças Miocárdicas ou Pericárdicas

\begin{tabular}{|c|c|c|}
\hline Classe de Recomendação & Indicações & Nível de Evidência \\
\hline \multirow[b]{2}{*}{ Ila } & Avaliação da anatomia pericárdica na suspeita de pericardite constrictiva & C \\
\hline & $\begin{array}{l}\text { Avaliação da morfologia ventricular direita em suspeita de cardiopatia arritmogênica do ventrículo } \\
\text { direito }\end{array}$ & C \\
\hline
\end{tabular}

Tabela 5 - Orientações para Seguimento na Insuficiência Cardíaca Crônica

\begin{tabular}{|c|c|c|}
\hline Classe de Recomendação & Indicações & Nível de Evidência \\
\hline I & Avaliar a cada consulta o estado funcional e volêmico, por anamnese e exame físico focados para IC & C \\
\hline I & Monitorar periodicamente eletrólitos e parâmetros de função renal & $\mathrm{B}$ \\
\hline I & Avaliar adesão do paciente a medidas de restrição hidrossalina & C \\
\hline Ila & $\begin{array}{c}\text { Reavaliação ecocardiográfica em pacientes cujo quadro clínico necessite readequar o manejo } \\
\text { terapêutico }\end{array}$ & C \\
\hline$\| \mathrm{lb}$ & $\begin{array}{l}\text { Medidas seriadas de BNP/NT-proBNP como complemento ao exame físico para guiar tratamento } \\
\text { em pacientes com IC }\end{array}$ & A \\
\hline Ilb & Telemonitoramento para o seguimento de pacientes com IC & A \\
\hline III & $\begin{array}{l}\text { Realizar ecocardiografia de forma seriada para avaliação de fração de ejeção de ventrículo } \\
\text { esquerdo em pacientes estáveis }\end{array}$ & C \\
\hline
\end{tabular}




\section{Diretrizes}

guiar tratamento ${ }^{32}$. Contudo, observou-se melhora na sobrevida de longo prazo no grupo guiado por peptídeos natriuréticos, em indivíduos abaixo de 75 anos. O estudo PRIMA também falhou em demonstrar superioridade do tratamento guiado por NT-proBNP em comparação ao manuseio convencional ${ }^{33}$ Metanálise de 8 ensaios clínicos envolvendo 1.726 pacientes mostrou redução de $30 \%$ na mortalidade no grupo guiado por peptídeos natriuréticos em comparação ao manuseio convencional, especialmente em indivíduos abaixo de 75 anos. Não houve, no entanto, redução nas taxas de hospitalização ${ }^{34}$.

Portanto, apesar de haver sugestão de aumento de sobrevida em pacientes mais jovens, essa é uma área ainda controversa e não há evidências no momento que sustentem a utilização rotineira de dosagens seriadas dos peptídeos natriuréticos para guiar tratamento.

\subsection{Telemonitoramento (Telemedicina)}

Os métodos de telemonitoramento (telemedicina) empregados em estudos foram através de telefone com transmissão de dados não invasivos ou de medidas hemodinâmicas invasivas, transmitidas para uma central, quer seja em tempo real ou para arquivos ou híbrido. Três métodos de transmissão podem ser utilizados: via dispositivos portáteis, "smart phones", e comunicação "wireless". Os sistemas podem ser somente de formação de arquivo ou resposta não imediata ou imediata. Estudos utilizando estratégias não invasivas de telemonitoramento não têm demonstrado benefício quanto à mortalidade, tendo dois estudos incluído número elevado de pacientes (Tele-HF com 1.653 e TIM-HF com 710 pacientes) ${ }^{35-37}$. A baixa adesão pode ter contribuído para os resultados neutros. A ausência de interação adequada entre paciente e profissional de saúde, de educação repetitiva e de conteúdo podem ser empecilhos para bons resultados, especialmente quando comorbidades como depressão são frequentes como na IC. A depressão pode estar relacionada a maior ativação neuro-hormonal e pior qualidade de vida ${ }^{38,39}$. Entretanto, no estudo HOME-HF, com 182 pacientes em que não se demonstrou diferença entre o grupo intervenção e o controle quanto ao desfecho primário (dias vivos fora do hospital), observou-se redução nas hospitalizações por IC e visitas à unidade de emergência no grupo de telemonitoramento ${ }^{40}$. Metanálises têm demonstrado efeito benéfico do telemonitoramento ${ }^{41}$.

O estudo multicêntrico CHAMPION com 550 pacientes, que avaliou a estratégia de manuseio baseado na transmissão sem fio de dados hemodinâmicos obtidos através de um cateter arterial pulmonar comparado ao manuseio convencional, em pacientes com IC classe funcional III e hospitalização prévia por IC, demonstrou com a telemonitorização redução significativa de $39 \%$ nas hospitalizações por IC ${ }^{42}$. O impacto na mortalidade não é conhecido. No estudo COMPASS-HF, com inclusão de 274 pacientes, o cuidado baseado em contínua avaliação hemodinâmica não reduziu eventos relacionados com IC, embora o número de pacientes possa não ter poder estatístico ${ }^{43}$.

Baseado nos estudos disponíveis no momento, não há dados suficientes para indicar a telemonitorização de forma rotineira no manuseio de pacientes com IC além de programas de educação e monitoramento usual ${ }^{44}$, embora possa haver benefícios de redução de hospitalizações em pacientes selecionados, de alto risco, com a utilização de dispositivos invasivos.

\subsection{Prognóstico}

Nos pacientes com etiologia chagásica, a presença de taquicardia ventricular sustentada ou não sustentada é preditor de prognóstico reservado, embora a FEVE $<40 \%$ seja o único preditor independente de mortalidade ${ }^{45}$. Pacientes chagásicos em lista de espera para transplante cardíaco também apresentam pior prognóstico em relação a outras etiologias ${ }^{46}$. O volume de átrio esquerdo na IC devido à doença de Chagas parece ter valor prognóstico independente ${ }^{47}$. Em pacientes de etiologia não chagásica, a largura do QRS > 120 ms quando associada à pressão de pulso estreita $(<40 \mathrm{mmHg})$ identificou pacientes ambulatoriais com significativo aumento de mortalidade e significativa correlação com função ventricular diminuída. Esta é uma ferramenta facilmente disponível e de baixo custo para identificar pacientes ambulatoriais de maior risco (aproximadamente 70\% de mortalidade em 5 anos) ${ }^{48}$.

\subsection{Avaliação Familiar (Tabela 6)}

Devido ao caráter familiar de algumas etiologias de IC, são necessários na suspeita destas a avaliação e o rastreamento familiar ${ }^{49}$. Nas cardiomiopatias dilatadas, avaliação de familiares de primeiro grau dos pacientes pode revelar cardiomiopatia dilatada em 20-35\% com componente familiar. Causa genética familiar é descrita em 30-35\% da cardiomiopatias dilatadas. Atualmente, 33 gens estão associados ao diagnóstico de cardiomiopatia dilatada. História de 3-4 gerações deve ser obtida, parentes de primeiro grau devem ser avaliados na cardiomiopatia dilatada idiopática a cada 3-5 anos, pois a manifestação pode ser idade dependente através de histórico, exame, ECG e ecocardiograma. Testes genéticos podem ser considerados na

Tabela 6 - Orientações para Avaliação Familiar e Rastreamento para Miocardiopatias (Hipertrófica, Dilatada, Cardiopatia Arritmogênica de VD, Não Compactada e Restritiva)

\begin{tabular}{lc}
\hline Classe de Recomendação & Indicações \\
\hline I & Avaliar história familiar por três ou mais gerações em pacientes com miocardiopatias. \\
\hline I & Rastreamento inicial, clínico e por método de imagem, de familiares em primeiro grau de pacientes \\
com miocardiopatias.
\end{tabular}

VD significa ventrículo direito 
cardiomiopatia dilatada de caráter familiar, com inclusão de parentes, mas a sensibilidade é baixa em torno de 15-25\%.

\section{Tratamento Não Farmacológico}

A Figura 2 sugere um fluxograma para tratamento da IC crônica.

\subsection{Ingestão de Sódio (Tabela 7)}

A orientação da atualização da Diretriz foi influenciada pela polêmica da quantidade permitida de sal adicionado à dieta de pacientes com IC. Dieta com baixo teor de sódio (2 g) foi associado à redução de ingestão de proteína, ferro, zinco, selenium, vitamina B12, e aumento da ativação neuro-hormonal, o que pode ser prejudicial para estado nutricional do paciente. Dieta com 6,6 g de sal reduziu ativação neuro-hormonal ${ }^{50}$. Restrição da ingesta de sal para $3 \mathrm{~g}$ só beneficiou pacientes com IC avançada ${ }^{51}$. Dieta com teor normal de sódio foi associada à melhor evolução ${ }^{52}$, e em metanálise a restrição de sódio aumentou mortalidade ${ }^{53}$. Entretanto, outros estudos mostraram benefício da restrição de sódio ${ }^{54,55}$. Assim, ainda não está bem definido o valor ideal de sódio a ser usado na dieta de pacientes com IC, que deve ser adaptado à situação clínica do paciente.

\subsection{Vacinação (Tabela 8)}

A taxa de vacinação para influenza e pneumococo é reduzida em nosso meio ${ }^{56}$. A vacina pneumocócica, polivalente, deve ser administrada em dose única com reforço após os 65 anos e em pacientes com alto risco (não realizar este reforço com intervalo menor que cinco anos) e a vacina anti-influenza deve ser administrada anualmente ${ }^{57}$.

\subsection{Clínicas de IC e Programas de Manejo de Doença Crônica em IC (Tabela 9)}

Programas de manejo de doença crônica com educação e monitoração em clínica de IC em nosso meio foram

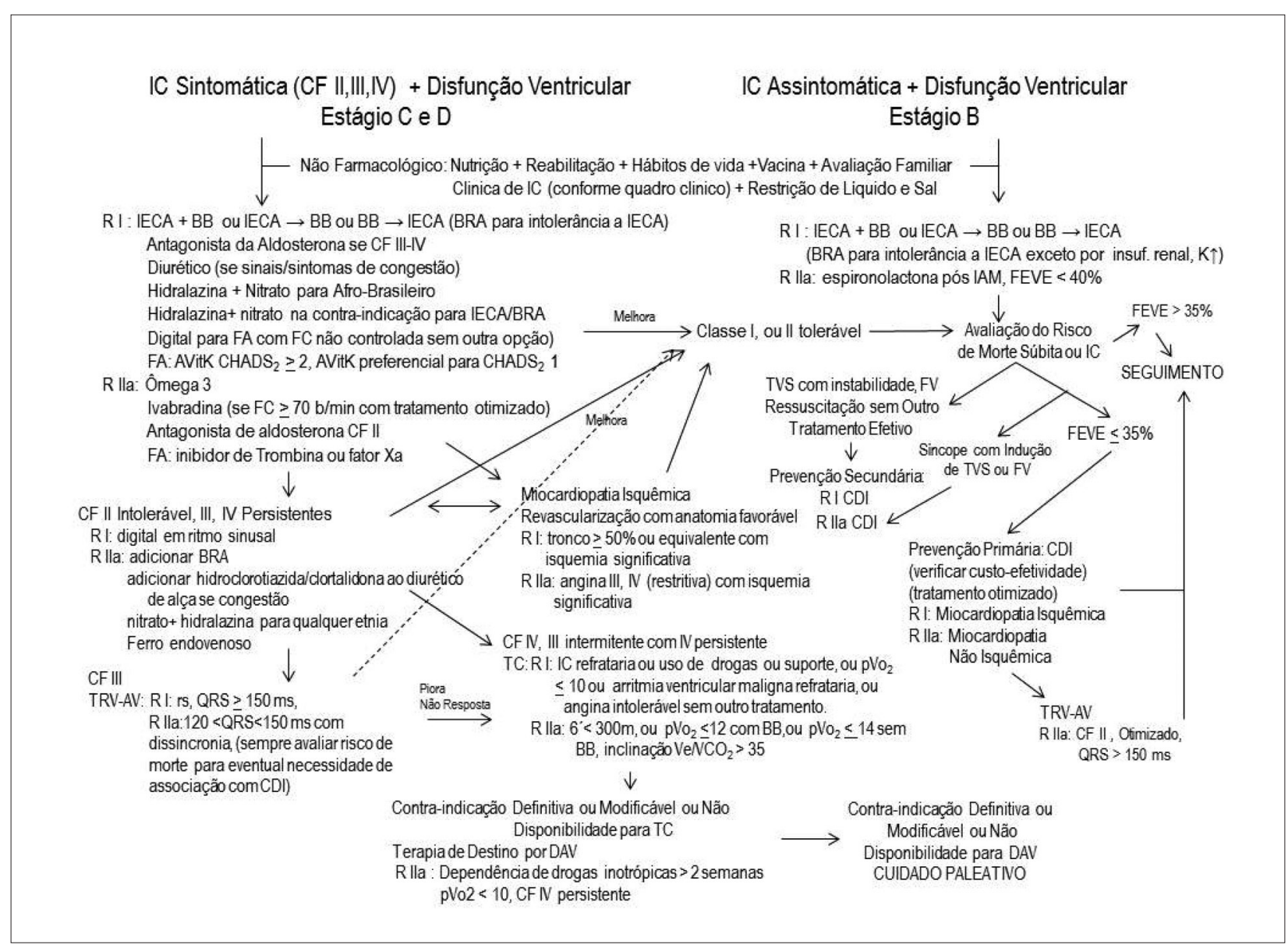

Figura 2 - Fluxograma de Tratamento da Insuficiência Cardíaca. Para aplicação de um método de tratamento, as respectivas contraindicações têm que ser consideradas. A figura é uma sugestão, e a decisão final cabe ao médico diante do seu paciente. IC significa insuficiência cardíaca; CF, classe funcional da New York Heart Association; $R$, classe de recomendação; IECA, inibidor da enzima conversora de angiotensina; $B B$, betabloqueador; $B R A$, antagonista do receptor de angiotensina l; $R S$, ritmo sinusal; $F A$, ritmo de fibrilação atrial; AVitK, antagonista da vitamina K; FC, frequência cardiaca; QRS, duração do complexo QRS; CDI, cardiodesfibrilador implantável; FEVE, fração de ejeção de ventrículo esquerdo; TVS, taquicardia ventricular sustentada; $F V$, fibrilação ventricular; TRV-AV, terapia de ressincronização ventricular e atrioventricular por dispositivo; $p$ VV ${ }_{2}$, pico de consumo máximo de oxigênio durante exercício; 6', distância caminhada no teste de 6 minutos; inclinação VeNCO2, coeficiente angular na relação Ve/NCO2; TC, transplante cardiaco; DAV, dispositivo de assistência ventricular. Figura modificada de Bocchi EA. Aula para Graduação. 


\section{Diretrizes}

associados à melhor adesão, menor número de dias internados, de hospitalizações, de atendimentos em unidades de emergência, de qualidade de vida, redução do desfecho combinado de hospitalização e mortalidade, e melhora do conhecimento do autocuidado $44,58,59$. Enfermeiras treinadas aparentam ter a mesma capacidade do que cardiologistas para fazer diagnóstico de congestão em $I C^{60}$. Avaliações e seguimento por enfermeiras podem diminuir hospitalização ${ }^{61}$. Revisão e metanálise sugerem redução de mortalidade e de hospitalização com programas de doença crônica na IC ${ }^{62}$. Entretanto, o estudo multicêntrico $\mathrm{COACH}$ com inclusão de 1.023 pacientes não demonstrou redução de mortalidade ou hospitalização ${ }^{63}$. As características do programa aplicado e o fato de ser operador dependente podem influenciar os resultados.

\subsection{Reabilitação e Treinamento Físico (Tabela 10)}

Em geral médicos não orientam pacientes com IC para a realização de exercício ${ }^{64}$. A reabilitação ou atividade física programada melhora a qualidade de vida, capacidade para exercício, contudo os resultados para sobrevida e hospitalizações são conflitantes ${ }^{65,66}$. A melhora de qualidade de vida pode ser mais importante na etiologia chagásica que apresenta maior comprometimento ${ }^{67}$. Na etiologia chagásica, o exercício em estudo randomizado prospectivo aumentou a capacidade de exercício e a qualidade de vida ${ }^{68}$. Estudo no nosso meio demonstrou que a idade não influencia a resposta ao exercício ${ }^{69}$. Outros métodos de treinamento têm sido utilizados como o treinamento complementar de músculos inspiratórios que pode ser indicado naqueles pacientes com IC que apresentam fraqueza da musculatura respiratória (> $70 \%$ da pressão inspiratória máxima predita) ${ }^{70-72}$; pilates p $^{73,74}$; treino intervalado e contínuo ${ }^{66,75,76}$; eletroestimulação ${ }^{77}$; e hidroterapia ${ }^{78,79}$. Intensidades diferentes de exercício podem ter ação diferente na fisiopatologia da $\mathrm{IC}^{80}$. Dentre os mecanismos de ação de alguns desses métodos de reabilitação, inclui-se a redução da sensibilidade dos quimiorreceptores descrita durante exercício ${ }^{81-83}$.

Revisão sistemática e metanálise sugerem que o procedimento é seguro, com efeitos positivos no perfil inflamatório ${ }^{84}$, na sobrevida e raros efeitos adversos relacionados ao exercício ${ }^{85}$. Contudo, no estudo com maior número de pacientes incluídos, ACTION-HF ${ }^{86}$, o resultado foi negativo para redução de mortalidade total e reinternações, com benefício para qualidade de vida. As conclusões deste estudo negativo para mortalidade e positivo para segurança podem ser criticadas pela baixa aderência. Apesar da limitação da efetividade, a prescrição de exercício parece ser custo-efetivo no nosso meio ${ }^{87}$.

Tabela 7 - Orientações para o Tratamento Nutricional de Pacientes com Insuficiência Cardíaca Crônica

\begin{tabular}{lcc}
\hline Classe de Recomendação & Indicações & Nível de Evidência \\
\hline I & Dieta saudável com adição de até $6 \mathrm{~g}$ de sódio, individualizada conforme as características do paciente. \\
\hline
\end{tabular}

Tabela 8 - Orientações para a Prevenção de Fatores Agravantes na Insuficiência Cardíaca Crônica

\begin{tabular}{lc}
\hline Classe de Recomendação & Indicações \\
\hline I & Vacinar contra Influenza e Pneumococcus caso não haja contraindicação \\
\hline
\end{tabular}

Tabela 9 - Clínicas de Insuficiência Cardíaca

\begin{tabular}{lcc}
\hline Classe de Recomendação & Indicações & Nível de Evidência \\
\hline & $\begin{array}{c}\text { O acompanhamento dos pacientes em Clínicas de IC para melhorar a adesão ao tratamento, } \\
\text { a qualidade de vida, diminuir dias de hospitalização, e visitas em unidades de emergência } \\
\text { relacionadas à IC }\end{array}$ & A \\
\hline
\end{tabular}

IC significa insuficiência cardiaca

Tabela 10 - Reabilitação Cardiovascular em Insuficiência Cardíaca Crônica

\begin{tabular}{lcc}
\hline Classe de Recomendação & Indicações & Nível de Evidência \\
\hline I & Reabilitação Cardiovascular para pacientes com IC crônica estável em classe funcional II-III (NYHA) & A \\
\hline
\end{tabular}

IC significa insuficiência cardiaca; NYHA, New York Heart Association 


\section{Tratamento Farmacológico}

A Figura 2 esquematiza a estratégia de tratamento para uso de fármacos e dispositivos em pacientes com IC sintomática e disfunção sistólica.

A avaliação e valorização da relevância de resultados de grandes estudos randomizados prospectivos tem sido comprometida pela ausência de otimização ou de informações de maneira quantitativa relativas à otimização da medicação preconizada na IC. No estudo SHIFT, que pode refletir o mundo real na terapêutica otimizada da IC dos grandes estudos, $26 \%$ dos pacientes estavam utilizando a dose alvo e 56\% estavam em uso de 50\% da dose alvo de $\mathrm{BB}^{88}$. No SHIFT, as razões obrigatoriamente tinham que ser mencionadas para não utilização da dose preconizada, e foram: hipotensão (44-45\%), fadiga (32\%), dispneia (15\%), tonturas (12-13\%), bradicardia (6\%), e outras (9-10\%). Razões para o não uso de BB (11-10\%) foram: Doença Pulmonar Obstrutiva Crônica (DPOC), hipotensão, asma, descompensação, bradicardia, tonturas, fadiga, doença vascular periférica e outras. Nos outros grandes estudos, principalmente relacionados a dispositivos (ressincronizador/desfibriladores), a limitação pode ser ainda maior com menor uso da dose preconizada de BB, pois, no estudo SHIFT, o investigador era forçado a justificar a dose utilizada de BB, buscando criar um estímulo para uso da dose o mais próximo do preconizado.

\subsection{Betabloqueadores (Tabela 11)}

Os BB associados à IECA ou BRA determinam benefícios clínicos na mortalidade global, na morte por IC e na morte súbita, além de melhora dos sintomas e redução de reinternação por $\mathrm{IC}^{89-91}$. O primeiro estudo com BB com maior número de pacientes foi o estudo MDC, que incluiu 383 pacientes com cardiomiopatia dilatada idiopática e utilizou tartarato de metoprolol na dose alvo de 100-150 $\mathrm{mg}^{92}$. Obteve-se tendência a menor número de desfechos primários $(p=0,058)$ e de redução de pressão de capilar pulmonar $(p=0,06)$, melhora da FEVE $(p<0,0001)$ e da capacidade de exercício ( $p=0,046)$. No estudo MERIT$\mathrm{HF}$, houve redução de mortalidade com metoprolol CR/ XL (longa duração) dose alvo de $200 \mathrm{mg}$ uma vez ao dia ${ }^{90}$.
O estudo COMET, que comparou carvedilol 25 mg duas vezes dia versus tartarato de metoprolol (curta duração) 50 mg também duas vezes ao dia como doses alvos, demonstrou maior benefício na redução de mortalidade com carvedilol ${ }^{93}$. Entretanto, de acordo com autores do estudo MDC, carvedilol $25 \mathrm{mg}$ duas vezes deveria ter sido comparado a tartarato de metoprolol $50 \mathrm{mg}$ quatro vezes ao dia, que seria sua dose ideal ${ }^{94}$. Em relação ao nebivolol, no estudo SENIORS, análise não pré-especificada gerou a hipótese de que esse agente poderia beneficiar pacientes com a mesma característica dos estudos com outros BB, entretanto ainda precisa ser testado em população menos idosa ( $<70$ anos) para ter seu uso preconizado nesta faixa etária. Buscar benefício com BB em idosos com IC continua um desafio. No estudo SENIORS, que incluiu pacientes com idade $\geq 70$ anos, o nebivolol reduziu somente desfecho combinado de mortalidade total e hospitalização cardiovascular de 31,1\% para $35,3 \%{ }^{95}$. O nebivolol não reduziu mortalidade. A FEVE média foi $36 \%$ e $35 \%$ dos pacientes tinham FEVE > 35\%. Outros BB não foram testados especificamente em idosos com IC em adição à IECA/BRA, para ter seu uso clínico preconizado nesta faixa etária.

No estudo CIBIS III, demonstrou-se a não inferioridade do início do bisoprolol em relação a IECA em pacientes com média de idade de 72 anos $^{97}$. Recentemente, um estudo randomizado prospectivo com pequeno número de pacientes testou a manutenção de carvedilol versus substituição com propranolol (109 $\pm 43 \mathrm{mg}$ ao dia), mantendo o mesmo grau de betabloqueio avaliado através da frequência cardíaca semelhante em repouso e em exercício ${ }^{98}$. A FEVE aumentou no grupo propranolol sem modificação em outros parâmetros estudados.

Embora o benefício dos BB em pacientes assintomáticos na redução da mortalidade global e cardiovascular esteja comprovado somente nos pacientes com disfunção ventricular pós-infarto do miocárdio ${ }^{99}$, estes têm sido utilizados nos pacientes com cardiomiopatia dilatada, isquêmica e miocardite ${ }^{100}$, com objetivo de redução da progressão da disfunção ventricular, efeito de remodelagem reversa e redução de morte súbita, e, nos pacientes com fibrilação atrial crônica, para o controle da resposta ventricular.

Tabela 11 - Recomendações para Betabloqueadores na Insuficiência Cardíaca Crônica Sistólica Incluindo Etiologia Chagásica

\begin{tabular}{|c|c|c|}
\hline Classe de Recomendação & Indicação & Nível de Evidência \\
\hline I & Bisoprolol, Carvedilol e Succinato de Metoprolol para o tratamento da IC com disfunção sistólica & $A,{ }^{*} B$ \\
\hline I & Classe funcional II-IV da NYHA com disfunção sistólica associado com IECA ou BRA & $A,{ }^{*} B$ \\
\hline I & Classe funcional II-IV da NYHA com disfunção sistólica como monoterapia inicial & $\mathrm{B},{ }^{*} \mathrm{C}$ \\
\hline I & $\begin{array}{l}\text { Pacientes assintomáticos com disfunção sistólica após infarto agudo do miocárdio, c/CMPD, CMPI, } \\
\text { Miocardite, em associação com IECA ou BRA }\end{array}$ & $\mathrm{B},{ }^{* *} \mathrm{C}$ \\
\hline Ilb & $\begin{array}{c}\text { Nebivolol em pacientes com idade }<70 \text { anos, e bisoprolol/carvedilol/succinato de metoprolol para idade }>70 \\
\text { anos, Classe funcional II-IV da NYHA com disfunção sistólica associado com IECA ou BRA }\end{array}$ & $\mathrm{B},{ }^{*} \mathrm{C}$ \\
\hline III & Propranolol e Atenolol para o tratamento da IC com disfunção sistólica & C \\
\hline
\end{tabular}




\section{Diretrizes}

5.2. Inibidores da Enzima Conversora da Angiotensina e

Bloqueadores dos Receptores da Angiotensina II

As indicações de IECA e BRA estão especificadas na Tabela 12.

\subsection{Antagonistas da Aldosterona (Tabela 13)}

Entre os bloqueadores de aldosterona espironolactona e eplerenone, somente a espironolactona está disponível no Brasil. Em modelos experimentais, podem ter diferentes efeitos na mediação de redução de apoptose de miócito por hormônio, questionando possível efeito de classe ${ }^{101}$. Em virtude dos efeitos mais seletivos, o eplerenone determina menor incidência de ginecomastia $^{102}$.

Recentemente, foi publicado o estudo EMPHASIS-HF em pacientes com IC leve, CF II, sendo incluídos na randomização 2.737 pacientes com $\mathrm{FE} \leq 30 \%{ }^{103}$. Os resultados mostraram que $25 \mathrm{mg} /$ dia de eplerenone, adicionados ao tratamento clínico otimizado, proporcionaram redução de $24 \%$ na mortalidade geral e $37 \%$ de redução nos eventos combinados, óbito cardiovascular e hospitalizações por IC, mesmo em pacientes pouco sintomáticos.

\subsection{Diuréticos (Tabela 14)}

Na III Diretriz de IC crônica, havia sugestão de que doses elevadas de diuréticos aumentariam a mortalidade ${ }^{104}$. Embora planejado para IC descompensada, estudo demonstrou que altas doses de diuréticos foram associadas à tendência de maior redução de sintoma sem diferença na função renal ${ }^{105}$. Entretanto, maior perda de peso de líquidos e melhora da falta de ar foram balanceadas por maior proporção de pacientes com piora de função renal ( $23 \%$ no grupo dose alta versus $14 \%$ no grupo dose baixa), o que não afetou a mortalidade. Um número menor de pacientes no grupo dose alta sofreu eventos adversos sérios. Subanálise do estudo BEST demonstrou que uso de altas doses de diuréticos em pacientes com níveis de ureia acima da média foi associado à maior mortalidade e, em pacientes com níveis de ureia abaixo da média, não foi associado com maior mortalidade ${ }^{106}$.

Tabela 12 - Recomendações para IECA e BRA na Insuficiência Cardíaca Crônica Sistólica Incluindo Etiologia Chagásica

\begin{tabular}{|c|c|c|}
\hline Classe de Recomendação & Indicação & Nível de Evidência \\
\hline I & $\begin{array}{l}\text { IECA para disfunção assintomática e sintomática de VE } \\
\text { BRA na disfunção sistólica em pacientes intolerantes a IECA exceto por insuficiência renal }\end{array}$ & A \\
\hline Ila & $\begin{array}{l}\text { Adicionar BRA em pacientes que persistam sintomáticos a despeito do uso da terapia otimizada } \\
\text { (IECA, BB) }\end{array}$ & $\mathrm{B}$ \\
\hline III & Adicionar BRA de forma rotineira em pacientes em uso da terapia otimizada- & A \\
\hline
\end{tabular}

Tabela 13 - Recomendações para Antagonista de Aldosterona na Insuficiência Cardíaca Crônica Sistólica incluindo Etiologia Chagásica

\begin{tabular}{|c|c|c|}
\hline Grau de Recomendação & Indicação & Nível de Evidência \\
\hline 1 & $\begin{array}{l}\text { Espironolactona em pacientes sintomáticos com disfunção sistólica do VE, classes funcionais III e IV } \\
\qquad \text { da NYHA, associado ao tratamento padrão }\end{array}$ & A \\
\hline Ila & $\begin{array}{l}\text { Espironolactona em pacientes com IC leve (CF II), associado ao tratamento clínico otimizado para } \\
\text { redução de mortalidade e hospitalizações por IC }\end{array}$ & C \\
\hline Ila & Espironolactona em pacientes pós IAM, c/disfunção do VE (FE < 40\%) & C \\
\hline III & $\begin{array}{l}\text { Espironolactona para pacientes com IC crônica, creatinina }>2,5 \mathrm{mg} / \mathrm{dl} \text { ou potássio sérico }>5,0 \\
\text { mEq./l, em uso de IECA ou BRA. }\end{array}$ & $C$ \\
\hline
\end{tabular}

IECA significa inibidor de enzima de conversão da angiotensina; BRA, bloqueador do receptor da angiotensina; FE, fração de ejeção de ventrículo esquerdo

Tabela 14 - Recomendações para o uso de Diuréticos na Insuficiência Cardíaca Crônica Sistólica incluindo Etiologia Chagásica

\begin{tabular}{|c|c|c|}
\hline Classe de Recomendação & Indicações & Nível de Evidência \\
\hline I & Pacientes sintomáticos com sinais e sintomas de congestão & $\mathrm{C}$ \\
\hline Ila & $\begin{array}{c}\text { Associação de hidroclorotiazida ou clortalidona nos pacientes resistentes à ação dos } \\
\text { diuréticos de alça }\end{array}$ & C \\
\hline III & $\begin{array}{c}\text { Introdução em pacientes com disfunção sistólica assintomáticos (Classe Funcional I) ou } \\
\text { hipovolêmicos }\end{array}$ & C \\
\hline
\end{tabular}




\subsection{Hidralazina e Nitrato, Digital (Tabela 15 e 16)}

Além da indicação para pacientes com piora da função renal, para aqueles que não estão evoluindo bem na vigência do tratamento medicamentoso otimizado ou que, em avaliação, documente-se que persistem com sinais de resistência periférica elevada, a hidralazina e o nitrato devem ser considerados como uma opção terapêutica para ser empregada em associação ao tratamento usual ${ }^{107}$.

\subsection{Anticoagulantes e Antiagregantes plaquetários (Tabela 17)}

Para indicação de medicações que tenham como objetivo diminuir a incidência de fenômenos tromboembólicos na IC, usualmente diante de fibrilação atrial, utiliza-se o $\mathrm{CHADS}_{2}$ para estratificação de risco $(C=$ insuficiência cardíaca ou FEVE reduzida, $\mathrm{H}=$ hipertensão, $\mathrm{A}=$ idade $>75$ anos, $\mathrm{D}=$ diabetes, $\mathrm{S}=$ acidente vascular cerebral ou episódio isquêmico transitório, que se somam). Cada fator de risco tem peso de um ponto, exceto o $\mathrm{S}$ que tem dois. Recentemente, tem sido preconizado o $\mathrm{CHA}_{2} \mathrm{DS}_{2}$ VASC incorporando novos fatores de risco ${ }^{108}$. A idade $\geq 75$ anos passa a pesar dois pontos, $V$ que significa IAM prévio ou doença vascular periférica ou placa na aorta pesa um ponto, A, idade entre 65-74, com um ponto, e $\mathrm{S}$, sexo feminino com um ponto. Baixo risco para fibrilação atrial na ausência de fator de risco e risco intermediário com escore de um ponto. Alto risco para escore $\geq 2$. A indicação de medicamentos deve ser avaliada diante do escore HAS-BLED $(\mathrm{H}=$ hipertensão arterial com sistólica $\geq 160$ mmhg com peso de um ponto, $A$ = função hepática ou renal anormal com um ponto cada, $\mathrm{S}=$ acidente vascular cerebral com um ponto, $\mathrm{B}=$ sangramento, um ponto, $\mathrm{L}=\mathrm{INR}$ lábil, um ponto, $\mathrm{E}=$ idoso $>75$ anos, um ponto, $\mathrm{D}=$ droga ou álcool com um ponto cada.) ${ }^{109}$ Três ( 3,74\% ao ano) ou mais pontos (para 4 é $8,7 \%$, para 5 é $12,5 \%$ ) indica alto risco de sangramento em um ano e o uso de medicações para prevenção de tromboembolismo precisa ser balanceado frente com o risco. Os ensaios clínicos RELY, ROCKET AF, e ARISTOTLE foram publicados recentemente e compararam dabigratan, rivaroxaban e apixaban versus varfarina para prevenção do desfecho primário de acidente vascular cerebral ou embolia sistêmica.

No RE-LY que testou o etexilato de dabigratan, que é transformado em dabigratam, um inibidor competitivo da trombina, de 18.113 pacientes com fibrilação atrial, 5.793 eram portadores de IC (32\%) ${ }^{110}$. Na análise de subgrupos préespecificada de pacientes sintomáticos para IC, dabigatran nas doses de 110 mg e 150 mg, duas vezes ao dia, não foi inferior ou superior à varfarina para prevenção do desfecho primário, embora, no grupo total na dose de $150 \mathrm{mg}$, tenha reduzido o desfecho primário de 1,53\% para 1,11\% ( $p<0,001$ para superioridade). Não houve diferença quanto à mortalidade. Pacientes com "clearance" de creatinina $<30 \mathrm{ml} / \mathrm{min}$ não devem receber dabigatran e pacientes com algum grau de insuficiência renal de menor peso devem receber dose menor ${ }^{111}$.

No estudo ROCKET, estudou-se o rivaroxaban, um inibidor direto do fator $X$ ativado, com inclusão de 14.264 pacientes, sendo 8.851 portadores de IC (62\%). O rivaroxaban não foi inferior a varfarina no grupo total e em portadores de IC na prevenção de acidente vascular ou embolia sistêmica ${ }^{112}$. O estudo ARISTOTLE testou o apixaban, inibidor do fator $X$ ativado, em 18.201 pacientes, sendo 6.451 com IC ${ }^{113}$. No grupo total, em comparação com a varfarina, o apixaban reduziu o desfecho primário de $1,6 \%$ para $1,27 \%$ ( $p=0,01$ para superioridade) e sangramento importante de $3,09 \%$ para $2,13 \%$ ( $P<0,001)$, mas a redução de

Tabela 15 - Recomendações para Hidralazina - Nitrato na Insuficiência Cardíaca Crônica Sistólica incluindo Etiologia Chagásica

\begin{tabular}{|c|c|c|}
\hline Classe de Recomendação & Indicações & Nível de Evidência \\
\hline \multirow{3}{*}{ । } & Afrodescendentes em CF III - IV (NYHA) em uso de terapêutica otimizada & A \\
\hline & $\begin{array}{l}\text { Pacientes de qualquer etnia, CF II -IV (NYHA) com contraindicação a IECA ou BRA (insuficiência } \\
\text { renal progressiva e/ou hipercalemia) }\end{array}$ & B \\
\hline & $\begin{array}{l}\text { Pacientes de qualquer etnia, CF I (NYHA) com contraindicação a IECA ou BRA (insuficiência renal } \\
\text { progressiva e/ou hipercalemia) }\end{array}$ & C \\
\hline Ila & Pacientes de qualquer etnia refratária ao tratamento otimizado & C \\
\hline
\end{tabular}

Tabela 16 - Recomendações para Digoxina na Insuficiência Cardíaca Crônica incluindo Etiologia Chagásica

\begin{tabular}{|c|c|c|}
\hline Classe de Recomendação & Indicações & Nível de Evidência \\
\hline \multirow{2}{*}{ I } & $\begin{array}{c}\text { Pacientes com FE }<45 \% \text {, ritmo sinusal, sintomáticos, terapêutica otimizada com BB e IECA, para } \\
\text { melhora dos sintomas }\end{array}$ & $A$ \\
\hline & $\begin{array}{c}\text { Pacientes com FE }<45 \% \text {, FA sintomáticos com terapêutica otimizada com BB e IECA, para } \\
\text { controle de FC }\end{array}$ & C \\
\hline III & Ritmo sinusal assintomático & C \\
\hline
\end{tabular}

FE significa fração de ejeção de ventrículo esquerdo; IECA, inibidor de enzima de conversão de angiotensina; BB, betabloqueador; FA, fibrilação atrial 


\section{Diretrizes}

mortalidade foi de 3,95\% para 3,52\% com $\mathrm{p}=0,047$, ou seja, próximo de 0,05. Entretanto, na análise de subgrupo em pacientes com IC, o apixaban não foi superior a varfarina. Não existem publicações com inclusão de pacientes com IC devido a doença de Chagas, o que seria importante, pois existe evidência de que tromboembolismo seria mais frequente na doença de Chagas ${ }^{114}$.

\subsection{Antiarrítmicos (Tabela 18)}

Os BB são os fármacos de maior impacto na redução da morte súbita arrítmica em pacientes com IC, quer seja terapêutica combinada com IECA/BRA ou como monoterapia ${ }^{89,90,97,115,116}$. Também têm indicação na terapia adjuvante ao cardiodesfibrilador implantável (CDI), aumentando a sua eficácia na redução da morte súbita ${ }^{117}$. A amiodarona não apresenta benefício na prevenção primária quando comparada ao placebo, independente da etiologia da IC, apresentando aumento da mortalidade no subgrupo isquêmico ${ }^{118}$. A amiodarona, quando associada aos BB, aumenta a eficácia do $\mathrm{CDI}$ por reduzir eventos de taquicardia ventricular e choques inapropriados ${ }^{119}$.

\subsection{Bloqueadores de cálcio (Tabela 19)}

Conforme Tabela 19, os bloqueadores de cálcio têm uso restrito na IC.

\section{Tabela 17 - Recomendações para Anticoagulantes e Antiagregantes Plaquetários na Insuficiência Cardíaca Crônica incluindo Etiologia Chagásica}

\begin{tabular}{|c|c|c|}
\hline Classe de Recomendação & Indicações & Nível de Evidência \\
\hline I & $\begin{array}{l}\text { Cumarínicos para } \mathrm{FE}<35 \% \text { em FA paroxística, persistente ou permanente com pelo menos um } \\
\text { fator de risco } \text { adicional }^{*}\end{array}$ & A \\
\hline I & Cumarínicos para trombos intracavitários ou embolia prévia & C \\
\hline I & Aspirina para cardiomiopatia de etiologia isquêmica com risco de evento coronariano & A \\
\hline I & Aspirina na contraindicação ao uso de anticoagulante oral por risco de sangramento & A \\
\hline Ila & $\begin{array}{l}\text { Inibidor competitivo da trombina ou inibidor do fator } X \text { ativado como alternativa ao cumarínico, em } \\
\text { pacientes com } \mathrm{FE}<40 \% \text { e FA persistente ou permanente, }>75 \text { anos, ou entre } 65 \text { e } 74 \text { anos com } \\
\text { DM ou HAS ou DAC }\end{array}$ & C \\
\hline Ila & $\begin{array}{l}\text { Cumarínicos ou Aspirina para FE }<35 \% \text { em FA paroxística, persistente ou permanente sem fator } \\
\text { de risco adicional }{ }^{*}\end{array}$ & B \\
\hline $\mathrm{Ilb}$ & $\begin{array}{l}\text { Cumarínicos nos primeiros seis meses após infarto agudo do miocárdio de parede anterior com } \\
\text { disfunção sistólica sem trombo }\end{array}$ & C \\
\hline Ila & Cumarínicos na miocardiopatia chagásica com aneurisma de ponta de ventrículo esquerdo & C \\
\hline III & Aspirina para miocardiopatia dilatada não isquêmica & B \\
\hline
\end{tabular}

*Índice $\mathrm{CHADS}_{2}$ (IC ou FE < 35\%, hipertensão e idade > 75 anos, diabetes, acidente vascular cerebral, cada fator de risco equivale a um ponto exceto acidente vascular cerebral que equivale a 2); FA, fibrilação atrial; DM, diabetes melito; HAS, hipertensão arterial sistêmica; DAC, doença arterial coronariana

\section{Tabela 18 - Recomendação para Antiarrítmicos na Insuficiência Cardíaca Crônica incluindo Etiologia Chagásica}

\begin{tabular}{|c|c|c|}
\hline Classe de Recomendação & Indicações & Nível de Evidência \\
\hline I & BB na insuficiência cardíaca com disfunção sistólica na prevenção de morte súbita & A \\
\hline 1 & $\begin{array}{l}\text { BB na insuficiência cardíaca com disfunção sistólica em portadores de CDI na prevenção de morte } \\
\text { súbita }\end{array}$ & B \\
\hline I & $\begin{array}{l}\text { BB associado à amiodarona na insuficiência cardíaca com disfunção sistólica em portadores de } \\
\qquad \mathrm{CDI} \text { na prevenção de choques }\end{array}$ & B \\
\hline Ila & Amiodarona para prevenção de choques recorrentes em portadores de CDI & B \\
\hline Ila & Amiodarona na doença de Chagas com arritmia ventricular complexa sintomática & C \\
\hline Ila & $\begin{array}{l}\text { Amiodarona para prevenção de taquiarritmias supraventriculares paroxísticas sintomáticas com } \\
\text { tratamento clínico otimizado }\end{array}$ & C \\
\hline Ilb & $\begin{array}{l}\text { Antiarritmico da classe IB (Mexiletine) como opção ou em associação à amiodarona em portadores } \\
\text { de CDI }\end{array}$ & C \\
\hline III & $\begin{array}{l}\text { Verapamil e antiarrítmicos da classe IA (Quinidina), IC (Propafenona) e da classe III (Sotalol), } \\
\text { exceto Amiodarona }\end{array}$ & B \\
\hline III & Dronedarona para prevenção de morte súbita na IC sistólica & B \\
\hline
\end{tabular}

BB significa betabloqueador; $\mathrm{CDI}$, cardiodesfibrilador implantável 


\subsection{Ivabradina (Tabela 20)}

A ivabradina inaugura uma nova classe terapêutica, pois é um inibidor específico e seletivo da corrente "If" do nódulo sinoatrial, modulando o influxo das correntes iônicas e determinando como consequência uma redução da frequência cardíaca, no repouso e no esforço ${ }^{120}$.

No estudo BEAUTIFUL, que incluiu 10.917 pacientes portadores de cardiopatia isquêmica, a associação da Ivabradina à terapêutica padrão, incluindo $\mathrm{BB}$, resultou em redução estatisticamente significante de $36 \%$ no risco de hospitalização por IAM fatal e não fatal e da necessidade de revascularização miocárdica em 30\% ${ }^{121}$. Subanálise específica do BEAUTIFUL, realizada com 1.507 pacientes que apresentavam angina limitante dentro do quadro clínico da cardiopatia isquêmica, demonstrou que a associação da ivabradina à terapêutica padrão, incluindo BB, reduziu com significância estatística a mortalidade cardiovascular em 24\% e o risco de internação por IAM em $42 \%{ }^{122}$.

Resultados do estudo SHIFT, que incluiu 6.505 pacientes com IC classe funcional NYHA II, III e IV, demostraram que a associação da ivabradina à terapêutica otimizada tolerada, incluindo $\mathrm{BB}$, reduziu o desfecho primário de morte cardiovascular e internação por piora da IC em 18\%, com significância estatística ${ }^{123}$. Essa redução do desfecho primário foi observada de forma consistente e independente da idade, sexo e histórico de diabetes melito ou hipertensão arterial. O estudo SHIFT mostrou também que a associação da ivabradina reduziu o risco de morte por IC em $26 \%$ e o risco de hospitalização por piora da IC em 26\%. Eventos adversos sérios foram raros nos pacientes que receberam ivabradina, e somente $1 \%$ dos pacientes apresentou bradicardia sintomática. Iniciou-se a ivabradina com dose de $5 \mathrm{mg}$ duas vezes ao dia, e houve otimização da dose para 7,5 mg duas vezes ao dia, conforme resposta da frequência cardíaca. Portanto, as evidências recomendam associação da ivabradina à terapêutica-padrão, incluindo BB, com o objetivo de melhorar a função ventricular e reduzir o risco cardiovascular através da redução da combinação de morte cardiovascular e hospitalização por IC, redução do risco de IAM fatal e não fatal e da redução da mortalidade por IC.

\subsection{0. Ômega 3 (Tabela 21)}

Diversos estudos epidemiológicos têm sugerido que o consumo de doses elevadas de ácidos graxos poli-insaturados ômega 3 (Ômega 3) encontrados no óleo de peixe, rico em ácido eicosapentaenóico (EPA) e docosaexaenóico (DHA), pode reduzir a incidência e a mortalidade por $\mathrm{IC}^{124}$. O Cardiovascular Health Study, envolvendo 4.738 pacientes com idade média de 65 anos, observou correlação inversa entre ingesta de peixe e incidência de $\mathrm{IC}^{125}$. Resultados semelhantes foram encontrados em outro estudo com 60.000 pacientes, com seguimento de 13 anos $^{126}$, bem como no estudo ARIC (Atherosclerosis Risk in Community) ${ }^{127}$.

No estudo GISSI-Prevenzione, a adição de ômega 3 após IAM reduziu a morte cardiovascular ${ }^{128}$. No estudo GISSI-HF, que incluiu 6.975 pacientes, 1 g de ômega 3 adicionado à terapêutica otimizada resultou em redução de mortalidade e de hospitalização ${ }^{129}$. Outros estudos menores também encontraram melhora da função sistólica ventricular, capacidade funcional e hospitalizações ${ }^{130}$, além de redução de BNP e outros marcadores inflamatórios ${ }^{131}$ quando do acréscimo do ômega 3 à terapia padrão para IC.

\section{Tabela 19 - Recomendações para Bloqueadores dos Canais de Cálcio na Insuficiência Cardíaca Crônica}

\begin{tabular}{lcc}
\hline Classe de Recomendação & Indicações & Nível de Evidência \\
\hline Ila & Besilato de anlodipino em pacientes com hipertensão arterial persistente apesar de tratamento \\
otimizado com disfunção sistólica
\end{tabular}

Tabela 20 - Orientações para Ivabradina na Insuficiência Cardíaca Crônica

\begin{tabular}{|c|c|c|}
\hline Classe de Recomendação & Indicações & Nível de Evidência \\
\hline Ila & $\begin{array}{l}\text { Pacientes em ritmo sinusal com FC > 70bpm e classe funcional II-IV da NYHA com disfunção } \\
\text { sistólica em uso de IECA ou BRA + BB em doses máximas toleradas }\end{array}$ & $A$ \\
\hline
\end{tabular}

Tabela 21 - Orientações para Omega 3 na Insuficiência Cardíaca Crônica Sistólica

\begin{tabular}{lrl}
\hline Classe de Recomendação & \multicolumn{1}{c}{ Indicações } \\
\hline Ila & Pacientes com IC crônica, classe funcional II-III da NYHA em uso de tratamento otimizado \\
\hline IC significa insuficiência cardiaca; NYHA, New York Heart Association & A
\end{tabular}




\section{Diretrizes}

Os mecanismos desse potencial benefício são complexos e não totalmente esclarecidos, tendo sido apontadas diversas vias, entre as quais: ação sobre a PPAR alfa e gama e regulação da expressão gênica de controle do consumo miocárdico de ácidos graxos e metabolismo ${ }^{132}$; aumento sérico da adiponectina plasmática e redução das citocinas séricas ${ }^{133,134}$ com melhora do remodelamento e da função cardíaca e com efeitos benéficos no quadro de caquexia cardíaca ${ }^{135}$.

\subsection{Uso de Inibidores da Fosfodiesterase 5}

Os inibidores da fosfodiesterase 5 atuam reduzindo a degradação do GMPc, preservando o óxido nítrico na circulação, com isto levando à vasodilatação, o que pode ser benéfico no contexto da hipertensão pulmonar secundária à IC crônica. O sildenafil pode reduzir a hipertensão pulmonar em pacientes em avaliação para transplante cardíaco ${ }^{136}$ e também pode reduzir a pressão arterial após o transplante cardíaco ${ }^{137}$. Estudos experimentais também apontam potenciais efeitos favoráveis da inibição da fosfodiesterase 5 no coração por meio bloqueio de sinalização adrenérgica, pró-apotótica e de hipertrofia do cardiomiócito ${ }^{138}$. Tal inibição pode proporcionar também melhora da capacidade funcional na IC em um estudo agudo, placebo controlado de dose única ${ }^{139}$. Redução da pressão sistólica na artéria pulmonar associada à melhora do consumo máximo de oxigênio foi demonstrada em estudo duplo cego, randomizado, placebo controlado com uso por quatro semanas de sildenafil $25 \mathrm{mg}$ 3x/dia. Sildenafil $50 \mathrm{mg}$ 3x/dia por 12 meses determinou reversão de parâmetros de remodelamento ventricular e melhora da fração de ejeção do ventrículo esquerdo ${ }^{140,141}$.

\subsection{Moduladores do Metabolismo Enérgico Miocárdico} (Tabela 22)

Dentre os agentes moduladores do metabolismo energético do miocárdio, a trimetazidina tem sido a mais estudada. A trimetazidina é um derivado da piperazina, usada como agente antianginoso, que promove a inibição seletiva de enzima envolvida na betaoxidação de AGL (thiolase 3-acetilCoenzima A de cadeia longa). A trimetazidina pode afetar o uso de substrato energético miocárdico ao inibir a fosforilação oxidativa, mudando assim a produção de energia de AGL para a oxidação da glicose.

Estudos com inclusão de pequeno número de pacientes demonstram benefício na IC com melhora na classe funcional, fração de ejeção, tolerância ao exercício ou diminuindo a mortalidade por todas as causas e hospitalização por $I^{142-147}$. Metanálise encontrou aumento da FEVE, redução da mortalidade por todas as causas e redução de eventos cardiovasculares ou hospitalização ${ }^{148}$.

\section{Tratamento Cirúrgico}

Inúmeros procedimentos cirúrgicos têm sido estudados para o tratamento da IC, mas muitos que já foram considerados potencialmente favoráveis, hoje não são mais empregados ${ }^{149-156}$.

\subsection{Cirurgia da Valva Mitral}

A cirurgia da válvula mitral (troca valvar ou plastia) em pacientes com disfunção ventricular esquerda e grave insuficiência valvar mitral pode aliviar os sintomas de IC em pacientes selecionados. O emprego da técnica percutânea para a inserção endovascular do "Mitral Clip" ainda é considerado experimental, sem qualquer evidência de impacto clínico significativo ${ }^{157}$.

\subsection{Revascularização Miocárdica com Disfunção Isquêmica de Ventrículo Esquerdo e Remodelamento Cirúrgico do Ventrículo Esquerdo (Tabela 23)}

Estudo de série de casos com limitação metodológica demonstrou que a cirurgia de revascularização miocárdica pode ser realizada com mortalidade de $3,7 \%$ em pacientes com IC isquêmica, FEVE de $29 \%$ e músculo viável para melhora da $\mathrm{FEVE}^{158}$. A cirurgia de revascularização miocárdica sem

Tabela 22 - Recomendações para Trimetazidina na Insuficiência Cardíaca Crônica

\begin{tabular}{lcc}
\hline Classe de recomendação & Indicação & Nível de evidência \\
\hline$\| b$ & Pacientes com IC sistólica sintomática, em adição à terapia otimizada, para redução de morbidade \\
e mortalidade.
\end{tabular}

IC significa insuficiência cardíaca

Tabela 23 - Indicações de Revascularização Miocárdica na Insuficiência Cardíaca Crônica Sistólica

\begin{tabular}{lc}
\hline Classe de Recomendação & Indicações \\
\hline I & $\begin{array}{c}\text { Revascularização do miocárdio em pacientes com disfunção ventricular esquerda e lesão obstrutiva } \\
\text { significativa do tronco da artéria coronariana esquerda } \geq 50 \% \text {, ou equivalente de tronco com área } \\
\text { isquêmica importante (estenose }>70 \% \text { proximal em artérias descendente anterior e circunflexa) }\end{array}$ \\
\hline Ila & $\begin{array}{c}\text { Revascularização do miocárdio em pacientes com disfunção ventricular esquerda com anatomia } \\
\text { favorável e angina com sintomatologia importante restritiva as atividades usuais ou isquemia } \\
\text { significante documentada }\end{array}$ \\
\hline
\end{tabular}


remodelamento cirúrgico em pacientes com IC e disfunção ventricular com músculo supostamente viável tem sido indicada na prática médica baseando-se principalmente nos resultados do atemporal Coronary Artery Surgery Study (CASS) com o objetivo de recuperar o músculo atordoado ou hibernado ${ }^{159}$. Vários métodos podem ser utilizados para avaliar o músculo viável ${ }^{160}$. Metanálise demonstrou que a revascularização pode ser realizada em pacientes com disfunção ventricular com aceitável mortalidade em torno de 5\% ${ }^{161}$. Entretanto, pode haver substrato heterogêneo consistindo da mistura de fibrose, músculo atordoado, hibernado e remodelado em várias proporções nos pacientes com miocardiopatia isquêmica ${ }^{162}$. Além desse estudo ter recebido sérias críticas, seu resultado poderia ser considerado neutro caso utilizássemos métodos estatísticos atuais, foi realizado sem a otimização da medicação para insuficiência cardíaca disponível atualmente, que pode tanto melhorar o músculo atordoado/hibernado como o remodelado ${ }^{163}$. Adicionalmente, evento coronariano pode ser raro em pacientes com $\mathrm{IC}^{164}$. Evidência recente sugere que estratégia conservadora pode não ser inferior ao procedimento invasivo para revascularizar pacientes com viabilidade miocárdica ${ }^{163}$. Estudos multicêntricos prospectivos são necessários para esclarecer o real papel da cirurgia em tais pacientes.

$\mathrm{O}$ estudo $\mathrm{STICH}$, randomizado e prospectivo, que incluiu 1.212 pacientes com $\mathrm{FEVE} \leq 35 \%$ não demonstrou benefício do tratamento cirúrgico em comparação com tratamento clínico em pacientes com doença coronariana e $\mathrm{IC}^{165}$. Pacientes com estenose de tronco $>50 \%$ e angina severa classe III e IV da Canadian Cardiovascular Society foram excluídos do estudo. Subestudo do STICH, que analisou pacientes com insuficiência coronariana e disfunção miocárdica isquêmica com músculo viável submetidos à revascularização miocárdica versus tratamento clínico, também não demonstrou maior benefício com tratamento cirúrgico ${ }^{166}$. Também em uma das hipóteses testadas no estudo STICH, a reconstrução cirúrgica ventricular adicionada à revascularização miocárdica em pacientes com
FEVE $\leq 35 \%$ não reduziu sintomas, não aumentou tolerância ao exercício, e nem reduziu morte ou hospitalização por causa cardíaca ${ }^{167}$.

\subsection{Transplante Cardíaco (Tabela 24)}

Quando a IC chega à refratariedade terapêutica, o transplante cardíaco permanece sendo reconhecido como tratamento padrão ${ }^{104,168-170}$. A sobrevida, no entanto, ainda é influenciada em curto prazo pela rejeição e infecção, e, a longo prazo, pela neoplasia e doença vascular do enxerto ${ }^{171}$. A Tabela 24 ilustra as indicações para transplante cardíaco ${ }^{168}$.

Alguns critérios de indicações e contraindicações têm sido modificados nos últimos anos, principalmente com relação à idade, consumo de oxigênio no teste cardiopulmonar (TCP), resistência vascular pulmonar (RVP), obesidade, câncer, diabetes melito, insuficiência renal (IR), pacientes sensibilizados, doença vascular periférica (DVP) e dependência de drogas.

Avaliação da RVP deve ser realizada em todos os candidatos como também o TCP. Na impossibilidade deste, o teste da caminhada de 6 minutos tem validade ${ }^{172}$. Alguns centros não realizam cateterismo direito quando a pressão sistólica da artéria pulmonar (PSAP) é < 45 mmhg ao ecodopplercardiograma ${ }^{173}$. Pacientes com índice de massa corporal (IMC) acima de $30 \mathrm{Kg} /$ $\mathrm{m}^{2}$ têm piores resultados; pacientes acima de 70 anos devem ser considerados para doadores de lista alternativa; portadores de neoplasias com remissão de cinco anos e de baixo grau de malignidade podem ser aceitos após avaliação oncológica; diabéticos com lesão de órgãos-alvo têm contraindicação relativa para transplante; a presença de IR e DVP são contraindicações relativas devendo ser bem avaliadas. Diante dos bons resultados de grupos brasileiros com o transplante em cardiomiopatia chagásica, não há contraindicação para pacientes chagásicos ${ }^{169,170,174-181}$. Deve ser ressaltada a experiência de cada centro com relação ao esquema de imunossupressão e monitoração da reativação da doença. Quanto aos pacientes

\section{Tabela 24 - Indicações de Transplante Cardíaco Incluindo a Etiologia Chagásica}

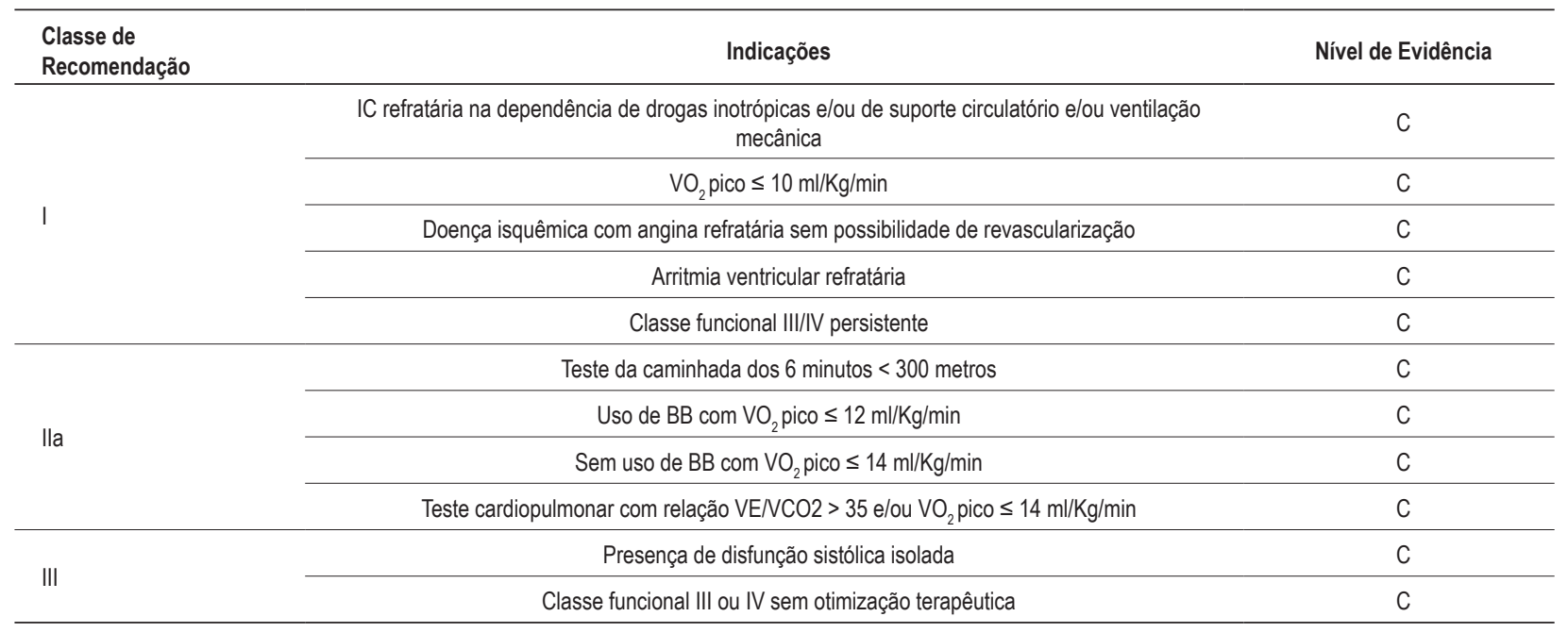

IC significa insuficiência cardiaca; $\mathrm{VO}_{2}$, consumo de oxigênio durante exercício; $B B$, betabloqueador 


\section{Diretrizes}

alossensibilizados, que apresentam painel linfocitário acima de $10 \%$, o transplante somente será indicado após prova cruzada prospectiva negativa. As contraindicações estão resumidas na Tabela $25^{169,182-185}$. Avaliação multidisciplinar é fundamental para o sucesso de transplante ${ }^{168}$.

\subsection{Dispositivo de Assistência Circulatória Mecânica (Tabela 26)}

Também em nosso meio, o uso de dispositivos de assistência circulatória mecânica tem sido empregado no tratamento do choque cardiogênico e na manutenção da condição circulatória em pacientes com IC refratária ao tratamento medicamentoso $^{186,187}$. O estudo REMATCH demonstrou benefícios do emprego de dispositivo de assistência mecânica implantável em relação à sobrevida e à qualidade de vida de pacientes com IC estágio D introduzindo o uso como terapia de destino ${ }^{188,189}$. O estudo HEARTMATE II demonstrou que dispositivos de fluxo contínuo podem ser melhores do que os de fluxo pulsátil, atingindo sobrevida de 58\% em dois anos em pacientes inelegíveis para transplante cardíaco ${ }^{190}$.

As principais causas de inelegibilidade para transplante cardíaco nos estudos foram idade avançada, câncer, DPOC, recusa, hipertensão pulmonar, insuficiência renal, diabetes insulino dependente, obesidade, hepatite, painel elevado, doença vascular periférica e múltiplas comorbidades. Entretanto, as causas podem ser modificáveis na indicação de transplante. Quando utilizado comercialmente o dispositivo de fluxo contínuo no registro INTERMACS (Interagency Registry for
Mechanically Assisted Circulatory Support) (National Heart Lung and Blood Institute (NHLBI) - sponsored collaborative database) foi associado à sobrevida de um ano em 74\% ${ }^{189,191}$. De acordo com o INTERMACS, desde junho de 2006 até setembro 2010, 2.858 dispositivos foram implantados nos EUA, mas de janeiro a junho de 2010, 614 dispositivos de fluxo contínuo intracorpóreos foram implantados contra somente oito pulsáteis. Os melhores perfis INTERMACS para indicação foram dois (progressiva piora), três (estável inotrópico dependente) e quatro (IC recorrente avançada) ("nem tão bem nem tão mal"). Índices associados com insucesso: idade avançada, choque cardiogênico crítico, diabetes, hipertensão pulmonar, ureia, sódio, cirurgia concomitante, biventricular, e fluxo pulsátil.

\subsection{Dispositivos Implantáveis de Estimulação Cardíaca- Terapia de Ressincronização Cardíaca e Cardioversor Desfibrilador Implantável (Tabelas 27, 28 e 29)}

Dois estudos multicêntricos e randomizados recentes avaliaram o impacto da associação de terapia de ressincronização ventricular e atrioventricular (TRV-AV) ao cardiodesfibrilador implantável (CDI) em IC menos avançada. No entanto, diferentemente do estudo SHIFT, as doses das medicações utilizadas nos pacientes não foram relatadas determinando importante limitação de metodologia. O estudo MADIT CRT-D com 1.820 pacientes avaliou o impacto da associação da TRV-AV ao CDI em pacientes com fração de ejeção $\leq 30 \%$, QRS $\geq 130 \mathrm{~ms}$ e em classes funcionais I (14\%) e II (74\%), que recebem o CDI para prevenção primária de morte súbita

\section{Tabela 25 - Contraindicações Absolutas e Relativas para Transplante Cardíaco}

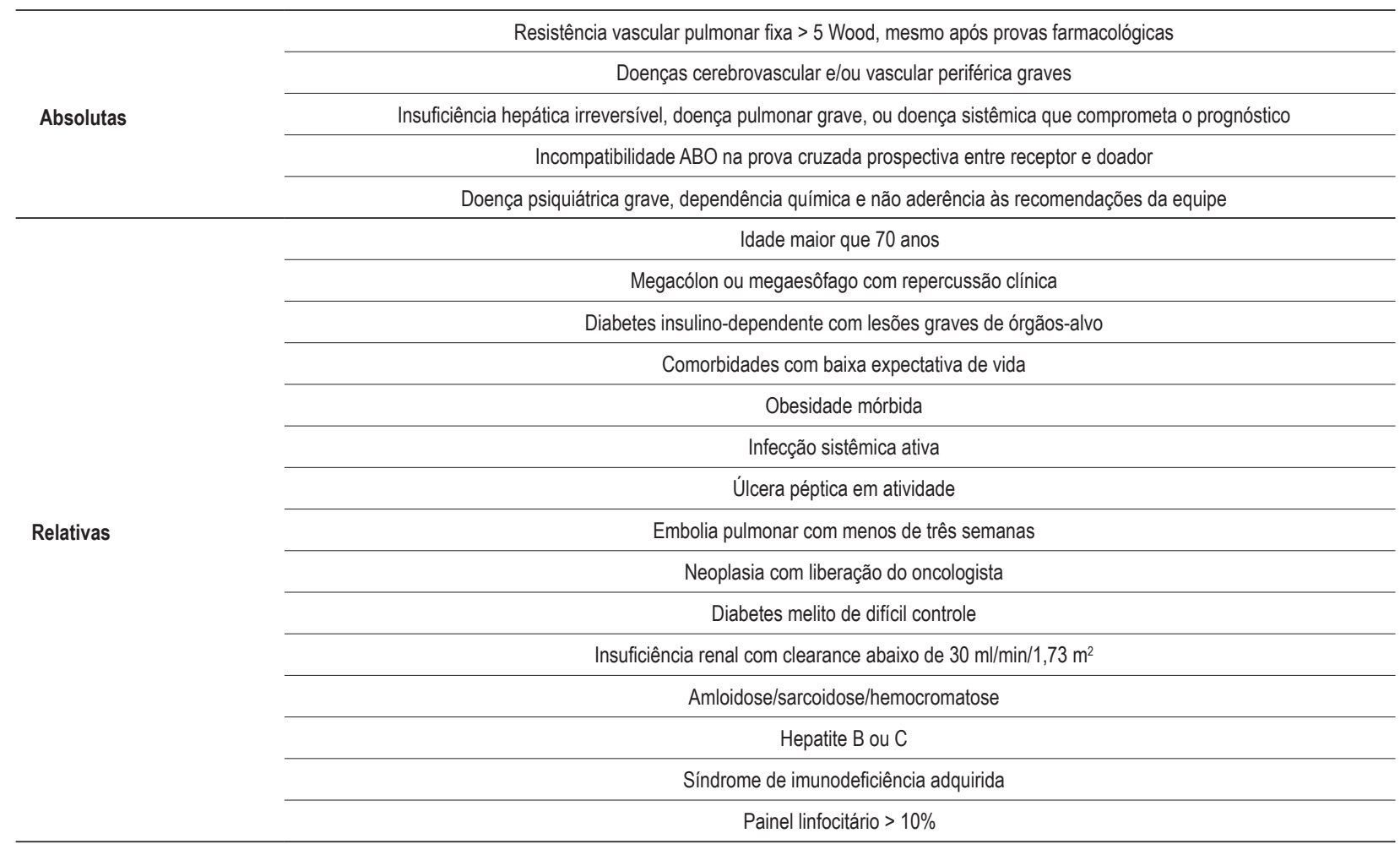


segundo Guidelines da American Heart Association. Esse estudo demonstrou que a associação da TRV-AV apresenta benefícios em redução de morbidade (internação por IC) e, em eventos combinados, reduziu os volumes ventriculares e melhorou a fração de ejeção, porém não alterou a mortalidade total ${ }^{192}$. Os efeitos benéficos só foram demonstrados em um subgrupo pré-especificados pacientes com duração de QRS $\geq 150$ ms. A mortalidade atual foi de $3 \%$.

O estudo RAFT com 1798 pacientes avaliou o impacto da associação da TRV-AV ao CDI em pacientes com fração de ejeção $\leq 30 \%$ e em classes funcionais II e III (19-21\%). Os critérios de indicação de CDI não foram esclarecidos, principalmente, no que diz respeito à prevenção primária ou secundária. Este estudo demonstrou benefícios da associação de TRV-AV em portadores de CDI com significativa redução de morbidade e mortalidade em classe II na população total do estudo ${ }^{193}$. Na análise de subgrupo, foi observado benefício para QRS $\geq 150$ ms e para ausência de fibrilação ou fluter atrial. Recentemente, o papel da dissincronia em pacientes com 120 $\mathrm{ms}<\mathrm{QRS}<150 \mathrm{~ms}$ tem sido questionada, pois somente $9 \%$ dos pacientes do estudo CARE-HF tinham esta característica ${ }^{194}$.

Estudo brasileiro encontrou somente moderada correlação entre duração do QRS e dissincronia intra e interventricular ${ }^{195}$.
Destaca-se que, embora os estudos MADIT CRT-D e RAFT tenham muitas semelhanças, inclusive quanto ao número de pacientes, apresentaram diferente resultado no que se refere à mortalidade isolada. A seleção dos pacientes é importante porque 35\% não respondem clinicamente a TRV-AV e 40-50\% não mudam o remodelamento ${ }^{196}$. Metanálise compilando quatro estudos, que incluíram pacientes em classes funcionais I e II, demonstrou que a TRV atuou na redução do risco relativo de morte de $20 \%$ frente ao tratamento clínico convencional ou ao implante isolado de $\mathrm{CDI}^{197}$. Estudo de custo efetividade demonstrou que a TRV é custo-efetiva no nosso meio enquanto a associação de CDI não é custo-efetiva ${ }^{198}$. Não existe estudo para a doença de Chagas, mas investigação recente demonstrou que a incidência de dissincronia interventricular nesta etiologia é de $34 \%$, não tendo relação com a duração do QRS e nem com outros eventos ${ }^{199}$.

No estudo COMBAT que incluiu pequeno número de pacientes, a TRV-AV, em comparação com o implante de Marcapasso Atrioventricular (MP-AV) convencional com eletrodo no Ventrículo Direito (VD) para pacientes com IC e bradiarritmia, foi associada a melhor qualidade de vida, melhor classe funcional, melhora da FEVE, mas sem diferença quanto à capacidade de exercício e insuficiência mitral ${ }^{200}$.

\section{Tabela 26 - Indicação de Dispositivo de Assistência Circulatória Mecânica como Terapia de Destino na Insuficiência Cardíaca Crônica Sistólica}

\begin{tabular}{lcc}
\hline Classe de Recomendação & Indicações & Nível de Evidência \\
\hline \multirow{2}{*}{ Ila } & IC refratária na dependência de drogas inotrópicas por mais de duas semanas & B \\
\cline { 2 - 3 } & Pacientes com $\mathrm{VO}_{2}$ pico $\leq 10 \mathrm{~m} / \mathrm{Kg} / \mathrm{min}$ & $\mathrm{B}$ \\
\cline { 2 - 3 } III & Classe funcional IV persistente & $\mathrm{B}$ \\
\hline
\end{tabular}

IC significa insuficiência cardíaca; $\mathrm{VO}_{2}$, consumo de oxigênio durante exercício máximo

Tabela 27 - Recomendações para Terapia de Ressincronização Cardíaca isolada na Insuficiência Cardíaca Crônica Sistólica ou associada ao Cardiodesfibrilador Implantável quando Indicado

\begin{tabular}{|c|c|c|}
\hline Classe de Recomendação & Indicações & Nível de Evidência \\
\hline \multicolumn{3}{|l|}{ Para reduzir mortalidade } \\
\hline I & $\mathrm{FE} \leq 35 \%$, ritmo sinusal, CF III, tratamento clínico otimizado e com duração do QRS $\geq 150 \mathrm{~ms}$ & A \\
\hline Ila & $\begin{array}{l}\text { FE } \leq 35 \% \text {, ritmo sinusal, CF III, tratamento clínico otimizado e com duração do QRS entre } 120 \text { - } \\
150 \text { ms com dissincronia ventricular }\end{array}$ & A \\
\hline \multicolumn{3}{|c|}{ Para reduzir morbidade/mortalidade ou prevenir progressão da doença em portadores de CDI } \\
\hline Ila & $\mathrm{FE} \leq 35 \%$, ritmo sinusal, CF II, tratamento clínico otimizado e com duração do QRS $\geq 150$ ms. & A \\
\hline \multicolumn{3}{|l|}{ Para reduzir morbidade } \\
\hline \multirow{3}{*}{$\| \mathrm{lb}$} & $\begin{array}{c}\text { Paciente com FA permanente, FE } \leq 35 \% \text {, CF III ou IV, tratamento otimizado com duração do QRS } \\
\quad \geq 130 \text { ms e dependente de marca-passo após ablação do no AV. }\end{array}$ & $\mathrm{B}$ \\
\hline & $\begin{array}{c}\mathrm{FE} \leq 35 \%, \mathrm{CF} \text { III/IV FA de baixa resposta bem controlada, tratamento clínico otimizado e com } \\
\text { duração do } \mathrm{QRS} \geq 130 \mathrm{~ms}\end{array}$ & C \\
\hline & $\begin{array}{l}\text { Paciente com indicação formal de marcapaso } \mathrm{FE} \leq 35 \% \text {, CF III ou IV tratamento otimizado, duração } \\
\text { do QRS } \geq 120 \mathrm{~ms}\end{array}$ & $\mathrm{~B}$ \\
\hline
\end{tabular}

FE significa fração de ejeção de ventrículo esquerdo; CF, classe funcional, FA, fibrilação atrial 


\section{Diretrizes}

Tabela 28 - Indicações de Cardiodesfibrilador Implantável para Prevenção Secundária de Morte Súbita em Portadores de Disfunção Ventricular Sistólica

\begin{tabular}{lccc}
\hline Classe de Recomendação & Indicações & Nível de Evidência \\
\hline I & $\begin{array}{c}\text { Pacientes com cardiomiopatia isquêmica, sobreviventes de parada cardiaca devido à FV/TV ou } \\
\text { TVS com instabilidade hemodinâmica, excluindo-se alguma causa totalmente reversível }\end{array}$ & A \\
\hline I & $\begin{array}{c}\text { Pacientes com cardiomiopatia não isquêmica ou chagásica, sobreviventes de parada cardíaca devido à } \\
\text { FVITV ou TVS com instabilidade hemodinâmica, excluindo-se alguma causa totalmente reversível. }\end{array}$ & $\mathrm{C}$ \\
\hline I & Paciente com doença cardiaca estrutural com documentação de TVS espontânea estável ou instável & B \\
\hline IIa & Síncope recorrente com indução de TVS instável ou FV no estudo eletrofisiológico invasivo & B \\
\hline III & Pacientes com pouca expectativa de vida em um ano ou co-morbidades graves ou tempestade & elétrica ou na espera de um transplante cardíaco iminente & C \\
\hline
\end{tabular}

FV significa fibrilação ventricular; TV, taquicardia ventricular; TVS, taquicardia ventricular sustentada

Tabela 29 - Indicações de Cardiodesfibrilador Implantável para Prevenção Primária de Morte Súbita em Portadores de Disfunção Ventricular Sistólica

\begin{tabular}{lcc}
\hline Classe de Recomendação & Indicações & Nível de Evidência \\
\hline I & $\begin{array}{c}\text { Cardiomiopatia isquêmica após infarto do miocárdio com pelo menos seis meses de evolução, FE } \\
\leq 35 \%, \text { CF II e III na vigência de tratamento clínico otimizado, sem indicação de revascularização } \\
\text { miocárdica e sem baixa expectativa de vida em um ano }\end{array}$ & A \\
\hline IIa & Cardiomiopatia dilatada não isquêmica, FE $\leq 35 \%$, CF II e III na vigência de tratamento clínico \\
otimizado & B & B \\
\hline III & $\begin{array}{c}\text { Infarto do miocárdio com menos de seis meses de evolução; cardiomiopatia isquêmica com } \\
\text { indicação de revascularização; cardiomiopatia com FE > 35\%; baixa expectativa de vida em um ano }\end{array}$ & B \\
\hline CDI significa cardiodesfibrilador implantável; FE, fração de ejeção de ventrículo esquerdo; CF, classe funcional
\end{tabular}

\section{Abordagem por Estágios (Figura 2)}

As recomendações de tratamento não farmacológico e farmacológico em cada estágio da IC estão resumidas na Figura 2. A prevenção de fatores de risco para doença cardiovascular é fundamental para prevenção da IC, porque esta é a manifestação tardia em pacientes que não tem morte súbita. A terapia antineoplásica com drogas de potencial cardiotoxicidade tem sido reconhecida como novo fator de risco para IC.

\section{Insuficiência Cardíaca com Fração de Ejeção de Ventrículo Esquerdo Preservada.}

A divisão clássica da IC em ICFEP e IC com FE reduzida tem sido questionada por diversos autores, que argumentam que se trata de uma mesma doença com diferentes fenótipos de apresentação ${ }^{201,202}$. Entretanto, existem muitos argumentos demográficos, epidemiológicos, estruturais, cardíacos e baseados no tipo de resposta terapêutica que corroboram a hipótese de que são duas entidades distintas. O diagnóstico continua sendo feito na presença destas quatro condiçõoes ${ }^{203}$ : presença de sinais e sintomas de IC; FEVE $\geq 50 \%$, VE não dilatado (volume telediastólico $<97 \mathrm{~mL} / \mathrm{m}^{2}$ ) e evidência de pressão de enchimento do VE elevada.

Recomenda-se cuidadosa atenção no diagnóstico diferencial de pacientes com ICFEP para se distinguir entre a variedade de outras afecções cardíacas cujo tratamento e abordagem são diferentes ${ }^{204}$. A ICFEP continua sendo pouco valorizada, não há novas evidências e seu tratamento, portanto, ainda é empírico ${ }^{205}$.

\section{Insuficiência Cardíaca e Comorbidades}

\subsection{Insuficiência Renal Crônica}

A prevalência de insuficiência renal em pacientes de ambulatório com IC pode chegar a $29,6 \%{ }^{206}$. A associação de doença cardíaca e renal persiste como marcador de mau prognóstico em pacientes com IC crônica ${ }^{207}$. Novos biomarcadores de lesão renal precoce, como cistatina $\mathrm{C}$ e NGAL (neutrophil gelatinase-associated lipocalin), podem estar associados a pior prognóstico mesmo em presença de creatinina normal ${ }^{208}$. Entretanto não há intervenções específicas para a prevenção ou tratamento desta condição. A prevalência de insuficiência renal parece ser menor em pacientes com ICFEP ${ }^{209}$.

\subsection{Anemia e/ou Deficiência de Ferro (Tabela 30)}

A anemia é marcador de gravidade em pacientes com IC crônica, inclusive na doença de Chagas $^{209-212}$. Ainda assim, persistem dúvidas quanto aos níveis alvo de hemoglobina, eficácia, modalidade e segurança do tratamento e administração de análogos da eritropoetina ${ }^{213,214}$ sobre desfechos secundários, e ainda são aguardados estudos prospectivos sobre efeitos de tais intervenções sobre o 
prognóstico. Transfusão de hemácias não é recomendada rotineiramente e está associada a aumento de mortalidade ${ }^{215}$.

Em pacientes com deficiência de ferro com e sem anemia manifesta, a infusão de ferro venoso foi segura e resultou em melhora da qualidade de vida, classe funcional e aumento da distância caminhada no teste de seis minutos; houve tendência à redução de hospitalizações ${ }^{216}$. Além da hemoglobina, o ferro é componente obrigatório da hemoglobina de muitas metaloproteinas que mediam funções importantes na mioglobina, enzimas de transporte de elétrons, síntese de ácido deoxiribonucleico síntese, monoamina oxidase, ciclooxigenase. Sua deficiência pode desencadear parada da mitose na fase $\mathrm{G}_{1} / \mathrm{S}_{\text {, }}$ apoptose, produção de catecolamina e hipertrofia ${ }^{217}$.

\subsection{Diabetes Melito}

A presença de diabetes melito constitui fator de risco para o desenvolvimento de $I C^{218,219}$, sendo comum a associação destas condições. O tratamento da diabetes em pacientes com IC ainda é alvo de controvérsia, e dados recentes confirmam risco de piora da IC com uso de tiazolidinedionas ${ }^{220}$. Por outro lado, estudos têm demonstrado ser seguro o uso de metformina, com possível efeito benéfico sobre o prognóstico ${ }^{221-223}$. Estudos têm também chamado a atenção para possibilidade de piora de mortalidade associada ao controle muito intenso da glicemia ${ }^{224,225}$

\subsection{Depressão}

A ocorrência de depressão em pacientes com IC crônica associa-se a menor capacidade funcional ${ }^{226}$ e pior prognóstico ${ }^{227,228}$. Depressão foi diagnosticada em $67 \%$ dos pacientes hospitalizados ${ }^{22}$. Resultados do estudo SADHART$\mathrm{CHF}$ mostraram que o uso de sertralina em pacientes com IC é seguro; entretanto, em comparação a placebo, seu uso não determinou melhora de sintomas depressivos ou do estado cardíaco ${ }^{230}$. Pacientes no estudo SADHART-CHF com remissão da depressão apresentaram menos eventos cardiovasculares $^{231}$. O uso de citalopram em idosos com IC também não melhorou depressão 232 .

\subsection{Cardiotoxidade dos Quimioterápicos (Tabelas 31 e 32)}

A disfunção ventricular secundária aos quimioterápicos nem sempre tem manifestação clínica evidente. Desta forma, devese proceder ao monitoramento cardiológico de rotina para a detecção precoce da cardiotoxicidade. A dosagem seriada de troponina e BNP, além da análise da função ventricular pelo ecocardiograma ou ventriculografia radioisotópica são os exames recomendados para este seguimento.

A cardiotoxidade é mais frequente nos portadores de certos fatores de risco, como extremos de idade, disfunção ventricular prévia, hipertensão arterial, diabetes, associação de quimioterápicos, radioterapia mediastinal e suscetibilidade genética ${ }^{233,234}$. Sabe-se que a cardiomiopatia dilatada secundária a quimioterápicos (CMQT) corresponde a $1 \%$ de todas as cardiomiopatias dilatadas ${ }^{235}$. A disfunção ventricular secundária a quimioterápicos é classificada em Tipo I e II e baseia-se na presença de lesão de miócitos e no potencial de reversibilidade da disfunção ventricular ${ }^{236}$. Dentre os principais agentes quimioterápicos relacionados ao desenvolvimento de IC, destacam-se as antraciclinas, agentes alquilantes, agentes microtúbulos, trastuzumabe, bevaczumabe e sunitinibe ${ }^{237}$.

No caso da prevenção da cardiotoxicidade, até o momento só existem evidências de medicações cardioprotetoras para terapia com antraciclinas. O dexrazoxane mostrou-se efetivo para prevenir a cardiotoxicidade, especialmente em mulheres tratadas de câncer de mama metastático quando a dose de antraciclina exceder $300 \mathrm{mg} / \mathrm{m}^{2238}$. Estudo placebo controlado aberto mostrou proteção do carvedilol contra o desenvolvimento de disfunção ventricular ${ }^{239}$. Dados recentes mostraram que pacientes submetidos à quimioterapia com antraciclina, que desenvolveram lesão miocárdica subclínica, caracterizada por elevação de troponina, beneficiaram-se da introdução de IECA ${ }^{240}$.

No caso de pacientes que desenvolveram disfunção ventricular após quimioterapia, observou-se que o tratamento com IECA e betabloqueadores foi efetivo para reversão desta disfunção em boa parte dos $\operatorname{casos}^{241}$. O benefício é mais evidente quanto mais precoce for detectada a alteração e prontamente for introduzido o tratamento.

A radioterapia também pode afetar o coração causando disfunção sistólica, diastólica e a miocardiopatia restritiva. Essas alterações dependem especialmente da dose de radiação, do volume do coração exposto e de técnicas específicas de aplicação ${ }^{242}$.

\section{Subgrupos Especiais}

\subsection{IC na Doença de Chagas}

É a primeira causa de IC em áreas endêmicas ${ }^{243}$, e a terceira causa no Brasil ${ }^{104}$. A morte súbita cardíaca acomete aproximadamente $50 \%$ dos pacientes com IC secundária à

\section{Tabela 30 - Orientações sobre o Manejo da Anemia e ou da Deficiência de Ferro na Insuficiência Cardíaca Crônica Sistólica}

\begin{tabular}{|c|c|c|}
\hline Classe de Recomendação & Indicações & Nível de Evidência \\
\hline \multirow{2}{*}{ Ila } & $\begin{array}{l}\text { Ferro venoso em pacientes com deficiência de ferro (ferritina < } 100 \text { ou ferritina entre } 100 \text { e } 299 \text { com } \\
\text { saturação de transferrina }<20 \% \text { ) para melhora de sintomas }\end{array}$ & B \\
\hline & $\begin{array}{c}\text { Transfusões de sangue em pacientes anêmicos }(\mathrm{Hb}<7 \mathrm{~g} / \mathrm{dl}) \text { e cardiomiopatia dilatada de etiologia } \\
\text { isquêmica ou não isquêmica }\end{array}$ & C \\
\hline $\mathrm{llb}$ & $\begin{array}{l}\text { Eritropoietina / ferro venoso para correção de anemia }(\mathrm{Hb}<12 \mathrm{~g} / \mathrm{dl}) \text { em pacientes com insuficiência } \\
\text { renal crônica dialítica e /ou pré-dialítica e IC }\end{array}$ & B \\
\hline
\end{tabular}

Hb significa hemoglobina; IC, Insuficiência cardiaca 


\section{Diretrizes}

doença de Chagas $^{244}$. A ativação neuro-hormonal é aumentada à semelhança de outras etiologias ${ }^{245,246}$. Assim, considerou-se que o tratamento da IC de origem chagásica deve ser semelhante ao de outras etiologias e somente o nível de evidência é diferente ${ }^{247-249}$. Em estudo prospectivo, o uso de betabloqueador foi associado a maior sobrevida ${ }^{250}$. O não uso de BB parece ser um fator de predição independente de mortalidade para esses pacientes ${ }^{247,248}$. Experimentalmente, o uso de espironolactona melhora a sobrevida e reverte o remodelamento ventricular esquerdo ${ }^{251}$. O nível sanguíneo de digoxina deve ser determinado nos pacientes de etiologia chagásica ${ }^{248,252}$. O tratamento específico, com agentes antiparasitários, na IC da cardiopatia chagásica crônica não possui evidências para sua recomendação ${ }^{253}$.

O CDI pode ser útil na prevenção primária de morte súbita cardíaca, pois este dispositivo reverteu FV em 20\% dos pacientes com IC chagásica, entretanto, ainda precisa ser testado em grandes estudos ${ }^{254}$. O transplante cardíaco deve ser oferecido para pacientes com IC chagásica terminal em virtude dos bons resultados obtidos ${ }^{183,255}$.

\subsection{IC na gestante}

A IC afeta aproximadamente $0,004 \%$ das parturientes da população geral, e até $12,5 \%$ de gestantes portadoras de cardiopatia ${ }^{256}$. A cardiomiopatia periparto tem incidência de 1:300 até 1:4000 gravidez ${ }^{257}$. Disfunção ventricular assintomática pode ser detectada em $0,85 \%$ das mulheres no puerpério ${ }^{258}$. FEVE $<40 \%$ é preditora de alto risco e a gravidez deve ser evitada. Pacientes devem ser informadas do risco de gravidez. Quando a FEVE é < 20\%, a mortalidade materna é muito alta e o término da gravidez deve ser avaliado. Os BB são as medicações mais importantes no tratamento da IC na gestante. Após o parto, o feto deve ser acompanhado por 24-48 horas devido ao risco de bradicardia, hipoglicemia e depressão respiratória pelo BB. Metoprolol e bisoprolol são os BB mais estudados. IECA, BRA e inibidores da renina não podem ser utilizados durante a gravidez. Atenol pode determinar malformações além de bradicardia e hipoglicemia no feto, embora não tenha indicação para tratamento da IC. A digoxina parece ser segura. A espironolactona pode levar a malformações no primeiro trimestre, e deve ser evitada.

Estudo randomizado prospectivo demonstrou que a bromocriptina adicionada ao tratamento pode melhorar a FEVE e a evolução de pacientes com cardiomiopatia no periparto ${ }^{259}$. Exceto se houver contraindicação obstétrica, diante de estabilidade hemodinâmica, o parto pode ser vaginal.

\subsection{IC no idoso}

A ICFEP é mais frequente nos idosos ${ }^{260}$. Associações de comorbidades nessa população, que limitam a atividade física ou trazem limitações de desempenho ${ }^{260}$ e de informações, dificultam o diagnóstico de IC.

\subsection{IC no paciente com SIDA}

A prevalência da IC, nesse grupo de pacientes, cresce à medida que a sobrevida aumenta e novos antirretrovirais são

Tabela 31 - Recomendações quanto à Avaliação Inicial e Monitoramento Cardiológico durante Tratamento com Quimioterápicos Associados a Risco de Disfunção Ventricular e Insuficiência Cardíaca Crônica

\begin{tabular}{|c|c|c|}
\hline Classe de Recomendação & Indicação & Nível de Evidência \\
\hline I & $\begin{array}{c}\text { Avaliação inicial da função ventricular por ecocardiograma transtorácico ou ventriculografia } \\
\text { radioisotópica }\end{array}$ & C \\
\hline I & $\begin{array}{l}\text { Análise de risco-benefício antes do início do tratamento em pacientes portadores de fatores de } \\
\text { risco para cardiotoxicidade }\end{array}$ & C \\
\hline I & $\begin{array}{l}\text { Avaliação periódica da função ventricular (mesmo método da avaliação inicial) durante o } \\
\text { tratamento quimioterápico, conforme periodicidade recomendada para cada droga }\end{array}$ & C \\
\hline Ila & Dosagem de troponina* basal e após cada ciclo (até $72 \mathrm{hs}$ ) de quimioterapia & C \\
\hline Ila & Dosagem tardia de troponina (um mês após o ciclo) & C \\
\hline Ila & Dosagem de peptídeos natriuréticos para seguimento ambulatorial de cardiotoxicidade & $\mathrm{C}$ \\
\hline
\end{tabular}

Tabela 32 - Recomendações para a Prevenção e Tratamento da Cardiotoxicidade por Antraciclinas

\begin{tabular}{|c|c|c|}
\hline Classe de Recomendação & Indicação & Nível de Evidência \\
\hline 1 & $\begin{array}{l}\text { Dexrazoxane para a prevenção de cardiotoxicidade em mulheres portadoras de câncer de mama } \\
\text { metastático cuja dose cumulativa ultrapasse } 300 \mathrm{mg} / \mathrm{m}^{2}\end{array}$ & $A$ \\
\hline 1 & $\begin{array}{l}\text { IECA em pacientes com evidências de lesão miocárdica pela elevação de troponina ou redução } \\
\text { da FEVE de pelo menos } 10 \% \text { logo após quimioterapia }\end{array}$ & $B$ \\
\hline Ila & $\begin{array}{l}\text { Betabloqueador em pacientes com evidências de lesão miocárdica pela elevação de troponina ou } \\
\text { redução da FEVE de pelo menos } 10 \% \text { logo após quimioterapia }\end{array}$ & C \\
\hline
\end{tabular}


utilizados $^{261}$. Vários mecanismos próprios estão envolvidos na cardiomiopatia da SIDA, incluindo a lesão pela infecção e a cardiotoxicidade do tratamento ${ }^{262-264}$, o que define um pior prognóstico em comparação com outras etiologias.

\subsection{IC direita e Hipertensão Pulmonar (Tabela 34)}

Na disfunção do VD, o tratamento deve contemplar a otimização da pré-carga (manejo de volume), póscarga (vasodilatadores) e contratilidade (inotrópicos e dispositivos de assistência circulatória) ${ }^{265-267}$. O uso agudo de vasodilatadores pulmonares na avaliação de candidatos à transplante cardíaco e no manejo do perioperatório do transplante cardíaco é bem estabelecido e inclui o óxido nítrico, prostaglandinas, inibidores de endotelina e inibidores de fosfodiesterase ${ }^{136}$. Recentemente, em estudo com 82 pacientes em fila de transplante cardíaco e utilizando bosentan, houve melhora dos parâmetros hemodinâmicos e inclusive de mortalidade ${ }^{268}$.

Em relação aos inibidores de fosfodiesterase, estudos nacionais randomizados, placebo controlado demonstraram o benefício desta classe de drogas na IC crônica. O primeiro, pioneiro na literatura, demonstrou segurança do uso neste perfil de pacientes com IC com melhora na capacidade de exercício ${ }^{139}$. O segundo revelou efeito sustentado do sildenafil após quatro semanas de uso com redução da HP e melhora funcional ${ }^{140}$. Mais recentemente, o uso prolongado de assistência circulatória mecânica esquerda (seis meses) pode ser considerado como estratégia para redução da HP permitindo posteriormente o transplante 269,270 .

\subsection{Miocardite (Tabela 35)}

$\mathrm{Na}$ investigação da miocardite aguda e da miocardiopatia dilatada idiopática, a biopsia endomiocárdica pode ser fundamental, muito além dos critérios de Dallas, através da utilização de técnicas de imuno-histoquímica para contagem de células inflamatórias (linfócitos e macrófagos), expressão de HLA classe II, moléculas de adesão (ICAM) e pesquisa de genoma viral por biologia molecular ${ }^{271}$. A realização da biopsia incluindo amostras de ambos os ventrículos aumentou a sensibilidade para o diagnóstico de miocardite ${ }^{272}$.

A ressonância magnética $(\mathrm{RM})$ tem sido considerada para o diagnóstico de miocardite aguda ${ }^{273}$. Consenso internacional de 2009 refere acurácia da RM de 56 a 78\% para diagnóstico de miocardite aguda em comparação à biopsia endomiocárdica, sendo o melhor desempenho obtido quando da presença de dois de três parâmetros (realce precoce, edema e/ou realce tardio $)^{274}$. Na miocardite crônica ${ }^{275}$, a acurácia comparada à biopsia endomiocárdica, utilizando um dos três parâmetros, variou de 49 a 72\%. Apesar de haver sugestão de benefício da biopsia guiada por $\mathrm{RM}^{276}$, estudo mais recente não confirmou este achado ${ }^{277}$. A pesquisa de sorologias em pacientes com miocardite não parece conferir benefício para elucidação de micro-organismos potencialmente envolvidos ${ }^{278}$.

Estudo de avaliação de prognóstico em pacientes com miocardite $^{279}$ (início de sintomas menor que seis meses) demonstrou que os três principais preditores de morte cardíaca ou transplante são a classe funcional NYHA III/IV, ausência de betabloqueador e presença de inflamação na biopsia endomiocárdica (expressão de HLA classe II, contagem

\section{Tabela 33 - Orientações para o Tratamento da Insuficiência Cardíaca Crônica Sistólica na Gestante}

\begin{tabular}{lcc}
\hline Classe de Recomendação & Indicações & Nível de Evidência \\
\hline & Manutenção ou início do BB em pacientes com IC durante a gestação & C \\
\cline { 2 - 3 } & Didralazina e nitrato \\
\hline III & Digoxina nos pacientes sintomáticos, em uso prévio à gravidez ou em fibrilação atrial com alta \\
resposta ventricular
\end{tabular}

BB significa betabloqueador; IC, insuficiência cardíaca; IECA, inibidor de enzima de conversão da angiotensina; BRA, bloqueador do receptor da angiotensina

Tabela 34 - Orientações para Tratamento de Pacientes com Hipertensão Pulmonar e Insuficiência Cardíaca Crônica Direita Sistólica

\begin{tabular}{|c|c|c|}
\hline Classe de Recomendação & Indicações & Nível de Evidência \\
\hline 1 & $\begin{array}{l}\text { Óxido nítrico, prostaglandinas, inibidores de endotelina e inibidores de fosfodiesterase para estudo } \\
\text { de responsividade da HP no pré-transplante cardíaco e no manejo perioperatório do transplante } \\
\text { cardíaco. }\end{array}$ & $\mathrm{B}$ \\
\hline Ila & Sildenafil em pacientes sintomáticos, com HP e IC com tratamento otimizado & $\mathrm{B}$ \\
\hline $\mathrm{Ilb}$ & Inibidores de endotelina em pacientes sintomáticos, com HP e IC com tratamento otimizado. & $\mathrm{B}$ \\
\hline
\end{tabular}

HP significa hipertensão pulmonar 


\section{Diretrizes}

de células T e macrófagos na imuno-histoquímica). Neste estudo, não houve relação de prognóstico com a presença de genoma viral na biopsia endomiocárdica.

Nos pacientes com IC de início recente e evolução desfavorável de sintomas e da função ventricular, a biopsia endomiocárdica tem indicação, especialmente para descartar a presença de miocardite de células gigantes. Apesar de baixa incidência, a evolução para óbito ou transplante cardíaco é elevada nesta entidade, especialmente quando não realizada imunossupressão ${ }^{280}$; além disso, existe risco de recorrência fatal com a suspensão da imunossupressão.

Na miocardiopatia dilatada idiopática (sintomas de IC acima de um ano), de maneira pioneira, estudo holandês utilizando técnica de biologia molecular quantitativa $(P C R$ Real Time) demonstrou melhora da função ventricular em pacientes tratados com imunoglobulina que apresentavam títulos elevados de genoma viral de parvovírus B19 no tecido miocárdico ${ }^{281}$.

O estudo italiano randomizado, placebo controlado, TIMIC ${ }^{282}$ demonstrou benefício da imunossupressão no tratamento da miocardiopatia inflamatória, na ausência de genoma viral. Incluiu pacientes com sintomas de IC acima de seis meses, inflamação na biopsia endomiocárdica e ausência de genoma viral. O grupo que recebeu prednisona + azatioprina apresentou melhora de fração de ejeção e redução das cavidades em comparação ao grupo placebo.

\subsection{Miocárdio não Compactado (Tabela 36)}

O miocárdio não compactado isolado é uma cardiomiopatia primária cuja etiologia é desconhecida, porém com origem genética autossômica dominante 283,284 , tendo prevalência estimada em 0,05\%. Ele se caracteriza por apresentar trabeculações numerosas e proeminentes com recessos intratrabeculares que penetram profundamente no miocárdio e não estão em comunicação com os vasos coronários. Pode apresentar-se com manifestações de IC por disfunção sistólica e/ou diastólica, ou com arritmias cardíacas ou ainda com fenômenos tromboembólicos. O ecocardiograma e a ressonância magnética do coração são os exames complementares de escolha no diagnóstico ${ }^{285,286}$. Não existem estudos específicos no tratamento da IC nesse grupo de pacientes.

\section{Tabela 35 - Indicações de Investigação Diagnóstica Invasiva e Não Invasiva e de Tratamento da Miocardite}

\begin{tabular}{|c|c|c|}
\hline Classe de Recomendação & Indicações & Nível de Evidência \\
\hline \multirow[t]{2}{*}{ I } & $\begin{array}{l}\text { Biópsia endomiocárdica em quadros de IC até } 6 \text { meses com dilatação ventricular e arritmias } \\
\text { ventriculares frequentes, bloqueio atrioventricular de segundo ou terceiro grau, que apresentem } \\
\text { refratariedade após o tratamento clínico otimizado após exclusão de outros fatores causais }\end{array}$ & $\mathrm{B}$ \\
\hline & $\begin{array}{l}\text { Imunossupressão na presença de miocardite de células gigantes confirmada por biopsia } \\
\text { endomiocárdica. }\end{array}$ & $\mathrm{B}$ \\
\hline \multirow[t]{2}{*}{ Ila } & $\begin{array}{l}\text { Biopsia endomiocárdica em quadros de IC de início } 6 \text {-12meses com dilatação ventricular e arritmias } \\
\text { ventriculares frequentes, bloqueio atrioventricular de segundo ou terceiro grau, que apresentem } \\
\text { refratariedade após o tratamento clínico otimizado após exclusão de outros fatores causais }\end{array}$ & $B$ \\
\hline & $\begin{array}{l}\text { Ressonância magnética com técnicas de realce precoce, edema e de realce tardio em pacientes } \\
\qquad \text { com quadro de IC com até três meses do seu início }\end{array}$ & B \\
\hline \multirow{4}{*}{ Ilb } & $\begin{array}{l}\text { Imunossupressão na miocardiopatia inflamatória (tratamento clínico otimizado, acima de } 6 \text { meses } \\
\text { de sintomas de IC) comprovada por biopsia endomiocárdica através de imuno-histoquímica, na } \\
\text { ausência de genoma viral por biologia molecular. }\end{array}$ & $\mathrm{B}$ \\
\hline & $\begin{array}{l}\text { Cintilografia miocárdica para avaliação de inflamação com gálio } 67, \text { em pacientes com quadro de } \\
\text { IC com até três meses do seu início. }\end{array}$ & $\mathrm{B}$ \\
\hline & $\begin{array}{l}\text { Imunoglobulina na miocardite comprovada por biopsia endomiocárdica através de imuno- } \\
\text { histoquímica e presença de genoma viral no tecido miocárdico por biologia molecular. }\end{array}$ & $\mathrm{B}$ \\
\hline & Coleta de sorologias virais na investigação de miocardite e miocardiopatia dilatada idiopática. & $\mathrm{B}$ \\
\hline
\end{tabular}

IC significa insuficiência cardiaca sistólica

Tabela 36 - Orientações para Tratamento de Pacientes com Miocárdio não Compactado

\begin{tabular}{lll}
\hline Classe de Recomendação & Indicacões & Nivel de Evidência \\
\hline I & Anticoagulação oral em pacientes com FA ou embolia prévia & C \\
\hline lla & Anticoagulação oral em pacientes com disfunção ventricular & C \\
\hline
\end{tabular}

FA significa fibrilação atrial 


\section{Opções Diagnósticas ou Terapêuticas Controversas, ou em Desenvolvimento, sem Papel Definido para a IC}

\subsection{Monitorização Hemodinâmica}

Os dispositivos implantáveis reduziram apenas hospitalizações relacionadas à IC. O estudo PARTNERS HF, prospectivo, multicêntrico e não randomizado em pacientes com ressincronizador e CDI avaliou a positividade de um algoritmo diagnóstico para IC e demonstrou um aumento em 5,5 vezes a probabilidade de internação por IC com congestão pulmonar nos próximos 30 dias (alto risco) ${ }^{287}$. Porém, o custo-efetividade precisa ser comprovado por novos estudos.

\subsection{Bioimpedância Transtorácica (BTC)}

Em pacientes descompensados, o estudo $\mathrm{BIG}^{288}$ avaliou a BTC na medida do débito cardíaco e obteve correlação modesta com as medidas invasivas, sem fornecer informações sobre as pressões de enchimento ventricular e não teve valor prognóstico, portanto, parece não ter utilidade nesta população. A avaliação na IC ambulatorial ainda necessita de novos estudos.

\subsection{Hormônio do Crescimento}

Atualmente, o uso de hormônio de crescimento demonstrou alguns benefícios, porém com uma preocupação com os efeitos adversos. São necessários grandes estudos randomizados para avaliação da segurança e eficácia em longo prazo 289,290 .

\subsection{Antagonistas da Vasopressina}

Estes medicamentos estão associados com melhora das concentrações séricas de sódio, peso corporal, função cerebral, sintomas, porém não determinam benefícios na mortalidade, mortalidade cardiovascular ou hospitalização nos pacientes com IC ${ }^{291}$. Seu papel ainda é incerto, necessitando de novos estudos, inclusive de custo-efetividade, para a indicação apropriada.

\subsection{Antagonistas da Endotelina}

Pequeno estudo utilizando o bosentan em pacientes com IC refratária com hipertensão pulmonar (HP) que estavam aguardando transplante de coração demonstrou melhora clínica e hemodinâmica, porém estudos maiores e randomizados são necessários para confirmar esta opção terapêutica nestes pacientes ${ }^{292}$.

\subsection{Antagonistas do Receptor A1 da Adenosina}

O estudo piloto, fase IIb, (PROTECT Pilot Study) $)^{293}$ indicou que um antagonista seletivo dos receptores A1 da adenosina, a rolofilina, poderia promover aumento da diurese e melhora da função renal em pacientes com IC crônica ou IC agudamente descompensada. Contudo, os resultados publicados de um grande estudo clínico fase III (PROTECT Study) 294,295 mostraram que a rolofilina não preveniu a piora da função renal em pacientes com IC agudamente descompensada e com um efeito diurético discreto. Aos 60 dias, morte ou readmissão hospitalar por causa cardiovascular ou renal ocorreu em proporção semelhante nos grupos rolofilina e placebo.

De forma concordante ao que se observou no estudo PROTECT, dados preliminares de um estudo clínico fase IIb (TRIDENT 1) $)^{296}$, testando o uso de outro antagonista seletivo do receptor A1 da adenosina, a tonopofilina, não demonstraram qualquer efeito protetor sobre a função renal em pacientes com ICAD.

\subsection{Inibidores adrenérgicos centrais}

Nolomirole apresentou tendência à piora da mortalidade ou hospitalização por $\mathrm{IC}^{297}$. Permanecem contraindicados para uso na IC.

\subsection{G-CSF / Terapia Celular}

O estudo STAR-heart ${ }^{298}$, randomizado com implante intracoronário de células da medula óssea, mostrou melhora do desempenho ventricular, qualidade de vida e sobrevida sem efeitos colaterais. No Brasil, estudos preliminares com inclusão de número limitado de pacientes demonstraram que a utilização de células tronco da medula é segura e potencialmente efetiva em pacientes com IC $299,300$. Evidência mais robusta patrocinada pelo Ministério da Saúde não demonstrou benefícios para estes pacientes ${ }^{301}$. Uma importante limitação é a reduzida persistência de células tronco no coração em torno de 2,3\% ${ }^{302}$. Exercício também não aumentou células CD34+. ${ }^{303}$. Apesar dos avanços recentes, ainda a consideramos como terapia em investigação ${ }^{304}$.

\subsection{Relaxina}

Relaxina, um hormônio natural da família da insulina, conhecida por desempenhar papel nas adaptações fisiológicas da gravidez, por meio de estudos em animais e tecido humano isolado, demonstrou ter efeito vasodilatador nos homens e nas mulheres não grávidas. Parece agir através de múltiplas vias, incluindo o estímulo à gelatinases e ativação dos receptores de endotelina do tipo B e, subsequentemente, o óxido nítrico. Os resultados dos ensaios clínicos de fase I e II demonstraram tendências favoráveis sem grandes eventos adversos, sugerindo ser um tratamento potencial para IC aguda, porém ainda são necessários identificar a dose, duração do tratamento e eficácia ${ }^{305}$.

\subsection{Quelantes de Potássio (RLY5016 - PEARL-HF)}

O risco de indução de hipercalemia pelo bloqueio múltiplo do sistema renina-angiotensina-aldosterona (SRAA) ${ }^{306}$ tem resultado no emprego de menos da metade das doses máximas preconizadas desses agentes com impacto comprovado em aumentar a sobrevida. Dessa forma, drogas com efeito redutor dos níveis de potássio sérico seriam importantes coadjuvantes no tratamento da IC crônica. Um estudo clínico piloto, randomizado, placebo controlado (PEARL- 


\section{Diretrizes}

$\mathrm{HF})^{307}$, testou o emprego de um polímero não absorvível, chamado RLY5016, desenhado para ligar os ions potássio na luz do trato gastrointestinal. Nesse estudo, o uso de RLY5016 associou-se a menor incidência de hipercalemia, com maior proporção de pacientes atingindo a dose alvo de $50 \mathrm{mg} /$ dia de espironolactona. Entretanto, aumentou a hipopotassemia e a hipomagnesemia. Ainda são necessários grandes estudos para confirmar sua utilidade no tratamento da IC crônica.

\subsection{Ativadores da Miosina Cardíaca (omecamtiv} mecarbil)

Omecamtiv mecarbil, ativador seletivo da miosina cardíaca, é a primeira molécula de uma nova classe de drogas inotrópicas positivas que age por ativação direta da miosina cardíaca, destituída de efeitos indesejáveis, como o aumento do consumo de oxigênio, arritmia e aumento da frequência cardíaca ${ }^{308,309}$. Estudos recentes de fase II demonstram que esta medicação pode melhorar a função cardíaca ${ }^{310,311}$, porém não existem grandes estudos clínicos com desfechos de mortalidade e análise de segurança.

\subsection{Simpatectomia}

Pesquisadores brasileiros propuseram originalmente o bloqueio simpático endoscópico torácico esquerdo em pacientes com IC e obtiveram, em resultados preliminares, melhora da qualidade de vida e da FEVE ${ }^{312}$.

\subsection{Estimulação Elétrica do Vago ou do Baroreflexo do Seio Carotídeo}

Estudo experimental demonstrou que estimulação elétrica do seio carotídeo pode melhorar a função ventricular esquerda na $\mathrm{IC}^{313}$. Em estudo de fase II com pequeno número e pacientes, a estimulação do vago determinou melhora da classe funcional, na capacidade de exercício e na FEVE. Entretanto, eventos adversos foram frequentes ${ }^{314}$.

\subsection{Inibidores da Renina}

No estudo ALOFT, o alisquireno reduziu as concentrações de NT-pro-BNP e excreção de aldosterona ${ }^{315}$. No estudo ASPIRE, que incluiu pacientes com 2-8 semanas de infarto agudo do miocárdio com disfunção ventricular, não houve benefício quanto ao remodelamento ou eventos clínicos ${ }^{316}$. Os estudos ASTRONAUT e ATMOSPHERE estão em desenvolvimento e poderão esclarecer a importância do alisquireno no tratamento da IC.

\subsection{Inibidores de Outros Sistemas além do Sistema Renina-Angiotensina-Aldosterona}

O estudo PARADIGM-HF está planejado para testar o efeito do LCZ696, inibidor de receptor de angiotensina-neprilisin, que combina o efeito de BRA e inibidor da endopeptidase neutra com efeito adicional de evitar a degradação de hormônios natriuréticos sem afetar a bradicinina ${ }^{317}$.

11.16. Não Glicosídeos via Inibição da $\mathrm{Na}+/ \mathrm{K}+-\mathrm{ATPase}$ e via Ativação Cálcio do Retículo Sarcoplasmático (SERCA 2a)

A combinação de ativação de SERCA2a e inibição de Na-K ATPase pode aumentar contratilidade, facilitar o relaxamento. Istaroxime, que ativa SERCA2a e inibe a Na-K ATPase, em estudo de fase II, determinou melhora hemodinâmica ${ }^{318}$.

\section{Declaração de Conflito de Interesse}

A declaração de conflito de interesse informada é de única responsabilidade do participante: sem conflito de interesse ${ }^{1}$, participação de estudos clínicos e/ou experimentais subvencionados pela indústria farmacêutica ou de equipamentos ${ }^{2}$; palestrante ou qualquer atividade em eventos patrocinadas pela indústria ; foi (é) membro do conselho consultivo ou diretivo da indústria farmacêutica ou de equipamentos ${ }^{4}$; participar de comitês normativos de estudos científicos patrocinados pela indústria ${ }^{5}$; receber auxílio pessoal ou apoio institucional da indústria ${ }^{6}$; preparo de textos científicos em periódicos patrocinados pela indústria ${ }^{7}$, ter ações da indústria ${ }^{8}$ e outros ${ }^{9}$.

Almir Sergio Ferraz: ${ }^{2}$ Pfizer; ${ }^{3}$ Laboratório DaiichiSankyo; ${ }^{6}$ Cardios; Denilson Albuquerque: ${ }^{2}$ Pfizer, BMS, Otsuka, MSD, Servier; ${ }^{3}$ Servier, Sanofi-Aventis, AstraZeneca, ${ }^{5}$ Sanofi-Aventis, Pfizer/BM; Dirceu de Almeida Rodrigues: ${ }^{3}$ Pfizer, Baldacchi, Merck-Serono, Servier; ${ }^{2}$ Servier, Novartis, Amgen; Edimar Alcides Bocchi: ${ }^{3}$ Laboratório Servier, Baldacchi, participações; ${ }^{2}$ Amgen, Servier; ${ }^{6}$ Servier, Merck; Evandro Tinoco, ${ }^{3}$ AstraZeneca, Merck, Boheringer; ${ }^{7}$ Sigmafarma, Eurofarma; Fabiana Goulart Marcondes-Braga: ${ }^{6}$ Merck; Fabio Vilas-Boas: ${ }^{3}$ Novartis, Servier, Astrazeneca; ${ }^{2}$ Novartis, Sanofi, Sankyo, Janssen-Cilag, Takeda, PGX Health; Fátima Cruz 1; Fernando Bacal conflito: ${ }^{3}$ Novartis; ${ }^{6}$ Novartis; Humberto Villacorta ${ }^{1}$; Felix Ramires: ${ }^{2}$ Novartis, ${ }^{5}$ Novartis; João David de Souza Neto: ${ }^{2}$ Novartis, Amgen, Roche; ${ }^{3}$ MSD, Merck Serono, Novartis, ${ }^{7}$ Torrent; João Manoel Rossi Neto ${ }^{1}$; Lidia Zytynski Moura: ${ }^{2}$ Novartis, Amgen; ${ }^{6}$ Novartis; Luis Beckda-Silva: ${ }^{3}$ Astra-Zeneca e Roche; Luis Eduardo Rodhe ${ }^{1}$; Luiz Felipe Moreira ${ }^{1}$; Marcelo Montera: ${ }^{3}$ Merck Serome, Abbott, ${ }^{4}$ Laboratório Servier, Merck Serome; Marcus Vinicius Simões: ${ }^{2}$ Novartis, Amgen, Daichi-Sankyo; Maria da Consolação Vieira Moreira ${ }^{1}$; Nadine Clausell: ${ }^{2}$ Amgen; Reinaldo Bestetti: ${ }^{3}$ Saint-Jude; Ricardo Mourilhe-Rocha: ${ }^{2}$ Amgen, Servier; Salvador Rassi: ${ }^{2}$ MSD, Novartis, Servier, Astra-Zenica; ${ }^{3}$ Novartis, Biolab; ${ }^{6}$ Novartis; Sandrigo Mangini: ${ }^{1}$; Silvia Moreira Ayub-Ferreira: ${ }^{2}$ Amgen; Silvia Marinho Martins: ${ }^{3}$ Sanofi, ${ }^{2}$ Novartis, Amgem; Solange Bordignon: ${ }^{2}$ Amgen, Novartis; Victor Issa ${ }^{1}$. 


\section{Referências}

1. Moutinho MA, Colucci FA, Alcoforado V, Tavares LR, Rachid MB, Rosa ML, et al. Heart failure with preserved ejection fraction and systolic dysfunction in the community. Arq Bras Cardiol. 2008;90(2):132-7.

2. Goldraich L, Clausell N, Biolo A, Beck-da-Silva L, Rohde LE. Preditores clínicos de fração de ejeção de ventrículo esquerdo preservada na insuficiência cardíaca descompensada. Arq Bras Cardiol. 2010;94(3):364-71.

3. Mangini S, Silveira FS, Silva CP, Grativvol PS, Seguro LF, Ferreira SM, et al. Decompensated heart failure in the emergency department of a cardiology hospital. Arq Bras Cardiol. 2008;90(6):400-6.

4. Rosa ML, Giro C, Alves T de O, Moura EC, Lacerda Lda S, Sant Anna LP, et al. Analysis of mortality and hospitalization for cardiovascular diseases in Niterói, between 1998 and 2007. Arq Bras Cardiol. 2011;96(6):477-83.

5. Nogueira PR, Rassi S, Corrêa KdeS. Epidemiological, clinical etherapeutic profile of heart failure in a tertiary hospital. Arq Bras Cardiol. 2010;95(3):392-8.

6. Santo AH. Chagas disease-related mortality trends, state of São Paulo, Brazil, 1985 to 2006: a study using multiple causes of death. Rev Panam Salud Publica. 2009;26(4):299-309.

7. Balieiro HM, Osugue RK, Rangel SP, Brandão R, Balieiro TL, Bernardez S, et al. Clinical and demographic profile and quality indicators for heart failure in a rural area. Arq Bras Cardiol. 2009;93(6):637-42

8. Bocchi EA, Guimarães G, Tarasoutshi F, Spina G, Mangini S, Bacal F. Cardiomyopathy, adult valve disease and heart failure in South America. Heart. 2009;95(3):181-9.

9. Gaui EN, Klein $\mathrm{CH}$, Oliveira GM. Mortality due to heart failure: extended analysis and temporal trend in three states of Brazil. Arq Bras Cardiol. 2010;94(1):55-61.

10. Bahrami H, Kronmal R, Bluemke DA, Olson J, Shea S, Liu K, et al. Differences in the incidence of congestive heart failure by ethnicity: the multi-ethnic study of atherosclerosis. Arch Intern Med. 2008;168(19):2138-45.

11. Bahrami H, Bluemke DA, Kronmal R, Bertoni AG, Lloyd-Jones DM, Shahar $\mathrm{E}$, et al. Novel metabolic risk factors for incident heart failure and their relationship with obesity: the MESA (Multi-Ethnic Study of Atherosclerosis) study. J Am Coll Cardiol. 2008;51(18):1775-83.

12. Butt AA, Chang CC, Kuller L, Goetz MB, Leaf D, Rimland D, et al. Risk of heart failure with human immunodeficiency virus in the absence of prior diagnosis of coronary heart disease. Arch Intern Med. 2011;171(8):737-43.

13. Geiger S, Lange V, Suhl P, Heinemann V, Stemmler HJ. Anticancer therapy induced cardiotoxicity: review of the literature. Anticancer Drugs. 2010;21(6):578-90

14. Strauss DG, Cardoso S, Lima JA, Rochitte CE, Wu KC. ECG scar quantification correlates with cardiac magnetic resonance scar size and prognostic factors in Chagas' disease. Heart. 2011;97(5):357-61.

15. Ribeiro AL, Rocha MO, Terranova P, Cesarano M, Nunes MD, Lombardi F. T-wave amplitude variability and the risk of death in Chagas disease. J Cardiovasc Electrophysiol. 2011;22(7):799-805

16. Kociol RD, Pang PS, Gheorghiade M, Fonarow GC, O'Connor CM, Felker GM. Troponin elevation in heart failure prevalence, mechanisms, and clinical implications. J Am Coll Cardiol. 2010;56(14):1071-8.

17. Tsutamoto T, Kawahara C, Nishiyama K, Yamaji M, Fujii M, Yamamoto T, et al. Prognostic role of highly sensitive cardiac troponin I in patients with systolic heart failure. Am Heart J. 2010;159(1):63-7.

18. Velho FM, Cohen CR, Santos KG, Silvello D, Martinelli N, Biolo A, et al. Polymorphisms of matrix metalloproteinases in systolic heart failure: role on disease susceptibility, phenotypic characteristics, and prognosis. J Card Fail. $2011 ; 17(2): 115-21$

19. Kelder JC, Cowie MR, McDonagh TA, Hardman SM, Grobbee DE, Cost B, et al. Quantifying the added value of BNP in suspected heart failure in general practice: an individual patient data meta-analysis. Heart. 2011;97:959-63.
20. Mant J, Al-Mohammad A, Swain S, Laramée P. Management of chronic heart failure in adults: synopsis of the National Institute for Health and clinical excellence guideline. Ann Intern Med. 2011;155(4):252-9.

21. Marinho FC, Vargas FS, Fabri J Jr, Acencio MM, Genofre EH, Antonangelo $\mathrm{L}$, et al. Clinical usefulness of B-type natriuretic peptide in the diagnosis of pleural effusions due to heart failure. Respirology. 2011;16(3):495-9.

22. Moreira Mda C, Wang Y, Heringer-Walther S, Wessel N, Walther T. Prognostic value of natriuretic peptides in Chagas' disease: a head-to-head comparison of the 3 natriuretic peptides. Congest Heart Fail. 2009;15(2):75-81.

23. Bonow RO, Maurer G, Lee KL, Holly TA, Binkley PF, Desvigne-Nickens P, et al. STICH Trial Investigators. Myocardial viability and survival in ischemic left ventricular dysfunction. N Engl J Med. 2011;364(17):1617-25.

24. Taylor AJ, Cerqueira M, Hodgson JM, Mark D, Min J, O'Gara P, et al. ACCF/ SCCT/ACR/AHA/ASE/ASNC/SCAI/SCMR 2010 appropriate use criteria for cardiac computed tomography: a report of the American College of Cardiology Foundation Appropriate Use Criteria Task Force, the Society of Cardiovascular Computed Tomography, the American College of Radiology, the American Heart Association, the American Society of Echocardiography, the American Society of Nuclear Cardiology, the Society for Cardiovascular Angiography and Interventions, and the Society for Cardiovascular Magnetic Resonance. Circulation. 2010;122(21):e525-55.

25. Guimarães GV, Carvalho VO, Bocchi EA. Reproducibility of the selfcontrolled six-minute walking test in heart failure patients. Clinics. 2008;63(2):201-6.

26. Rubim VS, Drumond Neto C, Romeo JL, Montera MW. Prognostic value of the Six-Minute Walk Test in heart failure. Arq Bras Cardiol. 2006;86(2):120-5.

27. Chandrashekhar Y, Anand IS. Can common exercise indices determine peak exercise oxygen consumption and anaerobic threshold during stress testing in patients with chronic congestive heart failure? Indian Heart J. $1993 ; 45(6): 493-5$

28. Carvalho VO, Bocchi EA, Guimarães GV. The carvedilol's beta-blockade in heart failure and exercise training's sympathetic blockade in healthy athletes during the rest and peak effort. Cardiovasc Ther. 2010;28(2):87-92.

29. Guimaraes GV, d'Avila VM, Silva MS, Ferreira SA, Ciolac EG, Carvalho VO et al. A cutoff point for peak oxygen consumption in the prognosis of heart failure patients with beta-blocker therapy. Int J Cardiol. 2010;145(1):75-7.

30. Guimarães GV, Silva MS, d'Avila VM, Ferreira SM, Silva CP, Bocchi EA. Peak VO2 and VE/VCO2 slope in betablockers era in patients with heart failure: a Brazilian experience. Arq Bras Cardiol. 2008;91(1):39-48.

31. Pfisterer $\mathrm{M}$, Buser P, Rickli H, Gutmann M, Erne P, Rickenbacher $\mathrm{P}$, et al BNP-guided versus symptom-guided heart failure therapy: the Trial of Intensified vs Standard Medical Therapy in Elderly Patients with Congestive Heart Failure (TIME-CHF) randomized trial. JAMA. 2009;301(4):383-92.

32. Lainchbury JG, Troughton RW, Strangman KM, Frampton CM, Pilbrow A, Yandle TG, et al. N-terminal pro-B-type natriuretic peptide-guided treatment for chronic heart failure: results from the BATTLESCARRED (NT-proBNP-Assisted Treatment to Lessen Serial Cardiac Readmissions and Death) Trial. J Am Coll Cardiol. 2010;55(1):53-60

33. Eurlings LW, van Pol PE, Kok WE, van Wijk S, Lodewijks-van der Bolt C, Balk AH, et al. Management of chronic heart failure guided by individual $\mathrm{N}$-terminal pro-B-type natriuretic peptide targets: results from the PRIMA (Can PRo-brain-natriuretic peptide guided therapy of chronic heart failure IMprove heart fAilure morbidity and mortality?) study. J Am Coll Cardiol. 2010;56(25):2090-100

34. Porapakkham P, Porapakkham P, Zimmet H, Billah B, Krum H. B-type natriuretic peptide-guided heart failure therapy: a meta-analysis. Arch Intern Med. 2010:170(6):507-14.

35. Bowles $\mathrm{KH}$, Holland DE, Horowitz DA. A comparison of in-person home care, home care with telephone contact and home care with telemonitoring for disease management. J Telemed Telecare. 2009;15(7):344-50. 
36. Chaudhry SI, Mattera JA, Curtis JP, Spertus JA, Herrin J, Lin $Z$, et al. Telemonitoring in patients with heart failure. N Engl J Med. 2010;363(24):2301-9.

37. Koehler F, Winkler S, Schieber M, Sechtem U, Stangl K, Böhm M, et al. Impact of remote telemedical management on mortality and hospitalizations in ambulatory patients with chronic heart failure: the telemedical interventional. Circulation. 2011;123(17):1873-80.

38. Aguiar VB, Ochiai ME, Cardoso JN, Del Carlo CH, Morgado PC, Munhoz RT, et al. Relationship between depression, BNP levels and ventricular impairment in heart failure. Arq Bras Cardiol. 2010;95(6):732-7.

39. Cruz LN, Fleck MP, Polanczyk CA. Depression as a determinant of quality of life in patients with chronic disease: data from Brazil. Soc Psychiatry Psychiatr Epidemiol. 2010;45(10):953-61.

40. Dar O, Riley J, Chapman C, Dubrey SW, Morris S, Rosen SD, et al. A randomized trial of home telemonitoring in a typical elderly heart failure population in North West London: results of the Home-HF study. Eur J Heart Fail. 2009;11(3):319-25.

41. Anker SD, Koehler F, Abraham WT. Telemedicine and remote management of patients with heart failure. Lancet. 2011;378(9792):731-9.

42. Abraham WT, Adamson PB, Bourge RC, Aaron MF, Costanzo MR, Stevenson $\mathrm{LW}$, et al. Wireless pulmonary artery haemodynamic monitoring in chronic heart failure: a randomised controlled trial. Lancet. 2011;377(9766):65866.

43. Bourge RC, Abraham WT, Adamson PB, Aaron MF, Aranda JM Jr, Magalski A, et al; COMPASS-HF Study Group. Randomized controlled trial of an implantable continuous hemodynamic monitor in patients with advanced heart failure: the COMPASS-HF study. J Am Coll Cardiol. 2008;51(11):1073-9.

44. Bocchi EA, Cruz F, Guimarães G, Pinho Moreira LF, Issa VS, Ayub Ferreira SM, et al. Long-term prospective, randomized, controlled study using repetitive education at six-month intervals and monitoring for adherence in heart failure outpatients: the REMADHE trial. Circ Heart Fail. 2008;1(2):115-24.

45. Sarabanda AV, Marin-Neto JA. Predictors of mortality in patients with Chagas' cardiomyopathy and ventricular tachycardia not treated with implantable cardioverter-defibrillators. Pacing Clin Electrophysiol. 2011;34(1):54-62.

46. Bertolino ND, Villafanha DF, Cardinalli-Neto A, Cordeiro JA, Arcanjo MJ, Theodoropoulos TA, et al. Prognostic impact of Chagas' disease in patients awaiting heart transplantation. J Heart Lung Transplant. 2010;29(4):449-53.

47. Nunes MC, Barbosa MM, Ribeiro AL, Colosimo EA, Rocha MO. Left atrial volume provides independent prognostic value in patients with Chagas cardiomyopathy. J Am Soc Echocardiogr. 2009;22(1):82-8.

48. Beck-da-Silva L, Goldraich L, Bonzanini L, Rossi G, Nuernberg G, Camey $\mathrm{SA}$, et al. Pulse pressure and QRS width evaluation as an inexpensive tool for heart failure assessment. Congest Heart Fail. 2009;15(5):222-7.

49. Hershberger RE, Siegfried JD. Update 2011: clinical and genetic issues in familial dilated cardiomyopathy. J Am Coll Cardiol. 2011;57(16):1641-9.

50. Nakasato M, Strunk CM, Guimarães G, Rezende MV, Bocchi EA. Is the lowsodium diet actually indicated for all patients with stable heart failure? Arq Bras Cardiol. 2010;94(1):92-101.

51. Lennie TA, Song EK, Wu JR, Chung ML, Dunbar SB, Pressler SI, et al. Three gram sodium intake is associated with longer event-free survival only in patients with advanced heart failure. J Card Fail. 2011;17(4):325-30.

52. Paterna S, Gaspare P, Fasullo S, Sarullo FM, Di Pasquale P. Normalsodium diet compared with low-sodium diet in compensated congestive heart failure: is sodium an old enemy or a new friend? Clin Sci (Lond). 2008;114(3):221-30.

53. Taylor RS, Ashton KE, Moxham T, Hooper L, Ebrahim S. Reduced dietary salt for the prevention of cardiovascular disease: a meta-analysis of randomized controlled trials (Cochrane Review). Am J Hypertens. 2011;24(8):843-53.

54. Arcand J, Ivanov J, Sasson A, Floras V, Al-Hesayen A, Azevedo ER, et al. A high-sodium diet is associated with acute decompensated heart failure in ambulatory heart failure patients: a prospective follow-up study. Am J Clin Nutr. 2011;93(2):332-7.

55. Son YJ, Lee Y, Song EK. Adherence to a sodium-restricted diet is associated with lower symptom burden and longer cardiac event-free survival in patients with heart failure. J Clin Nurs. 2011;20(20-21):3029-38

56. Martins Wde A, Ribeiro MD, Oliveira LB, Barros Lda S, Jorge AC, Santos $\mathrm{CM}$, et al. Influenza and pneumococcal vaccination in heart failure: a little applied recommendation. Arq Bras Cardiol. 2011;96(3):240-5.

57. Vacina pneumocócica polivalente. [Acessado em 2011 jun 20] Disponível em: http://www.cdc.gov/vaccines/pubs/vis/downloads/vis-ppv.pdf

58. Cruz FD, Issa VS, Ayub-Ferreira SM, Chizzola PR, Souza GE, Moreira LF, et al. Effect of a sequential education and monitoring programme on qualityof-life components in heart failure. Eur J Heart Fail. 2010;12(9):1009-15.

59. Domingues FB, Clausell N, Aliti GB, Dominguez DR, Rabelo ER. Education and telephone monitoring by nurses of patients with heart failure: randomized clinical trial. Arq Bras Cardiol. 2011;96(3):233-9.

60. Sauer I, Rabelo ER, Castro RA, Goldraich L, Rohde LE, Clausell N, et al. Nurses' performance in classifying heart failure patients based on physical exam: comparison with cardiologist's physical exam and levels of N-terminal pro-B-type natriuretic peptide. J Clin Nurs. 2010;19(2324):3381-9.

61. Bento VF, Brofman PR. Impact of the nursing consultation on the frequency of hospitalizations in patients with heart failure in Curitiba, Parana State. Arq Bras Cardiol. 2009;92(6):454-60, 473-9, 490-6.

62. Roccaforte R, Demers C, Baldassarre F, Teo KK, Yusuf S. Effectiveness of comprehensive disease management programmes in improving clinical outcomes in heart failure patients: a meta-analysis. Eur J Heart Fail. 2005;7(7):1133-44.

63. Jaarsma T, van der Wal MH, Lesman-Leegte I, Luttik ML, Hogenhuis J, Veeger NJ, et al. Effect of moderate or intensive disease management program on outcome in patients with heart failure: Coordinating Study Evaluating Outcomes of Advising and Counseling in Heart Failure (COACH) Investigators. Arch Intern Med. 2008;168(3):316-24.

64. Guimarães GV, Carvalho VO, Torlai V, Bocchi EA. Physical activity profile in heart failure patients from a Brazilian tertiary cardiology hospital. Cardiol J. $2010 ; 17(2): 143-5$

65. Piepoli MF, Conraads V, Corrà U, Dickstein K, Francis DP, Jaarsma T, et al. Exercise training in heart failure: from theory to practice: a consensus document of the Heart Failure Association and the European Association for Cardiovascular Prevention and Reahbilitation. Eur J Heart Fail. 2011:13(4):347-57.

66. Carvalho VO, Ciolac EG, Guimarães GV, Bocchi EA. Effect of exercise training on 24-hour ambulatory blood pressure monitoring in heart failure patients. Congest Heart Fail. 2009;15(4):176-80.

67. Pelegrino VM, Dantas RA, Ciol MA, Clark AM, Rossi LA, Simões MV. Healthrelated quality of life in Brazilian outpatients with Chagas and non-Chagas cardiomyopathy. Heart Lung. 2011;40(3):e25-31.

68. Lima MM, Rocha MO, Nunes MC, Sousa L, Costa HS, Alencar MC, et al. A randomized trial of the effects of exercise training in Chagas cardiomyopathy. Eur J Heart Fail. 2010;12(8):866-73.

69. Antunes-Correa LM, Kanamura BY, Melo RC, Nobre TS, Ueno LM, Franco $\mathrm{FG}$, et al. Exercise training improves neurovascular control and functional capacity in heart failure patients regardless of age. Eur J Cardiovasc Prev Rehabil. 2011 Jun 22 [Epub ahead of print].

70. Ribeiro JP, Chiappa GR, Neder JA, Frankenstein L. Respiratory muscle function and exercise intolerance in heart failure. Curr Heart Fail Rep. 2009;6(2):95-101.

71. Stein R, Chiappa GR, Güths H, Dall'Ago P, Ribeiro JP. Inspiratory muscle training improves oxygen uptake efficiency slope in patients with chronic heart failure. J Cardiopulm Rehabil Prev. 2009;29(6):392-5. 
72. Winkelmann ER, Chiappa GR, Lima CO, Viecili PR, Stein R, Ribeiro JP. Addition of inspiratory muscle training to aerobic training improves cardiorespiratory responses to exercise in patients with heart failure and inspiratory muscle weakness. Am Heart J. 2009;158(5):768.e1-7.

73. Guimarães GV, Carvalho VO, Bocchi EA, d'Avila VM. pilates in heart failure patients: a randomized controlled pilot trial. Cardiovasc Ther 2011 Jul 10 [Epub ahead of print].

74. Ciolac EG, Bocchi EA, Bortolotto LA, Carvalho VO, Greve JM, Guimarães GV. Effects of high-intensity aerobic interval training vs. moderate exercise on hemodynamic, metabolic and neuro-humoral abnormalities of young normotensive women at high familial risk for hypertension. Hypertens Res. 2010;33(8):836-43

75. Ciolac EG, Bocchi EA, Greve JM, Guimarães GV. Heart rate response to exercise and cardiorespiratory fitness of young women at high familial risk for hypertension: effects of interval vs continuous training. Eur J Cardiovasc Prev Rehabil. 2011;18(6):824-30.

76. Silva MS, Bocchi EA, Guimaraes GV, Padovani CR, Silva MH, Pereira SF, et al. Benefits of exercise training in the treatment of heart failure: study with a control group. Arq Bras Cardiol. 2002;79(4):351-62.

77. Carvalho VO, Roque JM, Bocchi EA, Ciolac EG, Guimarães GV. Hemodynamic response in one session of strength exercise with and without electrostimulation in heart failure patients: a randomized controlled trial. Cardiol J. 2011;18(1):39-46.

78. Carvalho VO, Bocchi EA, Guimarães GV. Hydrotherapy in heart failure: a case report. Clinics (Sao Paulo). 2009;64(8):824-7.

79. Carvalho VO, Bocchi EA, Guimarães GV. The Borg scale as an important tool of self-monitoring and self-regulation of exercise prescription in heart failure patients during hydrotherapy: a randomized blinded controlled trial. Circ J. 2009;73(10):1871-6.

80. Pereira DA, Ribeiro-Samora GA, Vieira DS, Pereira LS, Coelho FM, Parreira $\mathrm{VF}$, et al. Evaluation of the inflammatory response to two different intensities of exercise in individuals with heart failure. Inflammation. 2011 May 10 [Epub ahead of print].

81. Bocchi EA, Moura LZ, Issa VS, Cruz F, Carvalho VO, Guimarães GV. Effects of the recombinant form of the natural human B-type natriuretic peptide and levosimendan on pulmonary hyperventilation and chemosensivity in heart failure. Cardiovasc Ther. 2011 Aug 3 [Epub ahead of print].

82. Guimarães GV, BelliJF, Bacal F, Bocchi EA. Behavior of central and peripheral chemoreflexes in heart failure. Arq Bras Cardiol. 2011;96(2):161-7.

83. Moura LZ, Guimarães GV, Pires PV, Cruz F, Stopa G, Bocchi EA. Exercise chemosensitivity in heart failure: ventilatory, chronotropic and neurohormonal responses. Arq Bras Cardiol. 2010;95(3):381-91.

84. Smart NA, Larsen Al, Le Maitre JP, Ferraz AS. Effect of exercise training on interleukin-6, tumour necrosis factor alpha and functional capacity in heart failure. Cardiol Res Pract. 2011;2011:532620.

85. Piepoli MF, Davos C, Francis DP, Coats AJ. Exercise training meta-analysis of trials in patients with chronic heart failure (ExTraMATCH). BMJ 2004;328(7433):189.

86. O'Connor CM, Whellan DJ, Lee KL, Keteyian SJ, Cooper LS, Ellis SJ, et al; ACTION Investigators. Efficacy and safety of exercise training in patients with chronic heart failure: HF-ACTION randomized controlled trial. JAMA. 2009;301(14):1439-50.

87. Kühr EM, Ribeiro RA, Rohde LE, Polanczyk CA. Cost-effectiveness of supervised exercise therapy in heart failure patients. Value Health. 2011;14(5 Suppl 1):S100-7.

88. Swedberg K, Komajda M, Böhm M, Borer JS, Ford I, Dubost-Brama A, et al. Ivabradine and outcomes in chronic heart failure (SHIFT): a randomised placebo-controlled study. Lancet. 2010;376(9744):875-85. Erratum in: Lancet. 2010;376(9757):1988

89. The Cardiac Insufficiency Bisoprolol Study II (CIBIS-II): a randomised trial. Lancet. 1999;353(9146):9-13.
90. Effect of metoprolol $\mathrm{CR} / \mathrm{XL}$ in chronic heart failure: Metoprolol $\mathrm{CR} / \mathrm{XL}$ Randomised Intervention Trial in Congestive Heart Failure (MERIT-HF). Lancet. 1999;353(9169):2001-7.

91. Packer M, Coats AJ, Fowler MB, Katus HA, Krum H, Mohacsi P, et al. Effect of carvedilol on survival in severe chronic heart failure. $\mathrm{N} \mathrm{Engl} \mathrm{J} \mathrm{Med.}$ 2001;344(22):1651-8.

92. Waagstein F, Bristow MR, Swedberg K, Camerini F, Fowler MB, Silver MA, et al. Beneficial effects of metoprolol in idiopathic dilated cardiomyopathy. Metoprolol in Dilated Cardiomyopathy (MDC) Trial Study Group. Lancet. 1993;342(8885):1441-6.

93. Poole-Wilson PA, Swedberg K, Cleland JG, Di Lenarda A, Hanrath P, Komajda $\mathrm{M}, \mathrm{COMET}$ investigators. Comparison of carvedilol and metoprolol on clinical outcomes in patients with chronic heart failure in the Carvedilol Or Metoprolol European Trial (COMET): randomised controlled trial. Lancet. 2003;362(9377):7-13.

94. Hjalmarson A, Waagstein F. COMET: a proposed mechanism of action to explain the results and concerns about dose. Lancet. 2003;362(9389):1077; author reply 1077-8.

95. Food and Drug Administration. January 11, 2010. Meeting of the Cardiovascular and Renal Drugs Advisory Committee.

96. Flather MD, Shibata MC, Coat AJ, Van Veldhuisen DJ, Parkhomenko A Borbola J, et al; SENIORS Investigators. Randomized trial to determine the effect of nebivolol on mortality and cardiovascular hospital admission in elderly patients with heart failure (SENIORS). Eur Heart J. $2005 ; 26(3): 215-25$.

97. Willenheimer R, van Veldhuisen DJ, Silke B, Erdmann E, Follath F, Krum $\mathrm{H}$, et al; CIBIS Investigators. Effect on survival and hospitalization of initiating treatment for chronic heart failure with bisoprolol followed by enalapril, as compared with the opposite sequence: results of the randomized Cardiac Insufficiency Bisoprolol Study (CIBIS) III. Circulation. 2005;112(16):2426-35.

98. Marques F, Castro RB, Nobre F, Pintya AO, Gallo L Jr, Maciel BC, et al. Replacement of carvedilol for propranolol in patients with heart failure. Arq Bras Cardiol. 2010;95(1):107-14.

99. Dargie HJ. Effect of carvedilol on outcome after myocardial infarction in patients with left-ventricular dysfunction: the CAPRICORN randomised trial. Lancet. 2001;357(9266):1385-90.

100. Pauschinger M, Rutschow S, Chandrasekharan K, Westermann D, Weitz A Peter Schwimmbeck $\mathrm{L}$, et al. Carvedilol improves left ventricular function in murine coxsackievirus-induced acute myocarditis association with reduced myocardial interleuckin-1 beta and MMP-8 expression and a modulated immune response. Eur J Heart Fail. 2005;7(4):444-52.

101. Sánchez-Más J, Turpín MC, Lax A, Ruipérez JA, Valdés Chávarri M, PascualFigal DA. Differential actions of eplerenone and spironolactone on the protective effect of testosterone against cardiomyocyte apoptosis in vitro. Rev Esp Cardiol. 2010;63(7):779-87.

102. Ezekowitz JA, McAlister FA. Aldosterone blockade and left ventricula dysfunction: a systematic review of randomized clinical trials. Eur Heart J. 2009;30(4):469-77.

103.Zannad F, McMurray JJ, Krum H, van Veldhuisen DJ, Swedberg K, Shi H, et al. Eplerenone in patients with systolic heart failure and mild symptoms. EMPHASIS-HF Study Group. N Engl J Med. 2011;364(1):11-21.

104. Bocchi EA, Braga FG, Ferreira SM, Rohde LE, Oliveira WA, Almeida DR, et al. / Sociedade Brasileira de Cardiologia. III Diretriz brasileira de insuficiência cardíaca crônica. Arq Bras Cardiol. 2009;93(1 supl.1):3-70.

105. Felker GM, Lee KL, Bull DA, Redfield MM, Stevenson LW, Goldsmith SR, et al. Diuretic strategies in patients with acute decompensated heart failure. $N$ Engl J Med. 2011;364(9):797-805

106. Testani JM, Cappola TP, Brensinger CM, Shannon RP, Kimmel SF Interaction between loop diuretic-associated mortality and blood urea nitrogen concentration in chronic heart failure. J Am Coll Cardiol. 2011;58(4):375-82. 


\section{Diretrizes}

107. Mullens W, Abrahams Z, Francis GS, Sokos G, Starling RC, Young JB, et al. Usefulness of isosorbide dinitrate and hydralazine as add-on therapy in patients discharged for advanced decompensated heart failure. Am J Cardiol. 2009;103(8):1113-9.

108. Lip GY, Nieuwlaat R, Pisters R, Lane DA, Crijns HJ. Refining clinical risk stratification for prediciting stroke and thromboembolism in atrial fibrillation using a novel risk factor-based approach: the Euro heart survey on atrial fibrillation. Chest. 2010;137(2):263-72.

109. Pisters R, Lane DA, Nieuwlaat R, de Vos CB, Crijns HJ, Lip GY. A novel userfriendly score (HAS-BLED) to assess 1-year risk of major bleeding in patients with atrial fibrillation: the Euro Heart Survey. Chest. 2010;138(5):1093-100.

110. Connolly SJ, Ezekowitz MD, Yusuf S, Eikelboom J, Oldgren J, Parekh A, et al; RE-LY Steering Committee and Investigators. Dabigatran versus Warfarin in Patients with Atrial Fibrillation. New Engl J Med. 2009;361(12):1139-51.

111. Gage BF. Can we rely on RE-LY? N Engl J Med. 2009;361(12):1200-2.

112. Patel MR, Mahaffey KW, Garg J, Pan G, Singer DE, Hacke W, et al; ROCKET AF Investigators. Rivaroxaban versus warfarin in nonvalvular atrial fibrillation. N Engl J Med. 2011;365(10):883-91.

113. Granger CB, Alexander JH, McMurray JJ, Lopes RD, Hylek EM, Hanna M, et $\mathrm{al}$; ARISTOTLE Committees and Investigators. Apixaban versus warfarin in patients with atrial fibrillation. N Engl J Med. 2011;365(11):981-92.

114. Jesus PA, Neville I, Cincurá C, Menezes DF, Vieira-de-Melo RM, Lacerda AM, et al. Stroke history and Chagas disease are independent predictors of silent cerebral microembolism in patients with congestive heart failure. Cerebrovasc Dis. 2011;31(1):19-23.

115. Adamson PB, Gilbert EM. Reducing the risk of sudden death in heart failure with beta-blockers. J Card Fail. 2006;12(9):734-46.

116. Naccarelli GV, Lukas MA. Carvedilol's antiarrhythmic properties: therapeutic implications in patients with left ventricular dysfunction. Clin Cardiol. 2005;28(4):165-73.

117. Brodine WN, Tung RT, Lee JK, Hockstad ES, Moss AJ, Zareba W, et al MADIT-II Research Group. Effects of beta-blockers on implantable cardioverter defibrillator therapy and survival in the patients with ischemic cardiomyopathy (from the Multicenter Automatic Defibrillator Implantation Trial-II). Am J Cardiol. 2005;96(5):691-5.

118. Bardy GH, Lee KL, Mark DB, Poole JE, Packer DL, Boineau R, et al; Sudden Cardiac Death in Heart Failure Trial. (SCD-HeFT) Investigators. Amiodarone or an implantable cardioverter-defibrillator for congestive heart failure. $\mathrm{N}$ Engl J Med. 2005;352(3):225-37.

119. Connolly SJ, Dorian P, Roberts RS, Gent M, Bailin S, Fain ES, et al. Comparison of beta-blockers, amiodarone plus beta-blockers, or sotalol for prevention of shocks from implantable cardioverter defibrillators: the OPTIC Study: a randomized trial. JAMA. 2006;295(2):165-71.

120. Bucchi A, Baruscotti M, DiFrancesco D. Current-dependent block of rabbit sino-atrial node I(f) channels by ivabradine. J Gen Physiol. 2002;120(1):1-13.

121. Fox K, Ford I, Steg PG, Tendera M, Ferrari R; BEAUTIFUL Investigators. Ivabradine for patients with stable coronary artery disease and leftventricular systolic dysfunction (BEAUTIFUL): a randomised, double-blind, placebo-controlled trial. Lancet. 2008;372(9641):807-16

122. Fox K, Ford I, Steg PG, Tendera M, Robertson M, Ferrari R; BEAUTIFUL Investigators. Relationship between ivabradine treatment and cardiovascular outcomes in patients with stable coronary artery disease and left ventricular systolic dysfunction with limiting angina: a subgroup analysis of the randomized, controlled BEAUTIFUL trial. Eur HeartJ. 2009;30(19):2337-45.

123. Swedberg K, Komajda M, Böhm M, Borer JS, Ford I, Dubost-Brama A, et al; SHIFT Investigators. Ivabradine and outcomes in chronic heart failure (SHIFT): a randomised placebo-controlled study. Lancet. 2010;376(9744):875-85.

124. Dijkstra SC, Brouwer IA, van Rooij FJ, Hofman A, Witteman JC, Geleijnse JM. Intake of very long chain n-3 fatty acids from fish and the incidence of heart failure: the Rotterdam Study. Eur J Heart Fail. 2009;11(10):922-8.
125. Mozaffarian D, Bryson CL, Lemaitre RN, Burke GL, Siscovick DS. Fish intake and risk of incident heart failure. J Am Coll Cardiol. 2005;45(12):2015-21.

126. Yamagishi K, Iso H, Date C, Fukui M, Wakai K, Kikuchi S, et al; Japan Collaborative Cohort Study for Evaluation of Cancer Risk Study Group. Fish, omega-3 polyunsaturated fatty acids, and mortality from cardiovascular diseases in a nationwide community-based cohort of Japanese men and women. J Am Coll Cardiol. 2008;52(12):988-96.

127. Yamagishi K, Nettleton JA, Folsom AR. Plasma fatty acid composition and incident heart failure in middle-aged adults: the Atherosclerosis Risk In Communities (ARIC) study. Am Heart J. 2008;156(5):965-74.

128. Dietary supplementation with $n-3$ polyunsaturated fatty acids and vitamin E after myocardial infarction: results of the GISSI Prevenzione trial Gruppo Italiano per lo Studio della Sopravvivenza nell'Infarto miocardico. Lancet. 1999;354(9177):447-55

129. Tavazzi L, Maggioni AP, Marchioli R, Barlera S, Franzosi MG, Latini R, et al. Effect of $n-3$ polyunsaturated fatty acids in patients with chronic heart failure (the GISSI-HF trial): a randomised, double-blind, placebo-controlled trial. Lancet. 2008;372(9645):1223-30.

130. Nodari S, Triggiani M, Campia U, Manerba A, Milesi G, Cesana BM, et al. Effects of n-3 polyunsaturated fatty acids on left ventricular function and functional capacity in patients with dilated cardiomyopathy. J Am Coll Cardiol. 2011;57(7):870-9.

131. Zhao YT, Shao L, Teng LL, Hu B, Luo Y, Yu X, et al. Effects of n-3 polyunsaturated fatty acid therapy on plasma inflammatory markers and $\mathrm{N}$-terminal pro-brain natriuretic peptide in elderly patients with chronic heart failure. J Int Med Res. 2009;37(6):1831-41.

132. Neschen S, Morino K, Rossbacher JC, Pongratz RL, Cline GW, Sono S, et al. Fish oil regulates adiponectin secretion by a peroxisome proliferatoractivated receptor-gamma-dependent mechanism in mice. Diabetes. 2006;55(4):924-8.

133. Itoh M, Suganami T, Satoh N, Tanimoto-Koyama K, Yuan X, Tanaka M, et al. Increased adiponectin secretion by highly purified eicosapentaenoic acid in rodent models of obesity and human obese subjects. Arterioscler Thromb Vasc Biol. 2007;27(9):1918-25.

134. Berg AH, Scherer PE. Adipose tissue, inflammation, and cardiovascular disease. Circ Res. 2005;96(9):939-49.

135. Mehra MR, Lavie CJ, Ventura HO, Milani RV. Fish oils produce antiinflammatory effects and improved body weight in severe heart failure. J Heart Lung Transplant. 2006;25(7):834-8.

136. Freitas Jr AF, Bacal F, Oliveira Jr Jde L, Santos RH, Moreira LF, Silva CP, et al. Impact of sublingual sildenafil on pulmonary hypertension in patients with heart failure. Arq Bras Cardiol. 2009;92(2):116-26.

137. Guimaraes GV, d'Avila VM, Pires P, Bacal F, Stolf N, Bocchi E. Acute effects of a single dose of phosphodiesterase type 5 inhibitor (sildenafil) on systemic arterial blood pressure during exercise and 24-hour ambulatory blood pressure monitoring in heart transplant recipients. Transplant Proc. 2007;39(10):31429

138. Guazzi M. Sildenafil and phosphodiesterase-5 inhibitors for heart failure. Curr Heart Fail Rep. 2008;5(2):110-4.

139. Bocchi EA, Guimarães G, Mocelin A, Bacal F, Bellotti G, Ramires JF. Sildenafil effects on exercise, neurohormonal activation, and erectile dysfunction in congestive heart failure: a double-blind, placebo-controlled, randomized study followed by a prospective treatment for erectile dysfunction. Circulation. 2002;106(9):1097-103.

140. Behling A, Rohde LE, Colombo FC, Goldraich LA, Stein R, Clausell N. Effects of 5'-phosphodiesterase four-week long inhibition with sildenafil in patients with chronic heart failure: a double-blind, placebo-controlled clinical trial. J Card Fail. 2008;14(3):189-97.

141. Guazzi M, Vicenzi M, Arena R, Guazzi MD. PDE5 inhibition with sildenafil improves left ventricular diastolic function, cardiac geometry, and clinical status in patients with stable systolic heart failure: results of a 1-year, prospective, randomized, placebo-controlled study. Circ Heart Fail. 2011;4(1):8-17. 
142. Marazzi G, Gebara O, Vitale C, Caminiti G, Wajngarten M, Volterrani M, et al. Effect of trimetazidine on quality of life in elderly patients with ischemic dilated cardiomyopathy. Adv Ther. 2009;26(4):455-61.

143. Gunes Y, Guntekin U, Tuncer M, Sahin M. Improved left and right ventricular functions with trimetazidine in patients with heart failure: a tissue Doppler study. Heart Vessels. 2009;24(4):277-82.

144. Belardinelli R, Lacalaprice F, Faccenda E, Volpe L. Trimetazidine potentiates the effects of exercise training in patients with ischemic cardiomyopathy referred for cardiac rehabilitation. Eur J Cardiovasc Prev Rehabil. 2008;15(5):533-40

145. Tuunanen H, Engblom E, Naum A, Någren K, Scheinin M, Hesse B, et al. Trimetazidine, a metabolic modulator, has cardiac and extracardiac benefits in idiopathic dilated cardiomyopathy. Circulation. 2008;118(12):1250-8.

146. Belardinelli R, Cianci G, Gigli M, Mazzanti M, Lacalaprice F. Effects of trimetazidine on myocardial perfusion and left ventricular systolic function in type 2 diabetic patients with ischemic cardiomyopathy. J Cardiovasc Pharmacol. 2008;51(6):611-5.

147. Gunes Y, Guntekin U, Tuncer M, Sahin M. The effects of trimetazidine on heart rate variability in patients with heart failure. Arq Bras Cardiol. 2009;93(2):154-8

148. Gao D, Ning N, Niu X, Hao G, Meng Z. Trimetazidine: a meta-analysis of randomised controlled trials in heart failure. Heart. 2011;97(4):278-86.

149. Bocchi EA, Moreira LF, Bellotti G, Barreto AC, Azul LG, Stolf N, et al. Hemodynamic study during upright isotonic exercise before and six months after dynamic cardiomyoplasty for idiopathic dilated cardiomyopathy or Chagas' disease. Am J Cardiol. 1991;67(2):213-4.

150. Moreira LF, Stolf NA, de Lourdes Higuchi M, Bacal F, Bocchi EA, Oliveira SA. Current perspectives of partial left ventriculectomy in the treatment of dilated cardiomyopathy. Eur J Cardiothorac Surg. 2001;19(1):54-60.

151. Bocchi EA, Bellotti G, Moreira LF, Bacal F, de Moraes AV, Fiorelli A, et al. Mid-term results of heart transplantation, cardiomyoplasty, and medical treatment of refractory heart failure caused by idiopathic dilated cardiomyopathy. J Heart Lung Transplant. 1996;15(7):736-45.

152. Moreira LF, Benício A, Bacal F, Bocchi EA, Stolf NA, Oliveira SA. Determinants of long-term mortality of current palliative surgical treatment for dilated cardiomyopathy. Eur J Cardiothorac Surg. 2003;23(5):756-63.

153. Metzger M, Higuchi ML, Moreira LF, Chaves MJ, Castelli JB, Silvestre JM, et al. Relevance of apoptosis and cell proliferation for survival of patients with dilated cardiomyopathy undergoing partial left ventriculectomy. Eur J Clin Invest. 2002;32(6):394-9.

154. Bocchi EA. Cardiomyoplasty for treatment of heart failure. Eur J Heart Fail. 2001;3(4):403-6.

155. Parga JR, Avila LF, Bacal F, Moreira LF, Stolf NG, Ramires JA, et al. Partial left ventriculectomy in severe idiopathic dilated cardiomyopathy: assessment of short-term results and their impact on late survival by magnetic resonance imaging. J Magn Reson Imaging. 2001;13(5):781-6.

156. Bocchi EA, Bellotti G, Vilella de Moraes A, Bacal F, Moreira LF, EstevesFilho A, et al. Clinical outcome after left ventricular surgical remodeling in patients with idiopathic dilated cardiomyopathy referred for heart transplantation: short-term results. Circulation. 1997;96(9 Suppl):II-165-71; discussion II-171-2.

157. Tamburino C, Ussia GP, Maisano F, Capodanno D, La Canna G, Scandura $\mathrm{S}$, et al. Percutaneous mitral valve repair with the MitraClip system: acute results from a real world setting. Eur Heart J. 2010;31(11):1382-9.

158. Hovnanian AL, Matos Soeiro A, Serrano CV, Oliveira SA, Jatene FB, Stolf NA, et al. Surgical myocardial revascularization of patients with ischemic cardiomyopathy and severe left ventricular disfunction. Clinics. 2010;65(1):3-8.

159. Passamani E, Davis KB, Gillespie MJ, Killip T. A randomised trial of coronary artery bypass surgery: survival of patients with a low ejection fraction. N Engl J Med. 1985:312(26):1665-71
160. Fernandes DR, Tsutsui JM, Bocchi EA, César LA, Sbano JC, Ramires JA, et al Qualitative and quantitative real time myocardial contrast echocardiography for detecting hibernating myocardium. Echocardiography. 2011;28(3):342-9.

161. Kunadian V, Zaman A, Qiu W. Revascularization among patients with severe left ventricular dysfunction: a meta-analysis of observational studies. Eur J Heart Fail. 2011;13(7):773-84.

162. Cleland JG, Freemantle N, Ball SG, Bonser RS, Camici P, Chattopadhyay S, et al. The heart failure revascularization trial (HEART): rationale design and methodology. Eur J Heart Fail. 2003;5(3):295-303.

163. Cleland JG, Calvert M, Freemantle N, Arrow Y, Ball SG, Bonser RS, et al. The Heart Failure Revascularisation Trial (HEART). Eur J Heart Fail. $2011 ; 13(2): 227-33$

164. Cleland JGF, Freemantle N. Revascularization for patients with heart failure. Inconsistencies between theory and practice. Eur J Heart Fail. 2011;13(7):694-7.

165. Velazquez EJ, Lee KL, Deja MA, Jain A, Sopko G, Marchenko A, et al. STICH Investigators. Coronary-artery bypass surgery in patients with left ventricular dysfunction. N Engl J Med. 2011;364(17):1607-16.

166. Bonow RO, Maurer G, Lee KL, Holly TA, Binkley PF, Desvigne-Nickens P, et al. STICH Trial Investigators. Myocardial viability and survival in ischemic left ventricular dysfunction. N Engl J Med. 2011;364(17):1617-25.

167. Jones RH, Velazquez EJ, Michler RE, Sopko G, Oh JK, O'Connor CM, et al. STICH Hypothesis 2 Investigators. Coronary bypass surgery with or without surgical ventricular reconstruction. N Engl J Med. 2009;360:1705-17.

168. Bacal F, Souza-Neto JD, Fiorelli Al, Mejia J, Marcodes-Braga FG, Mangini S, et al. / Sociedade Brasileira de Cardiologia. II Diretriz brasileira de transplante cardiaco. Arq Bras Cardiol. 2009;94(1supl1):e16-e73.

169. Bocchi EA, Fiorelli A. The paradox of survival results after heart transplantation for cardiomyopathy caused by Trypanosoma cruzi. First Guidelines Group for Heart Transplantation of the Brazilian Society of Cardiology. Ann Thorac Surg. 2001;71(6):1833-8

170. Bocchi EA, Fiorelli A; First Guideline Group for Heart Transplantation of the Brazilian Society of Cardiology. The Brazilian experience with heart transplantation: a multicenter report. J Heart Lung Transplant. 2001;20(6):637-45

171. Bacal F, Veiga VC, Fiorelli A, Bellotti G, Bocchi EA, Stolf N, et al. Análise dos fatores de risco da doença vascular do enxerto em pacientes assintomáticos após transplante cardíaco. Arq Bras Cardiol. 2000;75(5):413-20.

172. Dickstein K, Cohen-Solal A, Filippatos G, McMurray JJ, Ponikowski P, PooleWilson PE, et al. ESC Guidelines for the diagnosis and treatment of acute and chronic heart failure 2008: the Task Force for the Diagnosis and Treatment of Acute and Chronic Heart Failure 2008 of the European Society of Cardiology. Developed in collaboration with the Heart Failure Association of the ESC (HFA) and endorsed by the European Society of Intensive Care Medicine (ESICM). Eur Heart J. 2008;29(19):2388-442.

173. Bacal F, de Freitas AF Jr, Moreira LF, Fiorelli Al, Mangini S, Abuhab A, et al. Validation of a cutoff value on echo Doppler analysis to replace right heart catheterization during pulmonary hypertension evaluation in heart transplant candidates. Transplant Proc. 2010;42(2):535-8.

174. Bocchi EA, Bellotti G, Uip D, Kalil J, de Lourdes Higuchi M, Fiorelli A, et al. Long-term follow-up after heart transplantation in Chagas' disease. Transplant Proc. 1993;25(1 Pt 2):1329-30.

175. Borghetti-Maio SA, Romano BW, Bocchi EA, Moreira LF, Barreto AC, Stolf NA, et al. Quality of life after cardiomyoplasty. I Heart Lung Transplant. 1994;13(2):271-5.

176. Fiorelli AI, Stolf NA, Honorato R, Bocchi E, Bacal F, Uip D, et al. Later evolution after cardiac transplantation in Chagas' disease. Transplant Proc. 2005;37(6):2793-8.

177. Bocchi EA, Higuchi ML, Vieira ML, Stolf N, Bellotti G, Fiorelli A, et al. Highe incidence of malignant neoplasms after heart transplantation for treatment of chronic Chagas' heart disease. J Heart Lung Transplant. 1998;17(4):399-405. 
178. Campos SV, Strabelli TM, Amato Neto V, Silva CP, Bacal F, Bocchi EA, et al. Risk factors for Chagas' disease reactivation after heart transplantation. J Heart Lung Transplant. 2008;27(6):597-602

179. Bacal F, Silva CP, Bocchi EA, Pires PV, Moreira LF, Issa VS, et al. Mychophenolate mofetil increased chagas disease reactivation in heart transplanted patients: comparison between two different protocols. Am J Transplant. 2005;5(8):2017-21.

180. Bocchi EA, Bellotti G, Mocelin AO, Uip D, Bacal F, Higuchi ML, et al. Heart transplantation for chronic Chagas' heart disease. Ann Thorac Surg. 1996;61(6):1727-33.

181. Bestetti RB, Souza TR, Lima MF, Theodoropoulos TA, Cordeiro JA, Burdmann EA. Effects of mycophenolate mofetil-based immunosuppressive regimen in Chagas heart transplant recipients. Transplantation. 2007;84(3):441-2.

182. Costanzo MR, Dipchard A, Starling R, Anderson A, Chan M, Desai S, et al. International Society of Heart and Lung Transplantation Guidelines for the care of heart transplants recipients. J Heart Lung Transplant. 2010;29(8):914-56.

183. Fiorelli AI, Santos RH, Oliveira JL Jr, Bacal F, Bocchi EA, Lourenço Fo DD, et al. Heart transplant in 107 cases of Chagas'disease. Transplant Proc. 2011;43(1):220-4.

184. Eckman PM, Hanna M, Taylor DO, Starling RC, Gonzalez-Stawinski GV. Management of sensitized adult heart transplant candidate. Clin Transplant. 2010;24(6):726-34

185. Gude E, Anderssen AK, Arora S, Gullestad L, Grov I, Hartmann A. Acute renal failure early after heart transplantation: risk factors and clinical consequences. Clin Transplant. 2010:24(6):E207-13.

186. Bocchi EA, Vieira ML, Fiorelli A, Hayashida S, Mayzato M, Leirner A, et al [Hemodynamic and neurohormonal profile during assisted circulation with heterotopic artificial ventricle followed by heart transplantation]. Arq Bras Cardiol. 1994;62(1):23-7.

187. Galantier J, Moreira LF, Benício A, Leirner AA, Cestari I, Bocchi EA, et al. Hemodynamic performance and inflammatory response during the use of VAD-InCor as a bridge to transplant. Arq Bras Cardiol. 2008;91(5):327-34.

188. Rose EA, Gelijns AC, Moskowitz AJ, Heitjan DF, Stevenson LW, Dembitsky W, etal. Long-term use of a left ventricular assist device for end-stage heart failure. N Engl J Med. 2001;345(20):1435-43.

189. Kirklin JK, Naftel DC, Kormos RL, Stevenson LW, Pagani FD, Miller MA, et al. Third INTERMACS Annual Report: the evolution of destination therapy in the United States. J Heart Lung Transpl. 2011;30(2):115-23.

190. Slaughter MS, Rogers JG, Milano CA, Russell SD, Conte JV, Feldman D, et al; HeartMate II Investigators. Advanced heart failure treated with continuousflow left ventricular assist device. N Engl J Med. 2009;361(23):2241-51.

191. Slaughter MS, Meyer AL, Birks EJ. Destination therapy with left ventricular assist devices: patient selection and outcomes. Curr Opin Cardiol. $2011 ; 26(3): 232-6$

192. Moss AJ, Hall WJ, Cannom DS, Klein H, Brown MW, DaubertJP, etal. Cardiacresynchronization therapy for the prevention of heart failure events. $\mathrm{N}$ Engl J Med. 2009;361(14):1329-38.

193. Tang AS, Wells GA, Talajic M, Arnold MO, Sheldon R, Connolly S, et al. Resynchronization-Defibrillation for Ambulatory Heart Failure Trial Investigators. Cardiac-resynchronization therapy for mild-to-moderate heart failure. N Engl J Med. 2010;363(25):2385-95

194. Holzmeister J, Leclercq C. Implantable cardioverter defibrillators and cardiac resynchronisation therapy. Lancet. 2011;378(9792):722-30.

195. Neto NR, Fonseca GC, Torres GG, Pinheiro MA, Miranda GB. Correlation between electrocardiographic features and mechanical dyssynchrony in heart failure patients with left bundle branch block. Ann Noninvasive Electrocardiol. $2011 ; 16(1): 41-8$

196. Chung ES, Leon AR, Tavazzi L, Sun JP, Nihoyannopoulos P, Merlino J, et al. Results of the Predictors of Response to CRT (PROSPECT) trial. Circulation. 2008;117(20):2608-16.
197. Wells G. Parkash R, Healey JS, Talajic M, Arnold JM, Sullivan S. et al. Cardiac resynchronization therapy: a meta-analysis of randomized controlled trials. CMAJ. 2011;183(4):421-9.

198. Bertoldi EG, Rohde LE, Zimerman LI, Pimentel M, Polanczyk CA. Costeffectiveness of cardiac resynchronization therapy in patients with heart failure: the perspective of a middle-income country's public health system. Int J Cardiol. 2011 Jun 23 [Epub ahead of print].

199. Duarte J de O, Magalhães LP, Santana OO, Silva LB, Simões M, Azevedo DO, et al. Prevalence and prognostic value of ventricular dyssynchrony in Chagas cardiomyopathy. Arq Bras Cardiol. 2011;96(4):300-6.

200. Martinelli Filho M, de Siqueira SF, Costa R, Greco OT, Moreira LF, D'avila $A$, et al. Conventional versus biventricular pacing in heart failure and bradyarrhythmia: the COMBAT study. J Card Fail. 2010;16(4):293-300.

201. De Keulenaer GW, Brutsaert DL. Systolic and diastolic heart failure are overlapping phenotypes within the heart failure spectrum. Circulation. 2011;123(18):1996-2004.

202. Borlaug BA, Redfield MM. Diastolic and systolic heart failure are distinct phenotypes within the heart failure spectrum. Circulation. 2011;123(18):2006-2013.

203. Paulus WJ, Tschope C, Sanderson JE, Rusconi C, Flachskampf FA, Rademakers $\mathrm{FE}$, et al. How to diagnose diastolic heart failure: a consensus statement on the diagnosis of heart failure with normal left ventricular ejection fraction by the Heart Failure and Echocardiography Associations of the European Society of Cardiology. Eur Heart J. 2007;28(20):2539-50.

204. Maeder TM, Kaye DM. Heart failure with normal left ventricular ejection fraction. J Am Coll Cardiol. 2009;53(11):905-18.

205. Heart Failure Society of America, Lindenfeld, J, Albert NM, Boehmer JP, Collins SP, Ezekowitz JA, Givertz MM, etal. HFSA 2010 Comprehensive Heart Failure Practice Guideline. J Card Fail. 2010;16(6):e1-194.

206. Reis FJ, Fernandes AM, Bitencourt AG, Neves FB, Kuwano AY, França VH, et al. Prevalence of anemia and renal insufficiency in non-hospitalized patients with heart failure. Arq Bras Cardiol. 2009;93(3):268-74.

207. Feola M, Lombardo E, Taglieri C, Piccolo S, Vado A. Plasma BNP and renal failure as prognostic factors of mid-term clinical outcome in congestive heart failure patients. Int J Cardiol. 2011;149(1):114-5.

208. Scrutinio D, Passantino A, Lagioia R, Santoro D, Cacciapaglia E. Detection and prognostic impact of renal dysfunction in patients with chronic heart failure and normal serum creatinine. Int J Cardiol. 2011;147(2):228-33.

209. Villacorta H, Saenz-Tello BF, Santos EB, Steffen R, Wiefels C, Lima LC, et al. Renal dysfunction and anemia in patients with heart failure with reduced versus normal ejection fraction. Arq Bras Cardiol. 2010;94(3):357-63.

210. Ferreira SM, Guimarães GV, Cruz FD, Issa VS, Bacal F, Souza GE, etal. Anemia and renal failure as predictors of risk in a mainly non-ischemic heart failure population. Int J Cardiol. 2010;141(2):198-200.

211. Miguel CE, Bortoluzzi TB, OtavianoAP, Cardinalli-Neto A, Faria da Rocha B, Ferrari SJ, et al. Prognostic significance of anemia in patients with chronic systolic heart failure secondary to Chagas' cardiomyopathy. Acta Trop. 2011;120(3):219-23.

212. Santos EB, Tello BS, Villacorta H, Sales AL, Wiefels C, Teixeira PS, etal. Anemia and heart failure in a community-based cohort: comparison with a specialized outpatient clinic. Arq Bras Cardiol. 2010;94(1):102-8.

213. Abraham WT, Anand IS, Klapholz M, Ponikowski P, Scarlata D, Wasserman SM, et al. Treatment of anemia with darbepoetin alfa in heart failure. Congest Heart Fail. 2010;16(3):87-95

214. Kotecha D, Ngo K, Walters JA, Manzano L, Palazzuoli A, Flather MD. Erythropoietin as a treatment of anemia in heart failure: systematic review of randomized trials. Am Heart J. 2011;161(5):822-831.e2.

215. Kao DP, Kreso E, Fonarow GC, Krantz MJ. Characteristics and outcomes among heart failure patients with anemia and renal insufficiency with and without blood transfusions (public discharge data from California 2000-2006). Am J Cardiol. 2011;107(1):69-73. 
216.Anker SD, Comin Colet J, Filippatos G, Willenheimer R, Dickstein K, Drexler $\mathrm{H}$, et al. FAIR-HF Trial Investigators. Ferric carboxymaltose in patients with heart failure and iron deficiency. N Engl J Med. 2009;361(25):2436-48.

217. Okonko DO, Mandal AK, Missouris CG, Poole-Wilson PA. Disordered iron homeostasis in chronic heart failure prevalence, predictors, and relation to anemia, exercise capacity, and survival. J Am Coll Cardiol. 2011;58(12):1241-51.

218.Lind M, Bounias I, Olsson M, Gudbjörnsdottir S, Svensson AM, Rosengren A. Glycaemic control and incidence of heart failure in 20985 patients with type 1 diabetes: an observational study. Lancet. 2011;378(9786):140-6

219.VanMelle JP, Bot M, de Jonge P, de Boer RA, van Veldhuisen DI, Whooley MA. Diabetes, glycemic control, and new onset heart failure in patients with stable coronary artery disease: data from the heart and soul study. Diabetes Care. 2010;33(9):2084-9.

220. Komajda M, McMurray JJ, Beck-Nielsen H, Gomis R, Hanefeld M, Pocock $\mathrm{SJ}$, et al. Heart failure events with rosiglitazone in type 2 diabetes: data from the RECORD clinical trial. Eur Heart J. 2010;31(7):824-31.

221.MacDonald MR, Eurich DT, Majumdar SR, Lewsey JD, Bhagra S, Jhund PS, et al. Treatment of Type 2 diabetes and outcomes in patients with heart failure: a nested case-control study from the U.K. General Practice Research Database. Diabetes Care. 2010;33(6):1213-8.

222.Evans JM, Doney AS, AlZadjali MA, Ogston SA, Petrie JR, Morris AD, et al. Effect of metformin on mortality in patients with heart failure and type 2 diabetes mellitus. Am J Cardiol. 2010;106(7):1006-10.

223.Shah DD, Fonarow GC, Horwich TB. Metformin therapy and outcomes in patients with advanced systolic heart failure and diabetes. J Card Fail. 2010;16(3):200-6.

224.Aguilar D, Bozkurt B, Ramasubbu K, Deswal A. Relationship of hemoglobin $\mathrm{A} 1 \mathrm{C}$ and mortality in heart failure patients with diabetes. J Am Coll Cardiol. 2009;54(5):422-8.

225. Issa VS, Amaral AF, Cruz FD, Ayub-Ferreira SM, Guimarães GV, Chizzola PR, et al. Glycemia and prognosis of patients with chronic heart failure-subanalysis of the Long-term Prospective Randomized Controlled Study Using Repetitive Education at Six-Month Intervals and Monitoring for Adherence in Heart Failure Outpatients (REMADHE) trial. Am Heart J. 2010:159(1):90-7.

226. Shimizu Y, Yamada S, Miyake F, Izumi T; PTMaTCH Collaborators. The effects of depression on the course of functional limitations in patients with chronic heart failure. J Card Fail. 2011;17(6):503-10.

227. Milani RV, Lavie CJ, Mehra MR, Ventura HO. Impact of exercise training and depression on survival in heart failure due to coronary heart disease. Am J Cardiol. 2011;107(1):64-8.

228. Frasure-Smith N, Lespérance F, Habra M, Talajic M, Khairy P, Dorian $P$, Roy D, et al; Atrial Fibrillation and Congestive Heart Failure Investigators. Elevated depression symptoms predict long-term cardiovascular mortality in patients with atrial fibrillation and heart failure. Circulation. 2009;120(2):134-40.

229. Pena FM, Modenesi Rde F, Piraciaba MC, Marins RM, Souza LB, Barcelos $\mathrm{AF}$, et al. Prevalence and variables predictive of depressive symptoms in patients hospitalized for heart failure. Cardiol J. 2011;18(1):18-25.

230.O'Connor CM, Jiang W, Kuchibhatla M, Silva SG, Cuffe MS, Callwood DD, et al; SADHART-CHF Investigators. Safety and efficacy of sertraline for depression in patients with heart failure: results of the SADHARTCHF (Sertraline Against Depression and Heart Disease in Chronic Heart Failure) trial. J Am Coll Cardiol. 2010;56(9):692-9.

231.Jiang W, Krishnan R, Kuchibhatla M, Cuffe MS, Martsberger C, Arias RM, O'Connor CM; SADHART-CHF Investigators. Characteristics of depression remission and its relation with cardiovascular outcome among patients with chronic heart failure (from the SADHART-CHF Study). Am J Cardiol. 2011;107(4):545-51.
232. Fraguas R, da Silva Telles RM, Alves TC, Andrei AM, Rays J, losifescu DV et al. A double-blind, placebo-controlled treatment trial of citalopram for major depressive disorder in older patients with heart failure: the relevance of the placebo effect and psychological symptoms. Contemp Clin Trials. 2009;30(3):205-11

233. Singal P, Iliskovic N. Doxorubicin-induced cardiomyopathy. N Engl J Med. 1998;339(13):900-5

234. Chen MH, Kerkelä R, Force T. Mechanisms of cardiac dysfunction associated with tyrosine kinase inhibitor cancer therapeutics. Circulation. 2008;118(1):84-95.

235. Felker G, Thompson R, Hare J, Hruban R, Clemetson D, Howard D, et al. Underlying causes and long-term survival in patients with initially unexplained cardiomyopathy. N Engl J Med. 2000;342(15):1077-84 .

236. Ewer MS, Ewer SM. Cardiotoxicity of anticancer treatments: what the cardiologist needs to know. Nat Rev Cardiol. 2010;7(10):564-75.

237. Kalil Filho R, Hajjar LA, Bacal F, Hoff PM, Diz Mdel P, Galas FR, et al. / Sociedade Brasileira de Cardiologia. I Diretriz brasileira de cardio-oncologia. Arq Bras Cardiol. 2011;96(2 supl 1):1-52.

238. van Dalen EC, Caron HN, Dickinson HO, Kremer LC. Cardioprotective interventions for cancer patients receiving anthracyclines. Cochrane Database Syst Rev. 2008;(2):CD003917.

239. Kalay N, Basar E, Ozdogru I, Er O, Cetinkaya Y, Dogan A, et al. Protective effects of carvedilol against anthracycline-induced cardiomyopathy. J Am Coll Cardiol. 2006;48(11):2258-62.

240. Cardinale D, Colombo A, Sandri MT, Lamantia G, Colombo N, Civelli M, et al. Prevention of high-dose chemotherapy-induced cardiotoxicity in high-risk patients by angiotensin-converting enzyme inhibition. Circulation. 2006;114(23):2474-81.

241. Wells QS, Lenihan DJ. Reversibility of left ventricular dysfunction resulting from chemotherapy: can this be expected? Prog Cardiovasc Dis. 2010;53(2):140-8.

242. Kirova YM. Recent advances in breast cancer radiotherapy: Evolution or revolution, or how to decrease cardiac toxicity? World J Radiol. 2010;2(3):103-8

243. Bestetti RB, Theodoropoulos TA, Cardinalli-Neto A, Cury PM. Treatment of chronic systolic heart failure secondary to Chagas heart disease in the current era of heart failure therapy. Am Heart J. 2008;156(3):422-30.

244. Bestetti RB, Dalbó C, Arruda CA, Correia Filho D, Freitas OC. Predictors of sudden cardiac death for patients with Chagas disease: a hospital-derived cohort study. Cardiology. 1996;87(6):481-7.

245. Bellabarba G, Davila DF, Torres A, Donis JH, Gonzalez JC, Figueroa O, et al. Plasma renin activity in chagasic patients with and without congestive heart failure. Int J Cardiol. 1994;47(1):5-9.

246. Bestetti RB, Coutinho-Netto J, Staibano L, Pinto LZ, Muccillo G, Oliveira JS. Peripheral and coronary sinus catecholamine levels in patients with severe congestive heart failure due to Chagas disease. Cardiology. 1995;86(3):202-6.

247. Bestetti RB, Otaviano AP, Cardinalli-Neto A, da Rocha BF, Theodoropoulos TA, Cordeiro JA. Effects of B-Blockers on outcome of patients with Chagas' cardiomyopathy with chronic heart failure. Int J Cardiol. 2011;151(2):205-8

248. Theodoropoulos TA, Bestetti RB, Otaviano AP, Cordeiro JA, Rodrigues VC, Silva AC. Predictors of all-cause mortality in chronic Chagas' heart disease in the current era of heart failure therapy. Int J Cardiol. 2008;128(1):22-9.

249. Botoni FA, Poole-Wilson PA, Ribeiro AL, Okonko DO, Oliveira BM, Pinto AS, et al. A randomized trial of carvedilol after renin-angiotensin system inhibition in chronic Chagas' cardiomyopathy. Am Heart J. 2007:153(4):544-8

250. Issa VS, Amaral AF, Cruz FD, Ferreira SM, Guimarães GV, Chizzola PR, et al. Beta-blocker therapy and mortality of patients with Chagas' cardiomyopathy-a subanalysis of the REMADHE prospective trial. Circ Heart Fail. 2010;3(1):82-8. 
251. Ramires FJA, Salemi VMC, lanni BM, Fernandes F, Martins DG, Billate A, et al. Aldosterone antagonism in an inflammatory state: evidence for myocardial protection. J Renin Aniotensin Aldosterone Syst. 2006;7(3):162-7.

252. Ferrari SJ, Bestetti RB, Cardinalli-Neto A, Bortoluzzi TB. Digoxin serum levels in patients with Chagas' cardiomyopathy heart failure. Rev Soc Bras Med Trop. 2010;43(5):496-9.

253. Issa VS, Bocchi EA. Antitrypanosomal agents: treatment or threat? Lancet. 2010;376(9743):768-9.

254. Cardinalli-Neto A, Nakazone MA, Grassi LV, Tavares BG, Bestetti RB. Implantable cardioverter-defibrillator therapy for primary prevention of sudden cardiac death in patients with severe Chagas cardiomyopathy. Int J Cardiol. 2011;150(1):94-5.

255. Bestetti RB, Theodoropoulos TA. A systematic review of studies on heart transplantation for patients with end-stage Chagas' heart disease. J Card Fail. 2009;15(3):249-55.

256. Avila WS, Rossi EG, Ramires JA, Grinberg M, Bortolotto MR, Zugaib M, et al. Pregnancy in patients with heart disease: experience with 1,000 cases. Clin Cardiol. 2003;26(3):135-42.

257. Sliwa K, Hilfiker-Kleiner D, Petrie MC, Mebazaa A, Pieske B, Buchmann E, et al; Heart Failure Association of the European Society of Cardiology Working Group on Peripartum Cardiomyopathy. Current state of knowledge on aetiology, diagnosis, management, and therapy of peripartum cardiomyopathy: a position statement from the Heart Failure Association of the European Society of Cardiology ESC Working Group on peripartum cardiomyopathy. EurJ Heart Fail. 2010;12(8):767-78

258. Vettori DV, Rohde LE, Clausell N. Asymptomatic left ventricular dysfunction in puerperal women: an echocardiographic-based study. Int J Cardiol. 2011;149(3):353-7.

259. Sliwa K, Blauwet L, Tibazarwa K, Libhaber E, Smedema JP, Becker A, et al. Evaluation of bromocriptine in the treatment of acute severe peripartum cardiomyopathy: a proof-of-concept pilot study. Circulation. 2010;121(13):1465-73.

260. Haykowsky MJ, Brubaker PH, John JM, Stewart KP, Morgan TM, Kitzman DW. Determinants of exercise intolerance in elderly heart failure patients with preserved ejection fraction. J Am Coll Cardiol. 2011;58(3):265-74.

261. Reinsch N, Neuhaus K, Esser S, Potthoff A, Hower M, Brockmeyer NH, et al. Prevalence of cardiac diastolic dysfunction in HIV-infected patients: results of the HIV-HEART study. HIV Clin Trials. 2010;11(3):156-62.

262. Butt AA, Chang CC, Kuller L, Goetz MB, Leaf D, Rimland D, et al. Risk of heart failure with human immunodeficiency virus in the absence of prior diagnosis of coronary heart disease. Arch Intern Med. 2011;171(8):737-43.

263. Lewis W. Mitochondrial DNA replication, nucleoside reverse-transcriptase inhibitors, and AIDS cardiomiopathy. Prog Cardiovasc Dis. 2003;45(4):305-18.

264. Charbit B, Gayat E, Voiriot P, Boccara F, Girard PM, Funck-Brentano C. Effects of HIV protease inhibitors on cardiac conduction velocity in unselected HIVinfected patients. Clin Pharmacol Ther. 2011;90(3):442-8.

265. Banerjee D, Haddad F, Zamanian RT, Nagendran J. Right ventricular failure: a novel era of targeted therapy. Curr Heart Fail Rep. 2010;7(4):202-11.

266. Guglin M, Verma S. Rightside of heart failure. Heart Fail Rev. 2011 Jul 28. [Epub ahead of print].

267. Lahm T, McCaslin CA, Wozniak TC, Ghumman W, Fadl YY, Obeidat OS, et al. Medical and surgical treatment of acute right ventricular failure. J Am Coll Cardiol. 2010;56(18):1435-46

268. Hefke T, Zittermann A, Fuchs U, Schulte-Eistrup S, Gummert JF, Schulz U. Bosentan effects on hemodynamics and clinical outcome in heart failure patients with pulmonary hypertension awaiting cardiac transplantation. Thorac Cardiovasc Surg. 2011 Mar 22. [Epub ahead of print]

269. Mikus E, Stepanenko A, Krabatsch T, Loforte A, Dandel M, Lehmkuhl HB, et al. Reversibility of fixed pulmonary hypertension in left ventricular assist device support recipients. Eur J Cardiothorac Surg. 2011;40(4):971-7.
270. BeyersdorfF, Schlensak C, Berchtold-HerzM, Trummer G. Regression of "fixed" pulmonary vascular resistance in heart transplant candidates after unloading with ventricular assist devices. J Thorac Cardiovasc Surg. 2010;140(4):747-9.

271. Calabrese F, Angelini A, Carturan E, Thiene G. Myocarditis and inflammatory cardiomyopathy: histomorphological diagnosis. Ernst Schering Res Found Workshop. 2006;(55):306-21.

272. Yilmaz A, Kindermann I, Kindermann M, Mahfoud F, Ukena C, Athanasiadis A, et al. Comparative evaluation of left and right ventricular endomyocardial biopsy: differences in complication rate and diagnostic performance. Circulation. 2010;122(9):900-9.

273. Röttgen R, Christiani R, Freyhardt P, Gutberlet M, Schultheiss HP, Hamm B, et al. Magnetic resonance imaging findings in acute myocarditis and correlation with immunohistological parameters. Eur Radiol. 2011;21(6):1259-66.

274. Friedrich MG, Sechtem U, Schulz-Menger J, Holmvang G, Alakija P. Cardiovascular magnetic resonance in myocarditis: a JACC white paper. J Am Coll Cardiol. 2009;53(17):1475-87.

275. Gutberlet M, Spors B, Thoma T, Bertram H, Denecke T, Felix R, etal. Suspected chronic myocarditis at cardiac MR: diagnostic accuracy and association with immunohistologically detected inflammation and viral persistence. Radiology. 2008;246(2):401-9.

276. Mahrholdt H, Goedecke C, Wagner A, Meinhardt G, Athanasiadis A, Vogelsberg $\mathrm{H}$, et al. Cardiovascular magnetic resonance assessment of human myocarditis: a comparison to histology and molecular pathology. Circulation. 2004;109(10):1250-8.

277. Yilmaz A, Kindermann I, Kindermann M, Mahfoud F, Ukena C, Athanasiadis A, et al. Comparative evaluation of left and right ventricular endomyocardial biopsy: differences in complication rate and diagnostic performance. Circulation. 2010;122(9):900-9.

278. Mahfoud F, Gärtner B, Kindermann M, Ukena C, Gadomski K, Klingel K, et al. Virus serology in patients with suspected myocarditis: utility or futility? Eur Heart J. 2011;32(7):897-903.

279. Kindermann I, Kindermann M, Kandolf R, Klingel K, Bültmann B, Müller T, et al. Predictors of outcome in patients with suspected myocarditis. Circulation. 2008;118(6):639-48

280. Cooper LT Jr, Hare JM, Tazelaar HD, Edwards WD, Starling RC, Deng $M C$, et al. Giant cell myocarditis treatment trial investigators: usefulness of immunosupression for giantcell myocarditis. Am JCardiol. 2008;102(11):1535-9.

281. Dennert R, Velthuis S, Schalla S, Eurlings L, van Suylen RJ, van Paassen P, et al.Intravenous immunoglobulin therapy for patients with idiopathic dilated cardiomyopathy and endomyocardial biopsy-proven high PVB19 viral load. Antivir Ther. 2010;15(2):193-201.

282. Frustaci A, Russo MA, Chimenti C. Randomized study on efficacy of immunosuppressive therapy in patients with virus-negative inflammatory cardiomyopathy: the TIMIC study. Eur HeartJ. 2009;30(16):1995-2002.

283. Captur G, Nihoyannopoulos P. Left ventricular non-compaction: genetic heterogeneity, diagnosis and clinical course. Int J Cardiol. 2010;140(2):145-53.

284. Luedde M, Ehlermann P, Weichenhan D, Will R, Zeller R, Rupp S, et al. Severe familial left ventricular non-compaction cardiomyopathy due to a novel troponin T(TNNT2) mutation. Cardiovasc Res. 2010;86(3):452-60.

285. Martín M, Barriales V, Corros C, Santamarta E. Usefulness of cardiac magnetic resonance imaging in left ventricular non-compaction cardiomyopathy. Eur J Heart Fail. 2011:13(5):577.

286. Habib G, Charron P, Eicher JC, Giorgi R, Donal E, Laperche T, et al. Isolated left ventricular non-compaction in adults: clinical and echocardiographicfeatures in 105 patients: results from a French registry. Eur J Heart Fail. 2011;13(2):177-85.

287. Whellan DJ, Ousdigian KT, Al-Khatib SM, Pu W, Sarkar S, Porter CB, et al; PARTNERS Study Investigators. Combined heart failure device diagnostics identify patients at higher risk of subsequent heart failure hospitalizations: results from PARTNERS HF (Program to Access and Review Trending Information and Evaluate Correlation to Symptoms in Patients With Heart Failure) study. J Am Coll Cardiol. 2010;55(17):1803-10. 
288. Kamath SA, Drazner MH, Tasissa G, Rogers JG, Stevenson LW, Yancy CW. Correlation of impedance cardiography with invasive hemodynamic measurements in patients with advanced heart failure: the Biolmpedance CardioGraphy (BIG) substudy of the Evaluation Study of Congestive Heart Failure and Pulmonary Artery Catheterization Effectiveness (ESCAPE) Trial. Am Heart J. 2009;158(2):217-23.

289. Nguyen CT, Aaronson A, Morrissey RP, Agarwal M, Willix RD, Schwarz ER. Myths and truths of growth hormone and testosterone therapy in heart failure. Expert Rev Cardiovasc Ther. 2011;9(6):711-20.

290. Bocchi E, Moura L, Guimarães G, Conceição Souza GE, Ramires JA. Beneficial effects of high doses of growth hormone in the introduction and optimization of medical treatment in decompensated congestive heart failure. Int J Cardiol. 2006;110(3):313-7.

291. Rosner MH, Ronco C. Hyponatremia in heart failure: the role of arginine vasopressin and its antagonism. Congest Heart Fail. 2010;16(Suppl 1):S7-14.

292. Guglin M, Khan H. Pulmonary hypertension in heart failure. J Card Fail. 2010;16(6):461-74

293. Cotter G, Dittrich HC, Weatherley BD, Bloomfield DM, O'Connor CM, Metra M, et al; Protect Steering Committee, Investigators, and Coordinators. The PROTECT pilot study: a randomized, placebo-controlled, dose-finding study of the adenosine $\mathrm{A} 1$ receptor antagonist rolofylline in patients with acute heart failure and renal impairment. J Card Fail. 2008;14(8):631-40.

294. Massie BM, O'Connor CM, Metra M, Ponikowski P, Teerlink JR, Cotter $\mathrm{G}$, et al; PROTECT Investigators and Committees. Rolofylline, an adenosine A1 - Receptor antagonist, in acute heart failure. N Engl J Med. 2010;363(15):1419-28.

295. Voors AA, Dittrich HC, Massie BM, DeLucca P, Mansoor GA, Metra M, et al. Effects of the adenosine $\mathrm{A} 1$ receptor antagonist rolofylline on renal function in patients with acute heart failure and renal dysfunction: results from PROTECT (Placebo-Controlled Randomized Study of the Selective Adenosine A1 Receptor Antagonist Rolofylline for Patients Hospitalized with Acute Decompensated Heart Failure and Volume Overload to Assess Treatment Effect on Congestion and Renal Function). J Am Coll Cardiol. 2011;57(19):1899-907.

296. Abraham WT. Results of the TRIDENT- 1 trial: a phase $2 \mathrm{~b}$ study to assess the safety and tolerability of IV tonapofylline in subjects with acute decompensated heart failure and renal insufficiency. Paper presented at: the European Society of Cardiology Heart Failure Congress, Late Breaking Clinical Trials; May 30, 2010; Berlin, Germany.

297. Torp-Pedersen C, Kober L, Carlsen JE, Akkan D, Bruun NE, Dacoronias D, et al. A randomized trial of a pre-synaptic stimulator of DA2-dopaminergic and alpha2-adrenergic receptors on morbidity and mortality in patients with heart failure. Eur J Heart Fail. 2008;10(1):89-95.

298. Strauer BE, Yousef M, Schannwell CM. The acute and long-term effects of intracoronary stem cell transplantation in 191 patients with chronic heARt failure: the STAR-heart study. Eur J Heart Fail. 2010;12(7):721-9.

299. Vilas-Boas F, Feitosa GS, Soares MB, Pinho-Filho JA, Mota AC, Almeida AJ, et al. Bone marrow cell transplantation in chagas' disease heart failure: report of the first human experience. Arq Bras Cardiol. 2011;96(4):325-31.

300. Bocchi EA, Bacal F, Guimarães G, Mendroni A, Mocelin A, Filho AE, et al. Granulocyte-colony stimulating factor or granulocyte-colony stimulating factor associated to stem cell intracoronary infusion effects in non ischemic refractory heart failure. Int J Cardiol. 2010;138(1):94-7.

301. Carvalho ACC. Terapia celular no Brasil. In: IV Simpósio Internacional Terapias Avançadas \& Células-Tronco. Recife; 8 a 10 de Outubro; 2009.

302. Barbosa da Fonseca LM, Xavier SS, Rosado de Castro PH, Lima RS, Gutfilen $\mathrm{B}$, Goldenberg RC, et al. Biodistribution of bone marrow mononuclear cells in chronic chagasic cardiomyopathy after intracoronary injection. Int J Cardiol. 2011;149(3):310-4.
303. Carvalho VO, Ruiz MA, Bocchi EA, Carvalho VO, Guimarães GV. Correlation between CD34+ and exercise capacity, functional class, quality of life and norepinephrine in heart failure patients. Cardiol J. 2009;16(5):426-31.

304. Baldo MP, Rodrigues SL, Mill JG. Granulocyte colony-stimulating factor for ischemic heart failure: should we use it? Heart Fail Rev. 2010;15(6):613-23.

305. Grossman J, Frishman WH. Relaxin: a new approach for the treatment of acute congestive heart failure. Cardiol Rev. 2010;18(6):305-12.

306. Lima MV, Ochiai ME, Cardoso JN, Morgado PC, Munhoz RT, Barretto AC. Hyperkalemia during spironolactone use in patients with decompensated heart failure. Arq Bras Cardiol. 2008;91(3):177-82, 194-9.

307. Pitt B, Anker SD, Bushinsky DA, Kitzman D W, Zannad F, Huang IZ; PEARL-HF Investigators. Evaluation of the efficacy and safety of RLY5016, a polymeric potassium binder, in a double-blind, placebo-controlled study in patients with chronic heart failure (the PEARL-HF) Trial. Eur Heart J. 2011;32(7):820-8.

308. Malik FI, Hartman JJ, Elias KA, Morgan BP, Rodriguez H, Brejc K, et al. Cardiac myosin activation: a potential therapeutic approach for systolic heart failure. Science. 2011;331(6023):1439-43.

309. Morgan BP, Muci A, Lu PP, Qian X, Tochimoto T, Smith WW, et al. Discovery of omecamtiv mecarbil the first, selective, small molecule activator of cardiac myosin. ACS Med Chem Lett. 2010;1(9):472-7.

310. Teerlink JR, Clarke CP, Saikali K, Lee JH, Chen MM, Escandon RD, et al. Dose-dependent augmentation of cardiac systolic function with the selective cardiac myosin activator, omecamtiv mecarbil: a first-in-man study. Lancet. 2011:378(9792):667-75.

311. Cleland JGF, Teerlink JR, Senior R, Nifontov EN, McMurray JV, Lang CC et al.The effects of the cardiac myosin activator, omecamtiv mecarbil on cardiac function in systolic heart failure: a double-blind, placebo-controlled crossover, dose-ranging phase 2 trial. Lancet. 2011;378(9792):676-83.

312. Pêgo-Fernandes PM, Moreira LF, Souza GE, Bacal F, Bocchi EA, Stolf NA, et al. Endoscopic left sympathetic blockade in the treatment for dilated cardiomyopathy. Arq Bras Cardiol. 2010;95(6):685-90.

313. Sabbah HN, Gupta RC, Imai M, Irwin ED, Rastogi S, Rossing MA, et al. Chronic electrical stimulation of the carotid sinus baroreflex improves left ventricular function and promotes reversal of ventricular remodeling in dogs with advanced heart failure. Circ Heart Fail. 2011;4(1):65-70.

314. De Ferrari GM, Crijns HJ, Borggrefe M, Milasinovic G, Smid J, Zabel M, et al; CardioFit Multicenter Trial Investigators. Chronic vagus nerve stimulation: a new and promising therapeutic approach for chronic heart failure. Eur Heart J. 2011;32(7):847-55

315. McMurray JJ, Pitt B, Latini R, Maggioni AP, Solomon SD, Keefe DL, et al Aliskiren Observation of Heart Failure Treatment (ALOFT) Investigators. Effects of the oral direct renin inhibitor aliskiren in patients with symptomatic heart failure. Circ Heart Fail. 2008;1(1):17-24.

316. Solomon SD, Shin SH, Shah A, Skali H, Desai A, Kober L, et al; Aliskiren Study in Post-MI Patients to Reduce Remodeling (ASPIRE) Investigators. Effect of the direct renin inhibitor aliskiren on left ventricular remodelling following myocardial infarction with systolic dysfunction. Eur Heart J. 2011;32(10):1227-34.

317. Gu J, Noe A, Chandra P, Al-Fayoumi S, Ligueros-Saylan M, Sarangapani R, et al. Pharmacokinetics and pharmacodynamics of LCZ696, a novel dualacting angiotensin receptor-neprilysin inhibitor (ARNi). J Clin Pharmacol. 2010;50(4):401-14

318. Gheorghiade M, Blair JE, Filippatos GS, Macarie C, Ruzyllo W, Korewick J, et al; HORIZON-HF Investigators. Hemodynamic, echocardiographic, and neurohormonal effects of istaroxime, a novel intravenous inotropic and lusitropic agent: a randomized controlled trial in patients hospitalized with heart failure. I Am Coll Cardiol. 2008;51(23):2276-85. 